\title{
CELL ATLAS OF THE CHICK RETINA: SINGLE CELL PROFILING IDENTIFIES 136 CELL TYPES
}

Masahito Yamagata*, Wenjun Yan*, and Joshua R. Sanes

Center for Brain Science and Department of Molecular and Cellular Biology Harvard University

Cambridge MA, 02138

Running title: Chick retinal cell atlas

*equal contribution

For correspondence:

Joshua R. Sanes

Center for Brain Science

Harvard University

52 Oxford St.

Cambridge MA 02138

617-496-8683

sanesj@mcb.harvard.edu 


\section{SUMMARY}

Retinal structure and function have been studied in many vertebrate orders, but molecular characterization has been largely confined to mammals. We used single-cell RNA sequencing (scRNA-seq) to generate a cell atlas of the chick retina. From $\sim 40,000$ single cell transcriptomes, we identified 136 cell types distributed among the six classes conserved across vertebrates - photoreceptor, horizontal, bipolar, amacrine, retinal ganglion and glial cells. To match molecular profiles to morphology, we adapted a method for CRISPR-based integration of reporters into selectively expressed genes. For Müller glia, we found that transcriptionally distinct cells were regionally localized along the anterior-posterior, dorsal-ventral and central-peripheral retinal axes. We also identified immature photoreceptor, horizontal cell and oligodendrocyte types that persist into late embryonic stages. Finally, we analyzed relationships among chick, mouse and primate retinal cell classes and types. Taken together, our results provide a foundation for anatomical, physiological, evolutionary, and developmental studies of the avian visual system. (150 words)

\section{INTRODUCTION}

The retina is about as complex as other regions of the vertebrate central nervous system. It differs from many regions, however, in being particularly accessible to study. For example, its neurons can be imaged live without surgical intervention, visual stimuli can be precisely controlled in time and space, and the paucity of long-distance inputs facilitates analysis of the entire circuit ex vivo. These and other technical advantages, along with the intrinsic importance of the retina and the fact that most blinding diseases arise from retinal dysfunction, have combined to make the retina a popular model for analysis of neural structure, function, development and disease (Wässle, 2004; Dowling, 2012; Hoon et al., 2014). Accordingly, retinas of many vertebrate species have been studied in detail, including those of rodents (e.g., mice and rats), carnivores (e.g., cats and ferrets), primates (e.g., macaques, marmosets and humans), birds (e.g., chickens and pigeons), fish (e.g., zebrafish and goldfish), reptiles (e.g.,turtles and lizards) and amphibia (e.g., salamanders and frogs)(Dowling, 2012; Thoreson and Dacey, 2019; Baden et al., 2020). All of these studies depend on classification and characterization of the cell types that comprise the retina. Recently, this enterprise has been greatly enhanced by the introduction of methods for high throughput single cell transcriptomic profiling (scRNA-seq), which enable comprehensive and minimally biased sampling of cell types. To date, however, these methods have been applied only to mice and primates (Macosko et al., 2015, Shekhar et al., 2016, Rheaume et al., 2018, Peng et al., 2019, Tran et al., 2019, Yan et al., 2020a,b), restricting use of non-mammalian models and making it difficult to draw evolutionary relationships among species at the molecular level . Here, we address this limitation by using scRNA-seq to generate a cell atlas of the chick retina.

The basic plan of the retina is highly conserved among all vertebrates. Five neuronal classes are arranged in three cellular (nuclear) layers separated by two synaptic (plexiform) layers: photoreceptors (PRs) in an outer nuclear layer (ONL), three sets of interneurons (horizontal, bipolar and amacrine cells; HCs, BCs, ACs) in an inner nuclear layer (INL), and output neurons (retinal ganglion cells, RGCs), along with some ACs, in 
a ganglion cell layer (GCL; Cajal, 1892; Masland, 2012; Figure 1A-B). PRs form synapses with HCs and BCs in an outer plexiform layer (OPL), while RGCs, BCs and ACs form synapses in an inner plexiform layer (IPL). Axons of RGCs then exit the eye and travel through the optic nerve to a variety of retinorecipient areas in the brain (Dhande et al., 2015; Martersteck et al., 2017). Each of these classes is divided into types with specific patterns of connectivity among them endowing distinct RGC types with sensitivities to different visual stimuli, such as edges, moving or oriented objects, and color contrasts (Sanes and Masland, 2015). The retina also contains glial cells: Müller glia in the INL, and in many species, astrocytes and oligodendrocytes in and beneath the GCL (Reichenbach and Bringmann, 2013; Vecino et al., 2016). Altogether, transcriptomic and morphological studies have identified a total of $>130$ neural (neuronal and glial) cell types in mice and $~ 70$ in primates (Yan et al., 2020a,b; Peng et al., 2019)

Although the basic retinal plan is conserved, cell types and patterns of connectivity vary among species, serving their visual needs (Baden et al., 2020). Birds are highly visual animals with sizable eyes, generally high acuity and sophisticated retinas (Cook, 2000; Seifert et al., 2020). For example, whereas most mammals have two cone photoreceptor types, most birds are tetrachromatic, with cone photoreceptors selectively sensitive to red, green, blue, and ultraviolet light (Hart, 2001; Baden and Osorio, 2019). Many have regions specialized for high acuity vision, akin to the fovea found in primates. Indeed, histological and immunohistochemical studies have suggested that there may be more cell types in avian retinas than in those of mammals (Cajal, 1892; Mariani and Leure-duPree, 1977; Hayes, 1982; Quesada et al., 1988; Naito and Chen, 2004; Karten and Brecha, 1983; Brecha et al., 1984; Karten et al., 1990).

Among birds, the retina of the domestic chicken (Gallus gallus domesticus) has been the most intensively studied. In particular, it has been a favored model for developmental analyses, including studies on the generation and migration of retinal neurons, their diversification into classes and types, the growth and guidance of RGC axons to the optic tectum, and the capacity of retinal neurons and their axons to regenerate (Adler 2000; Mey and Thanos, 2000; Thanos and Mey, 2001; Wilken and Reh, 2016; Wisely et al., 2017). To complement and facilitate these studies, we used scRNA-seq to profile cells from the chick retina. From $\sim 40,000$ single cell

transcriptomes, we identified cells of all 6 classes named above (PR, HC, BC, AC, RGC and glia) and used unsupervised methods to divide them into 150 clusters. We show that 136 of the groups represent putative cell types, with others corresponding to developmental intermediates. We then devised a method for CRISPR-based somatic cell integration of fluorescent reporters into genes shown by scRNA-seq to be expressed by specific types. Using this technique along with other histological methods, we matched molecular profiles to morphology for many neuronal types. We also found a positional signature in Müller glia, with distinct expression patterns based on their location along the anterior-posterior, dorsal-ventral and central-peripheral retinal axes. Finally, we compared the cell classes and types of chick retina with those of three mammalian species - mouse, macaque and human - demonstrating conserved molecular features of all classes and some types, along with multiple differences 
between chick and mammals. Together, our results provide new insights into retinal structure and evolution, as well as a foundation for anatomical, physiological, and developmental studies of avian retina.

\section{RESULTS \\ Profiling chick retinal cells}

All known chick retinal cell types are born by $\mathrm{E} 14$, retinal structure is relatively mature by E18, and birds are visually competent at hatching (E21; Figure 1C; Hamburger and Hamilton, 1951; Prada et al., 1991; Cepko et al., 1996; Mey and Thanos, 2000; Yamagata and Sanes, 1995a,b; Drenhaus et al., 2003). We used a droplet-based method (Zheng et al., 2017) to obtain 30,022 high quality single cell transcriptomes from embryonic day 18 (E18) chick retina (Figure 1 - figure supplement $1 \mathrm{~A}$ ). We assigned cells to classes based on expression of previously established markers, using methods described in Peng et al. (2019) and Yan et al. (2020a). We identified five neuronal classes (PRs, HCs, BCs, ACs, and RGCs) as well as two glial types, Müller glia and oligodendrocytes (Figures 1D,E).

Of the E18 retinal cells profiled, 620 were RGCs (Figures 1E). This fraction ( 2\%) was similar to that observed in other species (Macosko et al., 2015, Peng et al., 2019) but was insufficient for extensive classification of what we anticipated would be a highly heterogeneous class. We therefore used magnetic beads coated with antibodies to the pan-RGC cell surface marker Thy1 (French and Jeffrey, 1986; Yamagata et al., 2002) to enrich RGCs from E16 retina before scRNA-seq. We obtained 9159 single cell transcriptomes, of which 8107 (89\%) were RGCs (Figure 1F; Figure 1-figure supplement $1 \mathrm{~B})$ that were used for subsequent analysis.

To resolve cell types within these classes, we re-clustered each one separately, and obtained a total of 152 clusters (Figure 1G). Each presumably corresponded to a cell type, a small group of closely related types or, since we profiled embryonic cells, a developmental intermediate.

Finally, to separate definitive types from developmental intermediates, we collected cells from E12 retina, obtaining single cell transcriptomes from PRs, HCs, BCs, RGCs and MGs as well as several putative precursor populations (Figure 1H; Figure1-figure supplement $1 \mathrm{C}-\mathrm{E})$.

\section{CRISPR-based cell type characterization}

Generation of a retinal cell atlas for mouse benefited from prior knowledge, numerous well characterized antibodies, and many transgenic lines that express a reporter in one or a few types (Macosko et al., 2015; Shekhar et al., 2016; Tran et al., 2019; Yan et al., 2020a). Lacking these advantages for chick, we tested methods for inserting fluorescent reporters into genes shown by scRNA-seq to be expressed by specific types, thereby allowing us to visualize those cells' morphology. In a method called SLENDR, guide RNAs, and plasmids encoding Cas 9 and a reporter are delivered to somatic cells to insert the reporter into a chromosomal site determined by the sequence of the guide RNAs and homologous sequences appended to the reporter (Mikuni et al., 2016). We 
were unsuccessful in applying this method to chick retina, and therefore modified it. We used in ovo electroporation to deliver a mixture consisting of guide RNAs, Cas 9 protein, and a single strand DNA containing a reporter sequence flanked by $\sim 70$ bases genespecific homology arms (Gurumurthy et al., 2019) (Figure 2A). We co-electroporated this mixture with piggyBac transposon reporter/transposase constructs encoding a spectrally distinct reporter to monitor the site and efficiency of electroporation, and optimized reagents to enhance homologous recombination (see Methods). We call the

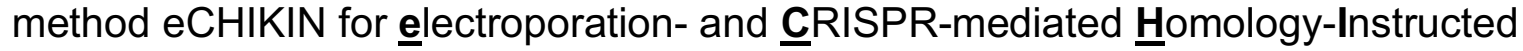
Knock-IN.

To test eCHIKIN, we targeted genes expressed in most cells of three retinal classes: VSX2 (Chx10) in BCs, TFAP2A in ACs and RBPMS2 in RGCs (Chen and Cepko, 2000; Bassett et al, 2007; Piri et al., 2006). We inserted a 9 amino acid hemagglutinin (HA) tag at the N-terminus of VSX2 and RBPMS2 and inserted GFP into the TFAP2A locus. In each case, the homologously inserted reporter specifically labeled the expected cell class, as verified by soma position and immunostaining: VSX2-HA-tagged cells were restricted in the outer part of the INL, as appropriate for BCs, and were VSX2-positive and TFAP2A-negative (Figure 2B-D). TFAP2A-GFP cells were present in the inner portion of the INL as appropriate for TFAP2A-expressing ACs (Figure 2E). In this case, GFP was not fused to the endogenous proteins, so it filled the cytoplasm, revealing dendrites of ACs in the IPL. In addition, the labeled cells still express the endogenous gene (Figure 2E), suggesting that only one allele was edited in most cells. Likewise, RBPMS2-HA-tagged cells were confined to the ganglion cell layer, as appropriate for RGCs (Figure 2F). In each case, the spectrally distinct co-electroporated reporter, which had its own regulatory elements and integrated non-homologously, was expressed in cells of all layers (Figure 2B-F).

To efficiently label cells that expressed target genes at low levels, we inserted Cre recombinase into the TFAP2A and RBPMS2 loci, and co-electroporated with a Credependent fluorescent protein (loxP-STOP-IoxP-GFP under the control of strong and ubiquitously expressed CAGS promoter and enhancer). Cell class specificity was similar in these cases to those in which the loci were tagged directly with a reporter (Figure 2G, $\mathrm{H})$.

Thus, eCHIKIN provides a means of matching molecular identity to cellular morphology without germline manipulation.

\section{Photoreceptors}

Chicks are tetrachromatic, with cone types that express red opsin (OPN1LW), green opsin (OPN1MSW), blue opsin (OPN2SW) or violet opsin (OPN1SW) (Kram et al., 2010; Enright et al., 2014). In addition to these conventional "single-cones" (SCs), the retina also contains rods that express rhodopsin (RHO) and OPN1LW -expressing "double-cones" (DCs) composed of tightly apposed principal and accessory cells, which together comprise about half of all photoreceptors (Smith et al., 1985; López-López et al., 2008; Oishi et al., 1990). This composition is unlike that of rodent and primate retinas, which are rod-dominated and contain no DCs. 
Reclustering of PRs revealed 12 clusters (numbered in order of descending abundance; Figure 3A; Figure 3-figure supplement $1 \mathrm{~A})$, including one each expressing $R H O$, OPN1MSW, OPN2SW, and OPN1SW (PR cluster 3, 5, 8, and 11), marking them as rods and green, blue, and violet SCs, respectively (Figure 3B).

As expected, in situ hybridizations to opsins labeled non-overlapping cells (Figure 3C and data not shown). These types were also distinguished by other differentially expressed genes, including PDE6B, PDE6G (phosphodiesterases) and MAFA (a transcription factor) in rods, SLC27A6 (a fatty acid transporter) in blue and violet SCs and LOC101750261 (a non-coding RNA) in green SCs.

Expression of OPN1LW was detected in four clusters (PR cluster 1, 2, 4 and 7; Figure 3B), representing red SCs and DCs. To distinguish among them, we localized cluster 7 with STRA6, a retinol transporter (Isken et al. 2008), and cluster 1, 2, and 4 with CALB1. STRA6+ cones were thin, as expected for SCs. In contrast, CALB1+ cells were broader, as expected for DCs (Figure 3D-F). We also generated an eCHIKIN probe for CALB1, which labeled DCs (Figure 3G). Thus, we identify PR7 as red SCs and PR1, 2 and 4 as components of DCs. PR cluster 1, 2 and 4 are quite similar at the gene expression level, so we were unable to distinguish principal from accessory cell components of DCs, or to determine why they formed three clusters rather than the expected two. Their close similarity raises the possibility that besides the gap junctions that connect them (Smith et al., 1985) there may be additional ways that enable exchange of mRNAs.

The transcriptomic relationships among these clusters are demonstrated by a dendrogram in Figure 3B. There were three major branches, of which two corresponded to rods and cones. Among the cones, SCs are more closely related to each other than to any components of DCs. Among SCs, red and green SCs are each other's closest relatives as are blue and violet SCs.

The third clade of PRs, comprising four clusters, expressed the PR fate determination gene, PRDM1 (Katoh et al., 2010; Brzezinski et al., 2013), but did not express opsins, suggesting that they were immature PRs. To relate these clusters to the definitive PRs, we used a supervised classification method, XGBoost (Chen and Guestrin, 2016) that predicts the best match among mature types for each putative immature type (Figure 3H). PR6 and 9 mapped mostly to the DC types, PR10 mapped to 3 out of the 4 SC types, and PR12 mapped almost exclusively mapped to rods. Consistent with this relationship, each immature cluster expressed markers of the corresponding mature PRs - for example, PR6 expressed the DC marker GRIK3, and PR10 expressed the rod markers MAFA and PDE6G.

To further test the idea that the opsin-negative PR-like cells represented immature PRs, we queried our E12 dataset together with the E18 PRs for clustering. E12 cells aligned with both immature and mature types of E18 were present (Figure 3-figure supplement 
$1 \mathrm{~B}, \mathrm{C})$ but, as expected, the proportions differed with age: immature types comprise $91 \%$ of the E12 data set but only $16 \%$ of the E18 data set.

Finally, we analyzed retinas from earlier (E12 and E16) and later (E20) stages by in situ hybridization with probes for ARHGAP18, and SLIT1, expressed by PR6 (immature DCs); OPN1LW (mature red SCs and DCs) and STRA6 (mature SCs). All PRs have been born by E12 (Prada et al., 1991), At E12, ARHGAP18 was expressed by PRs in the ONL, but OPN1LW was not detectable. Conversely, OPN1LW was expressed at E20 but ARGHAP18 was not (Figure 3-figure supplement 2A-D), suggesting that ARGHAP18 is transiently expressed in the ONL during development. At E16, consistent with the fact that retinal differentiation proceeds in a central to peripheral gradient (Kahn, 1974; Spence and Robson, 1989; Prada et al., 1991, Bruhn and Cepko, 1996), ARHGAP18 and SLIT1 were expressed by ONL cells selectively in peripheral retina, while OPN1LW and STRA6 were by ONL cells in central retina (Figure 3-figure supplement $2 \mathrm{E}-\mathrm{Q}$ ). Together, these results strongly suggest that immature and mature $\mathrm{PR}$ types co-exist at the same age but in different regions.

\section{Horizontal cells}

Initial histological studies of avian retina distinguished two HC types: Type I, which bears an axon, and Type II, which does not (Cajal, 1892; Mariani and Leure-duPree, 1977). Later studies combined immunohistochemical and morphological criteria to propose further subdivisions into three or four types (Fischer et al., 2007; Edqvist et al., 2008; Boije et al., 2016). Clustering of E18 HCs yielded 5 clusters, HC1-5 (Figure 4A, Figure 4-figure supplement 1A), all expressing the canonical HC marker ONECUT3. $L H X 1$ and ISL1 were detected in exclusive populations and other markers distinguished each type (Figure 4B). Based on prior immunohistochemical analysis (Fischer et al., 2007; Edqvist et al., 2008), we hypothesized that HC1 and HC3 corresponded to Type I and $\mathrm{HC} 2 / \mathrm{HC} 4 / \mathrm{HC} 5$ to Type II HCs.

The two type I clusters (HC1 and HC3; LHX1+ ISL1-) were closely related, with few genes differentially expressed between them showing large differences (Figure 4B). In situ hybridization for two such genes - IPCEF1 enriched in HC1 and OXT enriched in HC3 - confirmed partially overlapping expression (Figure 4C). The differences between IPCEF1+OXT- and IPCEF1-OXT+ cells might reflect graded expression in time and/or space. Spatiotemporal analysis of expression similar to that described for PRs above, indicated that OXT (enriched in HC3) was expressed throughout the retina at E14, restricted to peripheral at E18, and disappeared at E20 (Figure 4-figure supplement 1B-G). In contrast, IPCEF1 (enriched in HC1) was expressed selectively in central retina at $E 14$ and $E 18$, and strongly throughout retina at E20 (Figure 4-figure supplement $1 \mathrm{H}-\mathrm{M})$. Consistent with this conclusion, most of the $\mathrm{HCs}$ identified in the E12 collection expressed OXT but not IPCEF1 (Figure 4 - figure supplement $1 \mathrm{~N}-\mathrm{P}$ ). Thus, we conclude that HC1 is a mature type and $\mathrm{HC} 3$ its immature counterpart.

The ISL1+LHX1- types HC2, HC4, and HC5 were distinguished by selective and nonoverlapping expression of distinct receptor-type tyrosine kinases, NTRK1, EGFR and $L T K$, respectively (Figure 4B, D-I). In situ hybridization of en face sections demonstrated 
that these groups form mosaics of HCs, with the density of each mosaic corresponding roughly to the abundance of the type observed by scRNA-seq (NTRK1>EGFR>LTK; Figure 4J-L). NTRK1 (TrkA) is expressed by "Candelabrum" axon-less HCs (Edquvist et al., 2008) which correspond to the abundant HC2.

\section{Bipolar cells}

Using Golgi staining, Quesada et al. (1988) identified 14 types of bipolar cells in chick based on dendritic morphology, and noted that further subdivisions might be possible if axonal morphology was also considered. Unsupervised clustering of our data identified 22 groups of BCs (Figure 5A) ranging in frequency from 1.5 to $10.4 \%$ of all BCs (Figure 5 -figure supplement $1 \mathrm{~A})$. All expressed the canonical markers VSX2 and OTX2, and each was distinguished by selective expression of other genes (Figure 5B).

Immunostaining and in situ hybridization for several of these genes confirmed their expression by BC subsets (Figure 5 -figure supplement 1B-O).

In mammals, BCs are conventionally divided into two groups, based on whether they respond to illumination with depolarizing (ON) or hyperpolarizing (OFF) responses; BCs innervated by cones can be either ON or OFF whereas those innervated by rods are all ON type (Euler et al., 2016). In mammals, ON BCs are characterized by expression of TRPM1, ISL1 and GRM6; OFF BCs express GRIK1; and rod BCs express PRKCA in addition to canonical ON markers (Morgans et al., 2009, 2010; Shekhar et al., 2016). In our dataset, the expression of GRIK1 was mutually exclusive with that of TRPM1 and ISL 1 in all clusters but one, resulting in 11 likely ON types and 10 likely OFF types (Figure 5C). (GRM6, the canonical marker of mammalian ON BCs is missing in the current version of the chick genome, so we were unable to assess its expression.) In situ hybridization for GRIK1 and TRPM1 confirmed that these genes are also expressed in a largely non-overlapping pattern in chick retina (Figure 5 -supplement 1B,C; see below). Supporting this assignment, FEZF2, which marks some OFF BC types in mice (Shekhar et al., 2016) was enriched in 5 OFF types. PRKCA was expressed at highest levels in $\mathrm{BC} 19$, a putative ON cluster, suggesting that it might represent rod $\mathrm{BCs}$ (Greferath et al., 1990). BC10, which expresses both ON and OFF markers might have mixed properties, as has been seen in fish (Li et al., 2012). In general, ON BCs were transcriptomically more closely related to other ON BCs than to OFF BC and vice versa (Figure 5B, C), but the segregation was not as strict as in mice or primates, in which ON and OFF BCs form separate clades (Shekhar et al., 2016, Peng et al., 2019, Yan et al., 2020b).

A key feature of BC types is the IPL sublamina or sublaminae in which their axons arborize. We used eCHIKIN and immunohistochemistry to assess lamination, adopting the convention of dividing the IPL into 5 strata (S1-5). We generated eCHIKIN probes for 5 BC types: BC1 (ANGPT2), BC6 (TPBGL), BC8 (RRAD), BC12 (IRX3) and BC15 (SLC6A4). As shown in Figure 5D-H, BC1 axons terminated in S3, BC6 and BC8 axons in S3, and BC15 in S4; BC12 axons were bistratified with termini in S1 and S2. Antibodies to TPBGL (BC6) and SLC6A4 (BC15) stained S3 and S4, respectively, consistent with these assignments (Figure 5I,J); anti-STRA6 $(\mathrm{BC} 3,9)$ and anti-ERBB4 (BC12) stained S3-4 and S1-2 respectively (Figure 5 -figure supplement 1Q, R). 
In mammals, there is a relationship between the axonal lamination of BCs and their response properties, with $\mathrm{ON}$ cone, OFF cone and rod BC axons arborizing in the order OFF cone $>$ ON cone > rod proceeding from the INL to the GCL. In general, the lamination patterns observed with eCHIKIN and immunohistochemistry followed this rule with three putative OFF cone types (BC6, 8 and 12) laminating in S1 and S2, two putative ON cone types (BC3 and 18) laminating in S3 and S4, and putative rod bipolars (BC19; PRKCA+) laminating in S5 (Figure 5K). The sole exception was BC15, which was GRIK+ but laminated in S4.

Finally, we asked whether the positions of BC somata in the INL were related to the positions of their axons in the IPL. Somata of putative OFF (GRIK1+) and ON (TRPM1+) BCs, were situated in the outer and inner portions of the INL respectively, corresponding to the positions of their axon terminals (Figure 5 -supplement $1 \mathrm{~B}, \mathrm{C}$ ). To assess correspondence for individual types, we determined somata position by in situ hybridization and axon position as described above. For most types, somata position in INL was correlated with terminal arborization position in IPL (quantified in Figure 5 figure supplement 1P, and summarized in Figure 5L). Interestingly, the somata of BC10, the putative ON-OFF type (see above), populate the interface between ON and OFF regions in the INL as revealed by SOX5 immunostaining (Figure 5 -figure supplement $1 \mathrm{~J}, \mathrm{P}$ and Figure $5 \mathrm{~L}$ ). This correlation has not, to our knowledge, been observed for mammalian BCs.

\section{Amacrine cells}

$A C s$ are a diverse class of interneurons, most of which form inhibitory (GABAergic or glycinergic) synapses on BCs, RGCs and other ACs. In mammals ACs are the most heterogeneous retinal class (Yan et al. 2020a, 2020b; Peng et al.,2019). Similarly, ACs formed the most heterogeneous class in chicks, with 59 putative types (Figure 1G, 6A), ranging in frequency from 0.4 to $7.2 \%$ of all ACs (Figure 6 -figure supplement $1 \mathrm{~A}$ ). All expressed SLC32A1, a transporter that loads both GABA and glycine into synaptic vesicles, and each type expressed either GABAergic markers (GABA transporter, SLC6A1, and the GABA synthetic enzymes, GAD1 and GAD2, 40 clusters) or glycinergic markers (glycine transporter 1, SCL6A9, 19 clusters) (Figure 6B). AC somata were present in both the INL and the GCL. Expression of two broadly expressed member of the AP2 family of transcription factors, TFAP2A and TFAP2B, distinguished these populations: TFAP2A expression was restricted to ACs in the INL, while TFAP2B was expressed by $A C s$ in both locations (Figure 6B,D,E).

We identified markers selectively expressed by one or a few types (Figure 6C). Many were neuropeptides, consistent with classical immunohistochemical studies (Karten and Brecha,1983; Brecha et al., 1984; Karten et al., 1990); they included TAC1 (substance P), NPY (neuropeptide Y), PENK (enkephalin), NTS (neurotensin) and NMB (neuromedin-B). We used in situ hybridization or immunohistochemistry to validate selective expression of several markers in amacrine cell subsets (e.g., NMB in AC17, CHODL in AC40, NPY in AC52, NTS in AC31 and 58, PENK highest in AC31, 34 and 42, and MAFA in AC35 and 58; Figure 6C and Figure 6 -figure supplement $2 \mathrm{~B}$ - 
E). Double label studies distinguished sets of NTS+PENK+ and NTS+MAFA+ double positive ACs, corresponding to AC31 and AC58, respectively (Figure 6 -figure supplement $1 \mathrm{~F}-\mathrm{H}$ ). An eCHIKIN probe for NTS also labeled two AC types, a more abundant one with broad processes that ramify in S1, S3, and S4, morphologically reminiscent of pigeon NTS+ amacrine cells (Brecha et al., 1984), and a less abundant one with arbors in S5 (Figure 6-figure supplement 2J,K).

We further investigated two AC types that have been studied extensively in mammals. One is the starburst amacrine cell (SAC), the only retinal cholinergic cell type. It comprises cohorts in both layers, called ON (somata in the GCL, with dendrites in S4) and OFF (somata in the INL, with dendrites in S2; Figure 6F; Millar et al., 1987). Two $A C$ clusters, $A C 7$ and $A C 25$, expressed the cholinergic markers choline acetyltransferase (CHAT), choline transporter (SLC5A7), and vesicular acetylcholine transporter (SLC18A3), indicating their identity as SACs. We assign AC7 and AC25 to ON and OFF SACs, respectively, because AC7 expressed FEZF1, a transient marker of developing ON starburst marker in mouse, whereas AC25 expressed TENM3 and ZFHX3, transient OFF markers SAC markers in mouse (Peng et al., 2020; Figure 6 figure supplement $2 \mathrm{~A}$ ).

The other is an unusual excitatory AC, the VG3 amacrine, which expresses the vesicular glutamate transporter 3 (SLC17A8, VGlut3). Two closely related chick AC clusters, AC37 and AC39 were SLC17A8-positive, with levels higher in AC37 than AC39 (Figure 6C and Figure 6-figure supplement 2B). AC37 also expressed the recognition molecule Sidekick 2 (SDK2; Yamagata et al., 2002), which is also a selective marker of mouse VG3 ACs (Krishnaswamy et al., 2015; Yamagata and Sanes, 2019), suggesting that AC37 is the authentic chick VG3 AC (Figure 6 -figure supplement 2D). SDK1, the homologue of $S D K 2$, is expressed at highest levels in AC38, but not in chick VG3 AC (Figure 6-figure supplement 2B,C). We generated an eCHICK probe from ERBB4, which is expressed at highest levels in AC37 and AC38 among ACs, and used it to mark these cells. They stratified in S2 and S4 (Figure $6-$ figure supplement 2E), consistent with Sdk1 and Sdk2 localization reported previously (Yamagata et al., 2002) but distinct from mouse VG3 ACs, which stratify in S3.

\section{RGCs}

From 8107 single RGC transcriptomes, we resolved 41 clusters (Figure $7 \mathrm{~A}$ ) ranging in abundance from $0.6-5.1 \%$ of all RGCs (Figure 7 -figure supplement $1 \mathrm{~A}$ ). Like RGCs in mammals, all expressed the canonical RGC markers RBPMS and THY1, as well as one or more of the Brn3 (POU4F) transcription factors and the RBPMS homologue, RBPMS2 (Figure 7B). Each cluster could be specified by selective expression of one or, in some cases, a few genes (Figure 7B, C; Figure 7 -figure supplement 1B-I). They include genes that are expressed by subsets of RGCs in mammals such as SATB1 and SATB2 (Peng et al., 2019) (Figure 7D, E). Among the 41 putative RGC types, cluster 11 selectively expressed OPN4.1, a homolog gene to the defining marker of mammalian intrinsically photosensitive RGCs (ipRGCs), as well as the transcription factor EOMES (Tbr2)(Figure 7B; Figure 7 -figure supplement 1I), which is expressed in all but not 
only ipRGCs (Chaurasia et al., 2005; Mao et al., 2014), indicating that GC11 is a chick ipRGC type. We used eCHIKIN to reveal morphologies of three RGC types: GC23 (TFAP2D), with dendrites in S5; GC18 (MC5R), with dendrites in S5; and GC15 and/or 13 (ETV1) with dendrites in S4; (Figure 7F-H). GC15 selectively expresses the recognition molecule $S D K 1$, which we have shown to be concentrated in S4 (Yamagata et al., 2002) (Figure 7 -figure supplement 2A,B).

The main central target of chick RGCs is the optic tectum. Within the tectum axons of distinct RGC populations terminate in one of 5 retinorecipient laminae, called $B, C, D$ upper, D lower and F (Yamagata and Sanes, 1995a, 1995b, Yamagata et al., 2006). Based on expression of markers identified in previous studies, we conclude that GC25 targets tectal lamina B (TAC1[substance P]+, NMB [neuromedin B]+, $S S T$ [somatostatin I]+, and RELN [reelin]+) and GC1 targets tectal lamina F (CHRNB2 [neuronal acetylcholine receptor beta2 subunit]+, SS2 [somatostatin II], and EZR [ezrin]+) (Yamagata et al., 2006). GC1 is characterized by expression of a transcription factor RUNX2 (Figure 7B, Figure 7 -figure supplement 2C-E).

\section{Müller glia}

Müller glia, the major retinal glial type, has generally been viewed as a homogeneous population (see Discussion). However, we distinguished 5 clusters in the single cell dataset of E18 chick retina (Figure 8A and B). In examining genes differentially expressed among these clusters (Figure $8 \mathrm{C}$ ), we noted three that had been shown to exhibit topographically biased expression at early stages of retinal development, when most cells are still mitotically active: CHRDL1 (ventropin), expressed in ventral retina was enriched in cluster MG1 (Sakuta et a., 2001); and EPHA3 and FOXD1 (BF2), expressed in temporal retina, were enriched in MG5 (Cheng et al., 1995; Yuasa et al., 1996; Yamagata et al., 1999). This suggested that positional differences might underlie Müller glia heterogeneity.

We used in situ hybridization to test this idea. We documented selective expression of CHRDL1 (MG1) in ventral retina, WIF1 (MG2) in dorsal retina, FOXI2 (MG5) in temporal retina and FOXG1 (BF1) in nasal retina (Figure 8D-M). FOXG1 was detected in a subset of cells, that failed to form a single cluster but presumably comprise nasal cells (Figure 8C). Finally, in situ hybridization for genes selectively expressed in MG3 (PSCA) and MG4 (TMEM123) indicated that cells in these clusters were associated with central and peripheral retina, respectively (Figure $8 \mathrm{~N}-\mathrm{Q}$ ). Expression of all markers was graded with position. Co-staining for glutamine synthetase, an MG marker (Linser and Moscona, 1979), showed that all of these genes were selectively expressed in MG (Figure 8-figure supplement 1). Quantitative analysis confirmed both the distinct expression patterns of genes expressed by each cluster as well as the partial overlap expected for graded expression and the dual identity of, for example, cells in the ventral quadrant of central retina (Figure 8-figure supplement 2A). Together, these results reveal a striking positional map of gene expression in MG (Figure 8R).

In light of the central-to-peripheral developmental gradient documented above we wondered whether MG3 (central) and MG4 (peripheral) represented authentic positional 
differences or different developmental stages. To distinguish these alternatives, we performed two additional analyses. First, we queried the E12 dataset. Markers of dorsal, ventral, nasal and temporal retina were selectively expressed, but the peripheral marker at E18, TMEM123, was broadly expressed at E12, suggesting that it is a marker for an early developmental stage (Figure 8-figure supplement 2A, B; Figure 8-figure supplement 3A). PSCA was barely detectable expressed at this stage, but FGF8, known to mark a small central retinal region (da Silva and Cepko, 2017) was selectively expressed by a restricted group of cells (Figure 8-figure supplement 3A). Second, we used in situ hybridization to assess the distribution of key genes at E12 and E20. As development proceeds, PSCA and FGF8 are expressed in nested domains, suggesting further distinctions along the central-peripheral axis (Figure 8-figure supplement 3B). At later stages, FGF8 expression declines and TMEM123 is progressively restricted to peripheral regions (summarized in Figure 8-figure supplement 3C). Thus, MG3 represents a positionally restricted cell group, whereas MG4 may largely represente immature MGs. In summary, our analysis revealed a positional basis for the transcriptomic heterogeneity of MG.

\section{Oligodendrocytes}

Reclustering of oligodendrocytes revealed five clusters (Figure 9A; Figure 9-figure supplement A). All expressed the oligodendrocyte marker OLIG2 (Zhou et al., 2001), but they exhibited differential expression of other known markers of developing and mature oligodendrocytes (reviewed in Goldman and Kuypers, 2015), suggesting that they represented different developmental stages. Pseudotime analysis arranged the clusters in the order: OL5, OL3, OL1, OL2, and OL4, and selectively expressed markers supported this order. For example, HES1, a marker of oligodendrocyte precursors is expressed in the order OL5>OL3,OL1>OL2,OL4; myelin components such as PLP1 and $M B P$ are expressed at highest levels in OL2 and OL4; and CLDN11, a component of tight junctions formed in compacted myelin, is selectively expressed by OL4 (Figure 9B and Figure 9 - figure supplement 1B). Several other genes exhibited similar differential expression, making them candidate markers of successive stages in oligodendrocyte differentiation (Figure 9-figure supplement 1C).

We used in situ hybridization to localize oligodendrocytes in retina, using probes for PLP1 and BCAS1 (OL2 and OL4) and PDGFRA (OL1 and OL3). PLP1 and BCAS1 were co-expressed, whereas PDGFRA+ cells formed a distinct population (Figure 9B; Figure 9-figure supplement $1 \mathrm{~B}, \mathrm{C})$. Both populations were confined to the $\mathrm{GCL}$. $B C A S 1+P L P 1+$ cells were more abundant in central retina, near the optic disc, than in the periphery, whereas $P D G F R A+$ cells were more abundant peripherally than centrally (Figure 9C-L). These patterns are consistent with the idea that oligodendrocyte precursors enter from the optic nerve and migrate peripherally, with progeny maturing in a central to peripheral gradient (Ono et al., 1997; Fischer et al., 2010).

\section{Comparison of avian and mammalian retinal cell classes}

As noted in the Introduction, the basic retinal plan, including the structure and placement of its main cell classes, is conserved among vertebrates. We asked whether this morphological conservation is accompanied by transcriptomic conservation. To this 
end, we combined data from the E18/E16 chick atlas with those from our previously published retinal atlases of mouse (Macosko et al., 2015; Shekhar et al., 2016; Tran et al., 2019; Yan et al., 2020a), macaque (Peng et al., 2019) and human (Yan et al., $2020 \mathrm{~b})$, and submitted the entire group for clustering. This procedure generated 9 clusters, all of which contained cells from all species (Figure 10A,B). Each cluster could be identified with high confidence by expression of class-specific markers (Figure 10C) and by reference to prior assignments made when each species was analyzed individually (Figure 10D). Six of the clusters corresponded to major retinal cell classes: rods, cones, HCs, BCs, RGCs and MG. The other three clusters were composed of ACs distinguished by neurotransmitter type: GABAergic, glycinergic; and cholinergic+GABAergic (SACs); these distinctions are discussed in the next section.

Transcriptomic relationship among classes are shown in Figure 10E. The highest level split is between MG and neurons; the second separates photoreceptors from other neurons; the third separates HCs from other interneurons and RGCs; and the last separates GABAergic from glycinergic ACs. These patterns are consistent with structural and functional data, in that glia and neurons play largely non-overlapping roles, photoreceptors are highly specialized neuron-like cells, HCs are unique among interneurons generally, and the GABAergic and glycinergic ACs are inhibitory interneurons with similar functions and patterns of connectivity. The greater similarily of RGCs to ACs than to BCs is also not unexpected in that ACs and RGCs use conventional neurotransmission mechanisms, whereas $\mathrm{BC}$ bear ribbon synapses that are shared with photoreceptors but few other neuronal types. On the other hand, the distance placement of SACs is unexpected. All four species obey the same rules of similarity.

In contrast, relationships among species vary by class. Humans and macaques are each other's closest relatives in only 4 of 9 classes, and mice rather than chicks are outliers in 7 of 9 cases; both of these patterns are unexpected from phylogenetic considerations. The differences are small, however and may result from technical considerations: the highly variable genes used for clustering may not be sufficient to distinguish cells within any individual class, as the high dimensional space is saturated by genes for other classes. Indeed, the relationship among species differ when each class is clustered separately (Figure 11, see below). Nonetheless, when all cells are combined and compared by species, retinal cells from chick and mouse are transcriptomically more similar to each other than either is to primates (Figure 10F). One possible explanation is that chick and mouse retina are both more complex in terms of numbers of cell types than either human or macaque retina (Table 1).

\section{Comparison of avian and mammalian retinal cell types}

Finally, we examined the conservation of cell types within classes for the four species, using two methods: building a dendrogram based on similarity matrix of all types from all species (Figure 11 and Figure 11-figure supplements 1 and 2) or pooling cells within each class from all species and submitting the combined data for clustering (shown for ACs and RGCs in Figure 11-figure supplements 1 and 2). Only mature chick types were used for this analysis. Key findings by class are as follows: 
Cones (Figure 11A): Mammalian M/L and S cones form separate clades. (Primate $M$ and $L$ cones differ transcriptomically only at the opsin locus [Peng et al., 2091] and are combined here. Most mouse cones are $\mathrm{M}$ type, so we had insufficient power to analyze mouse $\mathrm{S}$ cones as a separate type.). Chick cones are outliers, but red (L) SCs are most closely with mammalian M/L cones, and blue and green SCs are most closely related to mammalian S cones. Violet SCs and red DCs are distant relatives of both $\mathrm{M} / \mathrm{L}$ and $\mathrm{S}$ clades, which does not correspond to the sequence relationships of their opsins (Shichida and Yamashita, 2003; Terakita, 2005) but does correspond to lineages deduced from evolutionary considerations (Baden and Osorio, 2019).

$\mathrm{HCs}$ (Figure 11B): The most notable distinction among $\mathrm{HC}$ cells is that some bear axons and other do not. Primate $\mathrm{H} 1$, chick $\mathrm{HC} 1$ and all mouse $\mathrm{HCs}$ are axon-bearing, while primate $\mathrm{H} 2$, chick $\mathrm{HC} 2,4$ and 5 do not. However, whereas mammalian axonbearing and axon-less HCs form separate groups, all chick HCs are outliers.

BCs (Figure 11C): The principal division among BCs is into ON and OFF subclasses, based on whether they depolarize or hyperpolarize to light. They form separate clades in each of the three mammalian species taken individually (Shekhar et al., 2016; Peng et al., 2019; Yan et al. 2020a). Chick BC types have not been characterized physiologically, but based on position and key markers that have been validated, we tentatively assigned all 21 types to ON or OFF subclasses, with the 22nd being potentially ON-OFF. Chick putative ON and OFF BCs also generally divide into transcriptomically separate groups (Figure 5B,C), but the distinction is less absolute than that for mammals. When all 4 species are considered together, the distinction remains, but one set of chick ON BCs clusters with most mammalian BC types 4 and 5 , leading to a division of ON BCs into two groups.

ACs (Figure 11-figure supplement 1): Most if not all ACs use GABA or glycine as a transmitter or co-transmitter. These subclasses form separate clusters when all retinal cells are analyzed together (Figure 10) and this distinction is largely maintained when ACs are reanalyzed separately. One type, SACs, form a distinct clade, which includes all 5 types from all 4 species (two in chicks) (Figure 10E and Figure 11-figure supplement $1 \mathrm{C}$ ). SACs are unique among ACs in many respects: They are the only cholinergic neuron in the retina, they have been found in all vertebrate retinas studied to date, they arise earlier in development than most other ACs, and once generated, their dendrites serve as scaffolds to patterns those of other retinal cell types (Peng et al., 2017; Ray et al., 2018; Duan et al., 2018; Yan et al., 2020a). They are transcriptomic outliers among ACs in each species separately; what is noteworthy is that SACs of all species are transcriptomically similar to each other.

It is difficult to discern similar chick-mammalian conservation for other AC types, at least in part because so few chick AC types have been characterized by structural or physiological criteria. One exception is the VG3 AC, which is identifiable by expression of the glutamate transporter. However, relating clusters derived from a pool of all ACs from all species to types classified in each species separately (Figure 11-figure 
supplement $1 \mathrm{C}$ ) provides several candidate chick homologues of characterized mammalian AC types.

RGCs (Figure 11-figure supplement 2): We showed previously that conservation of types between mouse and primates was lower for RGCs than other cell classes (Peng et al., 2019). This relationship extends to chicks. Comparison of the two clustering methods described above shows a conservation of intrinsically photosensitive RGCs but we detect no chick close relatives of well-studied mammalian RGC types such as midget or parasol RGCs (in primates), direction-selective or alpha RGCs (in mice).

\section{DISCUSSION}

We used scRNA-seq to profile $\sim 40,000$ cells from the retina of late embryonic chick retina, at which time all retinal neurons have been born and, as assessed structurally, complex neural circuits have formed (Prada et al., 1991; Cepko et al., 1996; Mey and Thanos, 2000; Yamagata and Sanes, 1995a,b; Drenhaus et al., 2003; Figure 1C). We used computational methods to divide the cells into 148 clusters or putative cell types (Table 1). We then determined the morphology and positions of many types, and in some cases compared them to transcriptomes from cells collected at E12, at which time nearly all retinal neurons have been born but many are immature. We found that 136 of the clusters represent mature retinal types, or potentially small groups of types, with the remaining 13 representing topographic variants or developmental intermediates. The mature types comprise what is to our knowledge the first retinal cell atlas for a nonmammalian vertebrate; the topographic variants demonstrate surprisingly long-lasting retention of positional information in Müller glia; and the developmental intermediates reveal stages in postmitotic maturation of several cell types. Finally, we compared the chick atlas to those we recently assembled for mice, monkeys and humans (Macosko et al., 2015; Shekhar et al., 2016; Peng et al., 2019; Tran et al., 2019; Yan et al., 2020a; Yan et al., 2020b), providing novel insights into the evolution and conservation of neuronal cell classes and types.

\section{eCHIKIN}

Germ-line transgenesis is well-established in most commonly used model organisms (mice, zebrafish, Drosophila, C. elegans) making it possible to generate reporter lines that can be used to reveal the morphology of molecularly-defined cell types. This approach has been a powerful one in our studies of mouse and fish retina (Shekhar et al., 2016; Tran et al., 2019, Yan et al., 2020a, Koelsch et al., 2020). Lacking this tool for chick, we modified methods for CRISPR-based genome modification in somatic cells (Mikuni et al., 2016; Matsuda and Oinuma, 2019; Mikuni, 2020) to insert reporters or Cre recombinase into genes identified as "cell-type specific" in our dataset. The use of short (70bp) homology arms to direct the reporter to appropriate loci made it straightforward to generate targeting fragments. The method can be used to assess the subcellular distribution of the gene product, by fusing the reporter to the coding sequence, or to assess cell morphology, by inserting a soluble fluorescent protein at the translational start site or coupling Cre with a cre-dependent reporter. Of 20 fragements tested, 16 (80\%) labeled cells in predicted patterns, including all cases in which we validated the expression pattern by in situ hybridization or antibodies. One potential 
drawback of the method is that gene disruption could alter properties of the targeted cells, including their morphology, but we saw no evidence for this in the cells we examined.

\section{Retinal atlas}

The 136 "mature" cell types in our atlas are distributed among 7 classes: 8 PRs, 4 HC, 22 BCs, 59 ACs, 41 RGCs, 1 MG (lumping positional variants, as discussed below), and 1 oligodendrocyte. The number is substantially greater than that deduced from morphological surveys (11 bipolars, 26 RGCs; Quesada et al., 1988; Naito and Chen; reviewed in Seifert et al., 2020). Nonetheless it may not be complete. First, we did not detect microglia, astrocytes or a variant glial type named diacytes (Rompani and Cepko, 2010), even though all are known to be present. Second, we do not know whether our RGCs include displaced types with somata in the INL, although these are known to be present in birds (Britto et al., 1988). Third, although the retina is quite mature at E1618 , we cannot exclude the possibility that additional types arise later. Fourth, the least abundant $A C$ and RGC types we identified comprised $0.4 \%$ (28/6642 ACs) and $0.6 \%$ (52/8107 RGCs) of the cells in each class. Our sample may have been insufficient to detect still less abundant types: they might have been lumped with related types or missed altogether.

Table 1 compares the number of cell types in the chick atlas to those in mouse, monkey and human. The number of types in chick is similar to those in mouse, and nearly twofold higher than those in monkey or human. Given the sampling limitation discussed above, however, and the larger number of mouse cells profiled ( 140,000 vs $\sim 40,000$ in chick) we suspect that the true number of types is higher in chick than in any mammals sampled to date. Thus, our results confirm the suspicion that the chick retina, and perhaps those of other birds, is more complex by this measure than those of mammals.

\section{Retinal cell types}

Many of the cell types we identified, such as PRs and HCs, could be matched to types previously characterized morphologically or immunohistochemically (e.g. Yamagata et al., 2002, 2006, 2012; Fischer 2007 Edqvist et al., 2008; Enright et al., 2015). For nearly all of these, we provide new markers that can be used to learn more about their structure, function and development of each cell type. For example, HCs types are distinguished by selective expression of receptor-type tyrosine kinases that have been implicated in neuronal differentiation (LTK, EGFR and NTRK1), and could play roles in their type-specific development or function (Lemmon and Schlessinger, 2010). Other intriguing cell types include a putative ON-OFF bipolar type (BC10), a putative serotonergic bipolar type (BC15, expresses the serotonin transporter [SLC6A2]; see Millar et al., 1988), a glutamatergic amacrine type (AC37, expresses the VGlut3 [SLC17A8]) related to the mammalian VG3 (Krishnaswamy et al., 2015), and RGC types corresponding to types we showed previously to project to distinct retinorecipient sublaminae in the optic tectum (GC25, B-RGCs; GC1, F-RGCs) (Yamagata and Sanes, 1995a, 1995b). 


\section{Retained positional information in Müller glia}

To date, only a single Müller glial type has been identified in mice and primates using scRNAseq (Macosko et al., 2015; Shekhar et al., 2016; Peng et al., 2019; Yan et al., 2020b; Wang et al., 2017). In contrast, unsupervised analysis of chick Müller glia generated five clusters, which were, however, less well separated from each other than types in other classes. In situ hybridization with probes for genes differentially expressed among these clusters revealed a positional basis for the heterogeneity. The five clusters were enriched in cells derived from dorsal, ventral, temporal, central and peripheral retina; and a sixth group, which did not cluster separately, contained cells from nasal retina. Several genes have been shown to exhibit position dependent expression in early embryos (prior to E8; Cheng et al., 1995; Yuasa et al., 1996; Yamagata et al., 1999; Sakuta et a., 2001); in each case, their expression at E18 was consistent with prior data. Five of these six groups appear to be authentically positiondependent, based on studies at earlier ages, while the sixth (peripheral) may largely reflect the center-to-peripheral gradient of retinal development that has been observed in several species (Kahn, 1974; Spence and Robson, 1989; Prada et al., 1991, Bruhn and Cepko, 1996).

Recently, Hoang et al. (2020) reported single cell transcriptomic data on P10 chicken retina. Reanalysis of their data suggests that similar graded expression of some of these topographic gene, such as CHRDL1, persist after hatching (data not shown). This result is tantalizing in light of recent reports on region- and lamina-selective differences in gene expression of mammalian astrocytes (Batiuk et al., 2020; Bayraktar et al., 2020). The positional map we describe for chick MG may provide a useful model for investigating the sources and roles of heterogeneity in glial types that were believed until recently to be indivisible.

\section{Retinal development}

Although our aim was to profile mature retinal types, we found 10 clusters that fit within cell classes by our criteria, but lacked mature features: 4 photoreceptors, 1 horizontal cell, 1 Müller glia and 4 oligodendrocytes. Several lines of evidence suggested that these clusters were composed of developmental intermediates. First, histological analysis showed that they were more abundant at earlier stages (E10-E12) than at E18 and, in some cases, less abundant still at E20. Second, at intermediate stages, their appearance and disappearance followed the known center to periphery gradient of retinal development (Kahn, 1974; Spence and Robson, 1989; Prada et al., 1991, Bruhn and Cepko, 1996) - that is, mature types were more abundant in central than peripheral retina and the opposite was true for the developmental intermediates. Third, we observed a larger proportion of immature PRs and HCs at E12. Finally, in some cases, their gene expression patterns were characteristic of immature cells. For example, immature PRs did not express opsin, but did express genes implicated in PR development (e.g., ARHGAP18, Maeda et al., 2011; SLIT1, Plump et al., 2002; PRDM1, Katoh et al., 2010; Brzezinski et al., 2013). Similarly, developing oligodendrocytes expressed genes previously associates with successive stages in oligodendrocyte maturation (Goldman and Kuypers, 2015) as well a variety of other genes that now become candidates for stage-specific markers. 


\section{Diversity and evolution of retinal cell types}

It has been known since the time of Cajal that the fundamental retinal plan is conserved throughout vertebrates: the same cell classes (PR, HC, BC, AC, RGC and MG) are present in every species studied to date (Cajal, 1892; Lamb et al., 2007). Cajal also recognized that in the vast majority of cases, each class is divided into multiple types that differ in morphological detail. Our retinal atlas has now allowed us to address two unanswered questions: Does the resemblance of cell classes across orders extend from morphological to molecular similarity and are types within classes conserved across orders?

The answer to first question is clearly yes. Despite the $>300$ million years since the mammalian and avian lineages diverged (Kumar and Hedges, 1998), all classes remained transcriptomically similar among species, and share expression of key genes that have been used to mark each class in mammals (Figure 10). In contrast, types within classes are less well conserved: in only a minority cases, such as PRs, SACs, VG3-ACs and ipRGCs, do chick types have orthologous mammalian types as their closest relatives. This differences between classes and types supports the idea that classes form a common plan within which species evolve distinct types to enable visual behaviors appropriate for their environment, behavioral repertoire, and other sensory capabilities. An open question is whether an underlying similarity might be discovered by examining additional species and/or probing type-specific transcriptional programs. Studies to test these possibilities are underway.

\section{Conclusions}

The chick has been used for thousands of studies on the development, structure and function of the retina and its projections to central targets (Nicol, 2015; Cepko et al., 1996; Adler, 2000; Mey and Thanos, 2000; Wilken and Reh, 2016; Wisely et al., 2017; pubmed search for chick+retina retrieves $>4000$ papers). Two bottlenecks in moving this work forward have been (a) lack of a global classification and characterization of chick retinal cell types and (b) metrics that can be used to relate chick to mammalian retinal cell types. Our goal in the study reported here has been to address these two challenges. Using the powerful method of high throughput scRNAseq, we provide the first chick retinal atlas since Cajal (1892), and a gene-specific Golgi-like method to study neuronal morphology, discovering new features of retinal diversity and development as well as insights into the extent to which retinal cell classes and types are conserved between chick and mammals. We hope that our results will facilitate further use of chick as a model for retinal structure, function and development. 


\section{METHODS}

\section{Single cell RNA-seq}

Animals were used in accordance with $\mathrm{NIH}$ guidelines and protocols approved by Institutional Animal Use and Care Committee at Harvard University. Fertilized chicken eggs (specific pathogen free) were obtained from Charles River Laboratories (Wilmington, MA), and incubated in a 1550 HATCHER (GQF MFG, Savannah, GA) at $37^{\circ} \mathrm{C}$. Retinas were dissected in Hanks' balanced salt solution supplemented with 20 mM HEPES, pH 7.4 (HBSS). After removing pigment epithelial cells and pecten, retinae were dissociated at $37^{\circ} \mathrm{C}$ for $30 \mathrm{~min}$ with papain (LK003160, Worthington, Lakewood, NJ). The same volume of Neurobasal medium (Thermo Fischer, Waltham, $\mathrm{MA}$ ) and $10 \mu \mathrm{g}$ of deoxyribonuclease I (DN25, Sigma, St. Louis, MO) were added, and cells were triturated. To remove debris, cells were then washed twice through a cushion of the ovomucoid protease inhibitor/BSA/HBSS in the papain dissociation medium. Cells were counted, resuspended in PBS with acetylated BSA, and processed with the Chromium Next GEM Single Cell 3' Library Construction Kit (version 2) (10x Genomics, Pleasanton, CA; Zheng et al., 2017). Briefly, single cells are partitioned into oil droplets containing single oligonucleotide-derivatized beads followed by cell lysis, barcoded reverse transcription of RNA, amplification, shearing, and attachment of $5^{\prime}$ adaptor and sample index oligos. Libraries were sequenced on the Illumina HiSeq 2500 (Paired end reads: Read 1, 26bp, Read 2, 98bp).

To enrich RGCs, cells dissociated as above were immunopurified with mouse monoclonal antibody to Thy-1 (BSJ-1: French and Jeffrey, 1986) using goat anti-mouse IgG conjugated magnetic beads (Miltenyi Biotec, Auburn, CA) (Yamagata et al., 2002). Cells were then resuspended in PBS with acetylated BSA and processed as above.

\section{Analysis of scRNA-seq data}

We analyzed scRNA-seq data using a pipeline modified from Peng et al. (2019). Steps are as follows.

(1) Sample demultiplexing was performed with cellranger mkfastq function (10X Genomics, version 2.1.0), and reads were aligned to the reference genome GRCg6a using cellranger count function (10X Genomics, version 2.1.0) with the option --forcecells $=8000$. A threshold of 600 genes detected per cell was applied to filter out low quality cells and debris.

(2) Clustering was performed using the R package "Seurat" to stratify cells into major classes using defining class-selective markers (Stuart et al., 2019; Mclnnes and Healy, 2018). Every class was then reanalyzed individually to maximize the dynamic range in feature space for each cell class.

(3) Because some contaminants became evident only following division into classes, we reexamined the clustered data to remove contaminant-like clusters and doublets. The quality of each cluster was assessed by transcriptomic complexity and expression of typical house-keeping genes (Eisenberg and Levanon, 2013), and low-quality cells were 
removed. Doublets were identified as cells that co-expresses genes from multiple classes, lacked uniquely expressed marker genes, and/or exhibited $>1.5$ fold higher number of Unique Molecular Identifiers than other clusters in the same cell class.

(4) Clusters closely related on the dendrogram were assessed using a generalized linear model from the R package "MAST" (Finak, et al., 2015), and iteratively merged if no differentially expressed genes were found.

Trajectory analysis of oligodendrocytes was performed using the R package "Monocle3" (Cao, et al., 2019).

For cross species analysis, types from each species were downsampled to a maximal of 200 before pooling. Genes of non-human species were converted to their human homologene using the R package "homologene" and only those with homologenes in all four species were retained for analysis. Clustering was performed using "Seurat" as described above, but with cells from different species aligned using the "Referencebased" integration with all four species as reference. Dendrograms were then built using scaled data after integration, with a total of 100 trees in each case; $80 \%$ of cells and $80 \%$ of the highly variable genes were used in each build. Final trees were generated using the "consensus" function from the "Clann" package (Creevey and Mclnerney., 2005; Figure10F, Figure 11 and y-axis of Figure 11-supplement 1C and 2C). Alternatively, trees were built from clusters identified in the integrated space (x-axis of Figure $11-$ supplement $1 \mathrm{C}$ and $2 \mathrm{C}$ ).

Initial assessment of the aligned data showed a complete absence of violet opsin (OPN1SW), which we found to result from incomplete sequence in the genome file GRCg6a. We therefore added the cDNA sequence to the annotation file.

\section{Antibodies and immunostaining}

Antibodies used in this study were: rabbit polyclonal antibodies to GFP (Millipore, AB3080P); mouse monoclonal anti-Brn3a (clone, 5A3.2, Millipore, MAB1585); rabbit anti-calretinin (Millipore, AB5054); rabbit anti-calbindin (Swant, CB38); rabbit antiprotein kinase C- a (PKCa) (Sigma, P4334); rabbit anti-VSX2 (Chx10, GeneTex, GTX114143); rat monoclonal anti-HA tag (Roche, 3F10); rabbit anti-Satb1(Abcam, ab109122); mouse monoclonal anti-Satb2 (Abcam, ab51502); rabbit anti-Metenkephalin (ImmunoStar, 20065); rabbit anti-neuropeptide Y (Abcam ab10980). Mouse monoclonal antibodies AP2A (clone, 3B5), OTX1 (Otx-5F5) and PAX6 were from Developmental Studies Hybridoma Bank (lowa City, IA). A mouse monoclonal antibody to neuromedin-B (NMB1) was previously described (Yamagata et al., 2006) and is available from Developmental Studies Hybridoma Bank.

Antibodies to cell surface proteins were generated by immunizing $L$ cells that had been stably transfected with cDNAs (Yamagata and Sanes, 2012). To generate stable cell lines, full length cDNAs were generated using SuperScript III (Thermo Fisher), amplified from cDNA obtained from chick retina using a high-fidelity Phusion DNA polymerase (NEB), cloned into a piggyBac transposon vector $\mathrm{pXL}-\mathrm{CAG}-\mathrm{Zeocin}-3 \times \mathrm{F} 2 \mathrm{~A}$ (Notl/Ascl 
sites; Martell et al., 2016) by Gibson assembly (NEBuilder HiFi DNA Assembly, NEB), transfected to $L$ cells together with a piggyBac transposase vector pCAG-PBorf using Transporter 5 transfection reagent (Polyscience), and selected in $1 \mathrm{mg} / \mathrm{ml}$ Zeocin (Invivogen) for 10-14 days. Cells resistant to Zeocin were pooled, grown, harvested, and rinsed with PBS three times. Female mice were then injected intraperitoneally with $10^{7}$ cells in $0.5 \mathrm{ml} 4-5$ times at $2-3$ weeks intervals, beginning at 6 weeks of age. Antiserum was then collected, incubated with paraformaldehyde-fixed untransfected $L$ cells to remove irrelevant antibodies, and used for immunostaining. To validate antibodies, 293T human embryonic kidney cells were transfected with each construct, and immunostained. In each case, the antibody stained cells transfected with a cDNA encoding the cognate immunogen but not untransfected cells or cells transfected with cDNA encoding other immunogents (data not shown).

For immunostaining, retinas were fixed with $4 \%(\mathrm{w} / \mathrm{v})$ paraformaldehyde/PBS overnight at $4^{\circ} \mathrm{C}$, sunk in $15 \%(\mathrm{w} / \mathrm{v})$ and $30 \%(\mathrm{w} / \mathrm{v})$ sucrose/PBS, and mounted in Tissue Freezing Medium (EM Sciences, Hatfield, PA). Sections were cut in a cryostat, either permeabilized with $0.1 \%(\mathrm{w} / \mathrm{v})$ TritonX-100/PBS for $5 \mathrm{~min}$ at room temperature or with $100 \%$ methanol for $15 \mathrm{~min}$ at $-20 \mathrm{C}$, blocked with $5 \%(\mathrm{w} / \mathrm{v})$ skim milk/PBS for $30 \mathrm{~min}$ at room temperature, incubated with appropriate antibodies overnight, rinsed, and incubated with appropriate secondary antibodies (Jackson ImmunoResearch, West Grove, PA) and NeuroTrace 640 (ThermoFisher/lnvitrogen). After rinsing with PBS, sections were mounted in VECTASHIELD (Vector Labs, Burlingame, CA) and imaged with a Zeiss Meta510 confocal microscope (Oberkochen, Germany).

\section{In situ hybridization}

cDNA for generating RNA probes were amplified from cDNA obtained from chick retina using SuperScript III (Thermo Fisher) and a high-fidelity Phusion DNA polymerase (NEB) and cloned into either $\mathrm{pCMV}$ vectors using Gibson Assembly or into pCR2.1 TOPO (Thermo Fisher) by TOPO cloning. Probe sequences are listed in Supplemental Table 1.

RNA probes were generated from the linearized plasmids using T7 RNA polymerase (Thermo Fisher) and digoxygenin- or fluorescein-labeled nucleotides (Roche), and hydrolyzed to around $500 \mathrm{bp}$ if needed. In situ hybridization using nitro-blue tetrazolium and 5-bromo-4-chloro-3'-indolyphosphate and double color in situ hybridization using TSA Plus (PerkinElmer) were performed as previously described (Yamagata et al.,1999; Yamagata and Sanes, 2012). For double color in situ hybridization, slides were incubated with $0.1 \mathrm{M}$ glycine- $\mathrm{HCl}, \mathrm{pH} 2.0$, for $30 \mathrm{~min}$ at room temperature following the first color reaction to remove peroxidase-conjugated anti-hapten antibodies and thereby avoid cross-reactivity. Sections were mounted in and imaged with a Zeiss Meta510 confocal microscope.

\section{eCHIKIN}

To label and visualize cells that express marker genes, we devised eCHIKIN (electroporation- and $\underline{\mathbf{C}} R I S P R-m e d i a t e d \underline{H}$ Homology-Instructed Knock-IN). nBriefly, our method resembles in several respects two others that adapted the initial SLENDR 
technology (Mikuni et al., 2016) to mouse embryos (Otsuka et al., 2018; Miura et al., 2018; Gurumurthy et al., 2019). We introduced CRISPR/Cas9 ribonucleoprotein complexes and single strand DNA to chick embryos by in ovo electroporation, using reagents from the Alt-R CRISPR-Cas9 System (IDT, Coralville, IA). Cas9 requires a CRISPR RNA (crRNA) to specify the DNA target sequence. The crRNA sequence was designed to target the sequence near the initiation codon (ATG) based on S. pyogenes PAM sequence and the MIT guide specificity score in the UCSC genome browser (https://genome.ucsc.edu) (Supplemental Table 2). The crRNA (0.1nmole) was first annealed with an equimolar amount of transactivating crRNA (tracrRNA) in $5 \mu$ in the annealing buffer (GenScript) by heating at $95^{\circ} \mathrm{C}$ for $5 \mathrm{~min}$ followed by rapid chilling. This product was then incubated with $S$. pyogenes Cas9 protein $(5 \mu \mathrm{g})$ for $60 \mathrm{~min}$ at room temperature to prepare a ribonucleoprotein complex. This complex was mixed with a single strand DNA (0.1-0.5 $\mu \mathrm{g})$ and the other components described below. Each single strand DNA possess $\sim 70$ bases gene-specific homology arms at the both ends (Supplemental Table 2). Short single strand DNAs were purchased from IDT (Coralville, lowa). Longer single strand DNA was prepared by asymmentric PCR using a 1:100 ratio of two primers. Templates included Venus (Aequorea coerulescens GFP variant) or Cre (Addgene plasmid \#14797). Following amplification with EconoTaq PLUS GREEN 2X Master Mix (Lucigen), products were agarose gel-purified to select single strand DNA using the QiaQuick Gel Extraction kit (Qiagen); 20\%(v/v) isopropanol was added to the solubilization solution before binding to spin columns.

The mixture of ribonucleoprotein and single strand DNA (0.1-0.5 $\mathrm{gg}$ ) was electroporated to developing chick embryos (Hamburger-Hamilton stage $\sim 10, E 1.5$ ) together with $1 \mu \mathrm{M}$ Cas9 electroporation enhancer (carrier DNA from IDT) and 0.1mM HDR enhancer (DNA ligase IV inhibitor from IDT) to enhance homologous recombination. We also added $1 \mu \mathrm{g}$ piggyBac transposon reporter ( $\mathrm{pXL}-\mathrm{CAG}-\mathrm{mCherry}$ ) and $0.1 \mu \mathrm{g}$ a transposase construct (pCAG-PBorf) to monitor successful electroporation. For Cre activation, $1 \mu \mathrm{g}$ of $\mathrm{pXL}-$ CAG-loxP-STOP-loxP-Venus was also included. All the DNA reagents were prepared in advance as ribonuclease-free by extensive phenol-chloroform extractions followed by ethanol precipitation and rinsing with $70 \%(\mathrm{v} / \mathrm{v})$ ethanol. $0.01 \%(\mathrm{w} / \mathrm{v})$ Fast Green (Sigma) was added to monitor injection.

Electroporation was with six square pulses of $7 \mathrm{~V}$ for $25 \mathrm{~ms}$ using ECM830 (Harvard Apparatus) after immersing electrodes with Hanks' balanced salt solution supplemented with $50 \mu \mathrm{g} / \mathrm{ml}$ kanamycin. After sealing eggshells with plastic tapes, eggs were returned to $37^{\circ} \mathrm{C}$ incubator.

\section{Image and statistical analysis}

Images were processed with Adobe Photoshop, and Image-J (Version 1.47d, Fiji). Position of spots were measured using Image-J. Single cell RNA-Seq data were analyzed using R 3.6.2 (The R foundation, https://www.r-project.org/).

\section{Data availability}

Single cell RNA-Seq dataset generated in the current study has been deposited at GEO with accession number: GSE159107. Data can be visualized at the Broad Institute 
Single Cell Portal using the link:

https://singlecell.broadinstitute.org/single_cell/study/SCP1159. Cells from other species are acquired from the following dataset:

\begin{tabular}{|c|c|}
\hline Cell classes and & GEO accession number: \\
\hline Mouse Rods & GSE63472 \\
\hline Mouse Bipolar cells & GSE81904 \\
\hline Mouse all other classes & GSE149715 \\
\hline Macaque all classes & GSE118852 \\
\hline Human all classes & GSE148077 \\
\hline
\end{tabular}

\section{ACKNOWLEDGEMENTS}

This work was supported by grants R01EY022073 and R37NS029169 from the NIH. We thank Mallory A. Laboulaye for participation in initial studies and Karthik Shekhar for advice. 


\section{REFERENCES}

Adler R (2000), A model of retinal cell differentiation in the chick embryo. Progress in retinal and eye research 19:529-557. 10.1016/s1350-9462(00)00008-2

Baden T, Euler T, Berens $P$ (2020), Understanding the retinal basis of vision across species. Nature Reviews Neuroscience 21:5-20. 10.1038/s41583-019-0242-1

Baden T, Osorio D (2019), The retinal basis of vertebrate color vision. Annual review of vision science 5:177-200. 10.1146/annurev-vision-091718-014926

Bassett EA, Pontoriero GF, Feng W, Marquardt T, Fini ME, Williams T, West-Mays JA (2007), Conditional deletion of activating protein $2 \alpha$ (AP-2 $\alpha$ ) in the developing retina demonstrates non-cell-autonomous roles for AP-2 $\alpha$ in optic cup development. Molecular and cellular biology 27:7497-7510. 10.1128/MCB.00687-07

Batiuk MY, Martirosyan A, Wahis J, de Vin F, Marneffe C, Kusserow C, Koeppen J, Viana JF, Oliveira JF, Voet T, Ponting CP, Belgard TG, Holt MG (2020), Identification of region-specific astrocyte subtypes at single cell resolution. Nat Commun. 11:1220. 10.1038/s41467-019-14198-8

Bayraktar OA, Bartels T, Holmqvist S, Kleshchevnikov V, Martirosyan A, Polioudakis D, Ben Haim L, Young AMH, Batiuk MY, Prakash K, Brown A, Roberts K, Paredes MF, Kawaguchi R, Stockley JH, Sabeur K, Chang SM, Huang E, Hutchinson P, Ullian EM, Hemberg M, Coppola G, Holt MG, Geschwind DH, Rowitch DH (2020) Astrocyte layers in the mammalian cerebral cortex revealed by a single-cell in situ transcriptomic map. Nat Neurosci. 23:500-509. 10.1038/s41593-020-0602-1

Boije H, Shirazi Fard S, Edqvist P-H, Hallböök F (2016), Horizontal cells, the odd ones out in the retina, give insights into development and disease. Frontiers in neuroanatomy 10:77. 10.3389/fnana.2016.00077

Brecha NC, Eldred W, Kuljis RO, Karten H (1984), Identification and localization of biologically active peptides in the vertebrate retina. Progress in retinal research 3:185226. 10.1016/0278-4327(84)90009-9

Britto LR, Keyser KT, Hamassaki DE, Karten HJ (1988), Catecholaminergic subpopulation of retinal displaced ganglion cells projects to the accessory optic nucleus in the pigeon (Columba livia). Journal of Comparative Neurology 269:109-117. 10.1002/cne.902690109

Bruhn SL, Cepko CL (1996), Development of the pattern of photoreceptors in the chick retina. Journal of Neuroscience 16:1430-1439. 10.1523/JNEUROSCI.16-04-01430.1996

Brzezinski 4th JA, Park KU, Reh TA (2013), Blimp1 (Prdm1) prevents re-specification of photoreceptors into retinal bipolar cells by restricting competence. Developmental biology 384:194-204. 10.1016/j.ydbio.2013.10.006

Cajal SR (1892), La retine des vertébrés (The structure of the retina) English translation edited by Thorpe, S. A. and Glickstein, M., Charles C. Thomas: Springfield, IL, USA.

Cao J, Spielmann M., Qiu X, Huang X, Ibrahim D, Hill A, Zhang F, Mundlos S, Christiansen L, Steemers F, Trapnell C, Shendure J (2019), The single-cell 
transcriptional landscape of mammalian organogenesis. Nature 566, 496-502. 10.1038/s41586-019-0969-x

Cepko CL, Austin CP, Yang X, Alexiades M, Ezzeddine D (1996), Cell fate determination in the vertebrate retina. Proceedings of the National Academy of Sciences 93:589-595. 10.1073/pnas.93.2.589

Chaurasia S, Rollag M, Jiang G, Hayes W, Haque R, Natesan A, Zatz M, Tosini G, et al. (2005), Molecular cloning, localization and circadian expression of chicken melanopsin (Opn4): differential regulation of expression in pineal and retinal cell types. Journal of neurochemistry 92:158-170. 10.1111/j.1471-4159.2004.02874.x

Chen C-MA, Cepko CL (2000), Expression of Chx10 and Chx10-1 in the developing chicken retina. Mechanisms of development 90:293-297. 10.1016/s0925-

4773(99)00251-8

Chen T, Guestrin C, (2016), Xgboost: A scalable tree boosting system, Proceedings of the 22nd acm sigkdd international conference on knowledge discovery and data mining, 2016, pp. 785-794. 10.1145/2939672.2939785

Cheng H-J, Nakamoto M, Bergemann AD, Flanagan JG (1995), Complementary gradients in expression and binding of ELF-1 and Mek4 in development of the topographic retinotectal projection map. Cell 82:371-381. 10.1016/0092-8674(95)904263

Cook RG (2000), The comparative psychology of avian visual cognition. Current Directions in Psychological Science 9:83-89. 10.1111/1467-8721.00066

Creevey CJ, Mclnerney JO (2005), Clann: Investigating phylogenetic information through supertree analyses. Bioinformatics 21: 390-392. 10.1093/bioinformatics/bti020

da Silva S, Cepko CL (2017), Fgf8 expression and degradation of retinoic acid are required for patterning a high-acuity area in the retina. Developmental cell 42:68-81. e66. 10.1016/j.devcel.2017.05.024

Dhande OS, Stafford BK, Lim J-HA, Huberman AD (2015), Contributions of retinal ganglion cells to subcortical visual processing and behaviors. Annual review of vision science 1:291-328. 10.1146/annurev-vision-082114-035502

Dowling JE (2012), The Retina: An Approachable Part of the Brain, Revised Edition. The Belknap Press of Harvard University Press, Cambridge, MA, USA

Drenhaus U, Morino P, Veh RW (2003), On the development of the stratification of the inner plexiform layer in the chick retina. Journal of Comparative Neurology 460:1-12. 10.1002/cne.10602

Duan X, Krishnaswamy A, Laboulaye MA, Liu J, Peng YR, Yamagata M, Toma K, Sanes JR (2018), Cadherin Combinations Recruit Dendrites of Distinct Retinal Neurons to a Shared Interneuronal Scaffold. 99:1145-1154. doi: 10.1016/j.neuron.2018.08.019.

Edqvist P-HD, Lek M, Boije H, Lindbäck SM, Hallböök F (2008), Axon-bearing and axon-less horizontal cell subtypes are generated consecutively during chick retinal 
development from progenitors that are sensitive to follistatin. BMC developmental biology 8:46. 10.1186/1471-213X-8-46

Eisenberg E, Levanon EY (2013), Human housekeeping genes, revisited. Trends in Genetics 29:569-574. 10.1016/j.tig.2013.05.010

Enright JM, Lawrence KA, Hadzic T, Corbo JC (2015), Transcriptome profiling of developing photoreceptor subtypes reveals candidate genes involved in avian photoreceptor diversification. Journal of Comparative Neurology 523:649-668. 10.1002/cne.23702

Euler T, Haverkamp S, Schubert T, Baden T (2014), Retinal bipolar cells: elementary building blocks of vision. Nature Reviews Neuroscience 15:507-519. 10.1038/nrn3783

Finak G, McDavid A, Yajima M, Deng J, Gersuk V, Shalek AK, Slichter CK, Miller HW, et al. (2015), MAST: a flexible statistical framework for assessing transcriptional changes and characterizing heterogeneity in single-cell RNA sequencing data. Genome biology 16:278. 10.1186/s13059-015-0844-5

Fischer AJ, Scott MA, Zelinka C, Sherwood P (2010), A novel type of glial cell in the retina is stimulated by insulin-like growth factor 1 and may exacerbate damage to neurons and Müller glia. Glia 58:633-649. 10.1002/glia.20950

Fischer AJ, Stanke JJ, Aloisio G, Hoy H, Stell WK (2007), Heterogeneity of horizontal cells in the chicken retina. Journal of Comparative Neurology 500:1154-1171.

10.1002/cne.21236

French P, Jeffrey P (1986), Partial characterization of chicken Thy-1 glycoprotein by monoclonal antibodies. Journal of neuroscience research 16:479-489.

10.1002/jnr.490160304

Goldman SA, Kuypers NJ (2015), How to make an oligodendrocyte. Development 142:3983-3995. 10.1242/dev.126409

Greferath U, Grünert U, Wässle H (1990), Rod bipolar cells in the mammalian retina show protein kinase C-like immunoreactivity. Journal of Comparative Neurology 301:433-442. 10.1002/cne.903010308

Gurumurthy CB, Sato M, Nakamura A, Inui M, Kawano N, Islam MA, Ogiwara S, Takabayashi S, et al. (2019), Creation of CRISPR-based germline-genome-engineered mice without ex vivo handling of zygotes by i-GONAD. Nature protocols 14:2452-2482. 10.1038/s41596-019-0187-x

Hamburger V, Hamilton HL (1951), A series of normal stages in the development of the chick embryo. Journal of morphology 88:49-92. [10.1002/aja.1001950404]

Hart NS (2001), The visual ecology of avian photoreceptors. Progress in retinal and eye research 20:675-703. 10.1016/s1350-9462(01)00009-X

Hayes B (1982), The structural organization of the pigeon retina. Progress in retinal research 1:197-226. 10.1016/0278-4327(82)90009-8

Hoang T, Wang J, Boyd P, Wang F, Santiago C, Jiang L, Yoo S, Lahne M, Todd LJ, Jia M, Saez C, Keuthan C, Palazzo I, Squires N, Campbell WA, Rajaii F, Parayil 
T, Trinh V, Kim DW, Wang G, Campbell LJ, Ash J, Fischer AJ, Hyde DR, Qian J, Blackshaw S (2020), Gene regulatory networks controlling vertebrate retinal regeneration Science 10.1126/science.abb8598

Hoon M, Okawa H, Della Santina L, Wong RO (2014), Functional architecture of the retina: development and disease. Progress in retinal and eye research 42:44-84. 10.1016/j.preteyeres.2014.06.003

Isken A, Golczak M, Oberhauser V, Hunzelmann S, Driever W, Imanishi Y, Palczewski K, von Lintig J (2008), RBP4 disrupts vitamin A uptake homeostasis in a STRA6deficient animal model for Matthew-Wood syndrome. Cell metabolism 7:258-268. 10.1016/j.cmet.2008.01.009

Kahn A (1974), An autoradiographic analysis of the time of appearance of neurons in the developing chick neural retina. Developmental biology 38:30-40. 10.1016/00121606(74)90256-5

Karten H, Keyser K, Brecha N (1990), Biochemical and morphological heterogeneity of retinal ganglion cells. Research publications-Association for Research in Nervous and Mental Disease 67:19. 10.1016/0012-1606(74)90256-5

Karten HJ, Brecha N (1983), Localization of neuroactive substances in the vertebrate retina: evidence for lamination in the inner plexiform layer. Vision research 23:11971205. 10.1016/0042-6989(83)90033-0

Katoh K, Omori Y, Onishi A, Sato S, Kondo M, Furukawa T (2010), Blimp1 suppresses Chx10 expression in differentiating retinal photoreceptor precursors to ensure proper photoreceptor development. Journal of Neuroscience 30:6515-6526. 10.1523/JNEUROSCI.0771-10.2010

Kölsch Y, Hahn J, Sappington A, Stemmer M, Fernandes AM, Helmbrecht TO, Lele S, Butrus S, Laurell E, Arnold-Ammer I, Shekhar $\mathrm{K}^{*}$, Sanes $\mathrm{JR}^{*}$, Baier $\mathrm{H}^{*}$. Molecular classification of zebrafish retinal ganglion cells links genes to cell types to behavior bioRxiv 2020.07.29.226050

Kram YA, Mantey S, Corbo JC (2010), Avian cone photoreceptors tile the retina as five independent, self-organizing mosaics. PloS one 5: e8992

10.1371/journal.pone.0008992

Krishnaswamy A, Yamagata M, Duan X, Hong YK, Sanes JR (2015), Sidekick 2 directs formation of a retinal circuit that detects differential motion. Nature 524:466-470. 10.1038/nature14682

Kumar S, Hedges SB (1998), A molecular timescale for vertebrate evolution. Nature. 392:917-920. doi: 10.1038/31927

Lamb TD, Collin SP, and Pugh EN Jr (2007), Evolution of the vertebrate eye: opsins, photoreceptors, retina and eye cup. Nat Rev Neurosci. 8:960-976. 10.1038/nrn2283

Langouet-Astrie CJ, Meinsen AL, Grunwald ER, Turner SD, Enke RA (2016), RNA sequencing analysis of the developing chicken retina. Scientific data 3:1-8.

10.1038/sdata.2016.117 
Lemmon MA, Schlessinger J (2010), Cell signaling by receptor tyrosine kinases. Cell 141:1117-1134. 10.1016/j.cell.2010.06.011

Li YN, Tsujimura T, Kawamura S, Dowling JE (2012), Bipolar cell-photoreceptor connectivity in the zebrafish (Danio rerio) retina. Journal of Comparative Neurology 520:3786-3802. 10.1002/cne.23168

Linser P, Moscona A (1979), Induction of glutamine synthetase in embryonic neural retina: localization in Müller fibers and dependence on cell interactions. Proceedings of the National Academy of Sciences 76:6476-6480. 10.1073/pnas.76.12.6476

López-López R, López-Gallardo M, Pérez-Álvarez M, Prada C (2008), Isolation of chick retina cones and study of their diversity based on oil droplet colour and nucleus position. Cell and tissue research 332:13. 10.1007/s00441-007-0572-6

Macosko EZ, Basu A, Satija R, Nemesh J, Shekhar K, Goldman M, Tirosh I, Bialas AR, Kamitaki N, Martersteck EM, Trombetta JJ, Weitz DA, Sanes JR, Shalek AK, Regev A, McCarroll SA (2015), Highly parallel genome-wide expression profiling of individual cells using nanoliter droplets. Cell 161:1202-1214. 10.1016/j.cell.2015.05.002

Maeda M, Hasegawa H, Hyodo T, Ito S, Asano E, Yuang H, Funasaka K, Shimokata K, et al. (2011), ARHGAP18, a GTPase-activating protein for RhoA, controls cell shape, spreading, and motility. Molecular biology of the cell 22:3840-3852. 10.1091/mbc.E1104-0364

Mao C-A, Li H, Zhang Z, Kiyama T, Panda S, Hattar S, Ribelayga CP, Mills SL, Wang SW (2014), T-box transcription regulator Tbr2 is essential for the formation and maintenance of Opn4/melanopsin-expressing intrinsically photosensitive retinal ganglion cells. Journal of Neuroscience 34:13083-13095. 10.1523/JNEUROSCI.102714.2014

Mariani AP, Leure-DuPree AE (1977), Horizontal cells of the pigeon retina. Journal of Comparative Neurology 175:13-26. 10.1002/cne.901750103

Martersteck EM, Hirokawa KE, Evarts M, Bernard A, Duan X, Li Y, Ng L, Oh SW, Ouellette B, Royall JJ, Stoecklin M, Wang Q, Zeng H, Sanes JR, Harris JA (2017), Diverse central projection patterns of retinal ganglion cells. Cell reports 18:2058-2072. 10.1016/j.celrep.2017.01.075

Masland RH (2012), The neuronal organization of the retina. Neuron 76:266-280. 10.1016/j.neuron.2012.10.002

Matsuda T, Oinuma I (2019), Optimized CRISPR/Cas9-mediated in vivo genome engineering applicable to monitoring dynamics of endogenous proteins in the mouse neural tissues. Sci Rep. 9:11309. 10.1038/s41598-019-47721-4

McInnes L, Healy J (2018), UMAP: Uniform Manifold Approximation and Projection for Dimension Reduction, ArXiv 1802.03426

Mey J, Thanos S (2000), Development of the visual system of the chick: I. Cell differentiation and histogenesis. Brain research reviews 32:343-379. 10.1016/s01650173(99)00022-3 
Mikuni T (2020), Genome editing-based approaches for imaging protein localization and dynamics in the mammalian brain. Neuroscience research 150:2-7.

10.1016/j.neures.2019.04.007

Mikuni T, Nishiyama J, Sun Y, Kamasawa N, Yasuda R (2016), High-throughput, highresolution mapping of protein localization in mammalian brain by in vivo genome editing. Cell 165:1803-1817. 10.1016/j.cell.2016.04.044

Millar T, Ishimoto I, Chubb I, Epstein M, Johnson C, Morgan I (1987), Cholinergic amacrine cells of the chicken retina: a light and electron microscope immunocytochemical study. Neuroscience 21:725-743. 10.1016/0306-4522(87)90033-9

Millar T, Winder C, Ishimoto I, Morgan I (1988), Putative serotonergic bipolar and amacrine cells in the chicken retina. Brain research 439:77-87. 10.1016/00068993(88)91463-1

Miura H, Quadros RM, Gurumurthy CB, Ohtsuka M (2018), Easi-CRISPR for creating knock-in and conditional knockout mouse models using long ssDNA donors. Nature protocols 13:195.

Morgans CW, Brown RL, Duvoisin RM (2010), TRPM1: The endpoint of the mGluR6 signal transduction cascade in retinal ON-bipolar cells. Bioessays 32:609-614.

Morgans CW, Zhang J, Jeffrey BG, Nelson SM, Burke NS, Duvoisin RM, Brown RL (2009), TRPM1 is required for the depolarizing light response in retinal ON-bipolar cells. Proceedings of the National Academy of Sciences 106:19174-19178.

Naito J, Chen Y (2004), Morphologic analysis and classification of ganglion cells of the chick retina by intracellular injection of Lucifer Yellow and retrograde labeling with Dil. Journal of Comparative Neurology 469:360-376.

Nicol CJ (2015), The behavioural biology of chickens. CABI Publishing, Oxfordshire, UK.

Ohtsuka M, Sato M, Miura H, Takabayashi S, Matsuyama M, Koyano T, Arifin N, Nakamura S, et al. (2018), i-GONAD: a robust method for in situ germline genome engineering using CRISPR nucleases. Genome biology 19:25.

Oishi T, Kawata A, Hayashi T, Fukada Y, Shichida Y, Yoshizawa T (1990), Immunohistochemical localization of iodopsin in the retina of the chicken and Japanese quail. Cell and tissue research 261:397-401.

Ono K, Yasui Y, Rutishauser U, Miller RH (1997), Focal ventricular origin and migration of oligodendrocyte precursors into the chick optic nerve. Neuron 19:283-292.

10.1016/s0896-6273(00)80939-3

Peng YR, Tran NM, Krishnaswamy A, Kostadinov D, Martersteck EM, Sanes JR (2017), Satb1 Regulates Contactin 5 to Pattern Dendrites of a Mammalian Retinal Ganglion Cell. Neuron. 95:869-883. doi: 10.1016/j.neuron.2017.07.019.

Peng Y-R, James RE, Yan W, Kay JN, Kolodkin AL, Sanes JR (2020), Binary fate choice between closely related interneuronal types is determined by a Fezf1-dependent postmitotic transcriptional switch. Neuron 105:464-474. 10.1016/j.neuron.2019.11.002 
Peng Y-R, Shekhar K, Yan W, Herrmann D, Sappington A, Bryman GS, van Zyl T, Do $\mathrm{MTH}$, et al. (2019), Molecular classification and comparative taxonomics of foveal and peripheral cells in primate retina. Cell 176:1222-1237. e1222.

10.1016/j.cell.2019.01.004

Piri N, Kwong JM, Song M, Caprioli J (2006), Expression of hermes gene is restricted to the ganglion cells in the retina. Neuroscience letters 405:40-45.

10.1016/j.neulet.2006.06.049

Plump AS, Erskine L, Sabatier C, Brose K, Epstein CJ, Goodman CS, Mason CA, Tessier-Lavigne M (2002), Slit1 and Slit2 cooperate to prevent premature midline crossing of retinal axons in the mouse visual system. Neuron 33:219-232.

10.1016/s0896-6273(01)00586-4

Prada C, Puga J, Pérez-Méndez L, López R, Ramírez G (1991), Spatial and temporal patterns of neurogenesis in the chick retina. European Journal of Neuroscience 3:559569. 10.1111/j.1460-9568.1991.tb00843.x

Quesada A, Prada F, Genis-Galvez J (1988), Bipolar cells in the chicken retina. Journal of morphology 197:337-351. 10.1002/jmor.1051970308

Ray TA, Roy S, Kozlowski C, Wang J, Cafaro J, Hulbert SW, Wright CV, Field GD, Kay JN (2018). Formation of retinal direction-selective circuitry initiated by starburst amacrine cell homotypic contact. Elife. 7:e34241.

Reichenbach A, Bringmann A (2013), New functions of Müller cells. Glia 61:651-678. 10.1002/glia.22477

Rheaume BA, Jereen A, Bolisetty M, Sajid MS, Yang Y, Renna K, Sun L, Robson P, et al. (2018), Single cell transcriptome profiling of retinal ganglion cells identifies cellular subtypes. Nature communications 9:1-17. 10.1038/s41467-018-05134-3

Rompani SB, Cepko CL (2010), A common progenitor for retinal astrocytes and oligodendrocytes. Journal of Neuroscience 30:4970-4980. 10.1523/JNEUROSCI.345609.2010

Sakuta H, Suzuki R, Takahashi H, Kato A, Shintani T, lemura S-i, Yamamoto TS, Ueno N , Noda M (2001), Ventroptin: a BMP-4 antagonist expressed in a double-gradient pattern in the retina. Science 293:111-115. 10.1126/science.1058379

Sanes JR, Masland RH (2015), The types of retinal ganglion cells: current status and implications for neuronal classification. Annual review of neuroscience 38:221-246. 10.1146/annurev-neuro-071714-034120

Seifert M, Baden T, Osorio D (2020) The retinal basis of vision in chicken. Seminars in Cell \& Developmental Biology 106:106-115. 10.1016/j.semcdb.2020.03.011

Shekhar K, Lapan SW, Whitney IE, Tran NM, Macosko EZ, Kowalczyk M, Adiconis X, Levin JZ, et al. (2016), Comprehensive classification of retinal bipolar neurons by single-cell transcriptomics. Cell 166:1308-1323. e1330. 10.1016/j.cell.2016.07.054 
Shichida Y, Yamashita T (2003), Diversity of visual pigments from the viewpoint of G protein activation-comparison with other $\mathrm{G}$ protein-coupled receptors. Photochemical Photobiological Science 2:1237-1246. 10.1039/b300434a.

Smith RL, Nishimura Y, Raviola G (1985) Interreceptor junction in the double cone of the chicken retina. J Submicroscopic Cytology 17:183-186. [DOI not available]

Spence SG, Robson J (1989), An autoradiographic analysis of neurogenesis in the chick retinain vitro and in vivo. Neuroscience 32:801-812.10.1016/0306-4522(89)90300 $\mathrm{x}$

Terakita A (2005), The opsins. Genome biology 6:213. 10.1186/gb-2005-6-3-213

Thanos S, Mey J (2001), Development of the visual system of the chick: II. Mechanisms of axonal guidance. Brain research reviews 35:205-245. 10.1016/s0165-

0173(01)00049-2

Thoreson WB, Dacey DM (2019), Diverse cell types, circuits, and mechanisms for color vision in the vertebrate retina. Physiological reviews 99:1527-1573.

10.1152/physrev.00027.2018

Tran NM, Shekhar K, Whitney IE, Jacobi A, Benhar I, Hong G, Yan W, Adiconis X, Arnold ME, Lee JM, Levin JZ, Lin D, Wang C, Lieber CM, Regev A, He Z, Sanes JR (2019), Single-cell profiles of retinal ganglion cells differing in resilience to injury reveal neuroprotective genes. Neuron 104:1039-1055. e1012. 10.1016/j.neuron.2019.11.006

Vecino E, Rodriguez FD, Ruzafa N, Pereiro X, Sharma SC (2016), Glia-neuron interactions in the mammalian retina. Progress in retinal and eye research 51:1-40. 10.1016/j.preteyeres.2015.06.003

Wang J, O'Sullivan ML, Mukherjee D, Puñal VM, Farsiu S, Kay JN (2017), Anatomy and spatial organization of Müller glia in mouse retina. J Comp Neurol. 525:1759-

1777. 10.1002/cne.24153

Wässle H (2004), Parallel processing in the mammalian retina. Nature Reviews Neuroscience 5:747-757. 10.1038/nrn1497

Wilken MS, Reh TA (2016), Retinal regeneration in birds and mice. Current opinion in genetics \& development 40:57-64. 10.1016/j.gde.2016.05.028

Wisely CE, Sayed JA, Tamez H, Zelinka C, Abdel-Rahman MH, Fischer AJ, Cebulla CM (2017), The chick eye in vision research: an excellent model for the study of ocular disease. Progress in retinal and eye research 61:72-97.

10.1016/j.preteyeres.2017.06.004

Yamagata M, Mai A, Pollerberg GE, Noda M (1999), Regulatory interrelations among topographic molecules CBF1, CBF2 and EphA3 in the developing chick retina. Development, growth \& differentiation 41:575-587. 10.1046/j.1440-169x.1999.00462.x

Yamagata M, Sanes JR (1995a), Lamina-specific cues guide outgrowth and arborization of retinal axons in the optic tectum. Development 121:189-200. [DOI not available] 
Yamagata M, Sanes JR (1995b), Target-independent diversification and target-specific projection of chemically defined retinal ganglion cell subsets. Development 121:37633776. [DOI not available]

Yamagata M, Sanes JR (2012), Expanding the Ig superfamily code for laminar specificity in retina: expression and role of contactins. Journal of Neuroscience 32:14402-14414. 10.1523/JNEUROSCI.3193-12.2012

Yamagata M, Sanes JR (2019), Expression and Roles of the Immunoglobulin Superfamily Recognition Molecule Sidekick1 in Mouse Retina. Frontiers in molecular neuroscience 11:485. 10.3389/fnmol.2018.00485

Yamagata M, Weiner JA, Dulac C, Roth KA, Sanes JR (2006), Labeled lines in the retinotectal system: markers for retinorecipient sublaminae and the retinal ganglion cell subsets that innervate them. Molecular and Cellular Neuroscience 33:296-310. 10.1016/j.mcn.2006.08.001

Yamagata M, Weiner JA, Sanes JR (2002), Sidekicks: synaptic adhesion molecules that promote lamina-specific connectivity in the retina. Cell 110:649-660. 10.1016/s00928674(02)00910-8

Yan W, Laboulaye MA, Tran NM, Whitney IE, Benhar I, Sanes JR (2020a), Mouse retinal cell atlas: molecular identification of over sixty amacrine cell types. Journal of Neuroscience. 40:5177-5195. 10.1523/JNEUROSCI.0471-20.2020

Yan W, Peng Y-R, van Zyl T, Regev A, Shekhar K, Juric D, Sanes J (2020b), Cell Atlas of the Human Fovea and Peripheral Retina. Scientific reports. 10:9802 $10.1038 / \mathrm{s} 41598-020-66092-9$

Yuasa J, Hirano S, Yamagata M, Noda M (1996), Visual projection map specified by topographic expression of transcription factors in the retina. Nature 382:632-635. 10.1038/382632a0

Zheng GX, Terry JM, Belgrader P, Ryvkin P, Bent ZW, Wilson R, Ziraldo SB, Wheeler TD , McDermott GP, Zhu J, Gregory MT, Shuga J, Montesclaros L, Underwood JG, Masquelier DA, Nishimura SY, Schnall-Levin M, Wyatt PW, Hindson CM, Bharadwaj R, Wong A, Ness KD, Beppu LW, Deeg HJ, McFarland C, Loeb KR, Valente WJ, Ericson NG, Stevens EA, Radich JP, Mikkelsen TS, Hindson BJ, Bielas JH (2017), Massively parallel digital transcriptional profiling of single cells. Nature communications 8:1-12. 10.1038/ncomms14049

Zhou Q, Choi G, Anderson DJ (2001), The bHLH transcription factor Olig2 promotes oligodendrocyte differentiation in collaboration with Nkx2.2. Neuron 31:791807. 10.1016/s0896-6273(01)00414-7 


\section{FIGURE LEGENDS}

\section{Figure 1 Datasets used to generate a chick retinal atlas}

A. Cross-section of chick retina stained with NeuroTrace to mark somata. The retina consists of three cellular layers: outer nuclear layer (ONL), inner nuclear layer (INL), and ganglion cell layer (GCL) separated by two synaptic layers, outer plexiform (OPL) and inner plexiform (IPL). Bar, 10 $\mu \mathrm{m}$

B. Sketch showing retinal cell classes. The ONL contains photoreceptors (PR): rods, single cones, and double cones. The INL contains horizontal, bipolar and amacrine cells (HC, BC, AC) and Müller glia (MG). The GCL contains retinal ganglion cells (RGCs) and ACs. Oligodendrocytes $(\mathrm{OL})$ are present in an axonal layer beneath the GCL.

C. Birthdates of each class, from Prada et al. (1991). Hatching (P0) is at embryonic day $(E) 21$. Arrows denote ages at which cells were obtained for scRNA-seq.

D. Expression of a subset of marker genes used to allocate E18 retinal cells to classes.

Plot shows transcript count per cell of a randomly down-sampled subset of all cells.

E. Fraction of E18 cells in each cell class, as determined by expression of canonical markers in D.

F. Fraction of E16 RGC-enriched cells in each cell class, determined as in D, E.

G. Number of clusters (putative cell types) in each retinal cell class, based on reclustering each class separately.

$H$. Fraction of E12 RGC-enriched cells in each cell class, determined as in D, E.

\section{Figure 1 -figure supplement 1}

A. Expression of housekeeping genes (Eisenberg and Levanon, 2013) in E18 retina. Clusters generated from initial unsupervised analysis are shown; following division into classes (Figure 1D,E), each class was reanalyzed to maximize the computational power in identifying clusters used in the remainder of the paper. Similar expression of these genes across clusters shows relatively uniform quality of cells analyzed.

B. Expression of house-keeping genes for E16 RGCs.

C. UMAP of E12 scRNA-seq data.

D. Expression patterns of a subset of marker genes used to allocate E12 retinal cells to classes, similar to Figure 1D.

E. Expression of house-keeping genes for E12 clusters.

\section{Figure 2 Introduction of tags and reporters to specific loci using eCHIKIN}

A. The eCHIKIN method. In ovo electroporation of Cas9/guideRNA ribonucleoprotein complexes edits the gene specified by the guide RNA, inserting a sequence encoding HA tag, GFP, or CRE. To identify transfected areas in tissues, a second fluorescent protein (GFP or mCherry) is expressed using the piggyBac transposon system. 
B-D. Insertion of HA epitope tag into the nuclear protein encoded by VSX2. Cells stained by the anti-HA antibody are in the inner (upper) portion of the INL where bipolar cells (labeled with anti-VSX2 in C) are located at E12. CAG-driven GFP is expressed in all the layers. No HA-labeled cells are present in the lower portion of the INL, which contains TFAP2-positive amacrine cells (D), and all HA-positive cells are TFAP2negative. In this and subsequent figures, sections were stained with NeuroTrace (blue) during mounting.

E, E', E'. GFP with a termination codon was inserted at the initiation codon of TFAP2A, an amacrine cell marker. In this case, GFP is not fused to TFAP2A protein, resulting in filling cytoplasm including neurites in the IPL at E12. TFAP2A protein is expressed by GFP-expressing cells, all of which are TFAP2A positive ACs. (Note that the eCHIKIN construct disrupts the TFAP2A open reading frame, so double labeling results from expression of endogenous TFAP2A and indicates that only a single TFAP2A allele was edited.

F. Insertion of HA epitope tag into the cytoplasmic protein encoded by RGC-specific RBPMS2 gene. Labeled cells are in the GCL at E10.

G. Insertion of Cre recombinase into the TFAP2A gene. The insertion construct was coelectroporated with a CAG- loxP-STOP-loxP-GFP construct, labeling a small number of amacrine cells with GFP at E14.

$\mathrm{H}$. Insertion of Cre recombinase into the RBPMS2 gene. The insertion construct was coelectroporated with CAG- loxP-STOP-loxP-GFP as in F, labeling a small number of RGCs with GFP at E14.

Bar in $\mathrm{H}, 10 \mu \mathrm{m}$ for $\mathrm{B}-\mathrm{E}, \mathrm{G} ; 5 \mu \mathrm{m}$ for $\mathrm{F}, \mathrm{H}$.

\section{Figure 3. Classification and characterization of photoreceptors}

A. Clustering of E18 PRs displayed in UMAP. Identities of each cluster are indicated to the right.

B. Dot plots showing expression of selected genes expressed in all or subsets of PRs. In this and subsequent figures, dot size indicates the proportion of cells that express each gene, and color indicates expression level normalized to its max value among clusters. Numbers correspond to clusters in A. Dendrogram above dots shows transcriptional relationships of clusters.

C-E. In situ hybridization of E16 sections (en face in C,D; vertical in E,F) with probes for cluster-specific genes. C, OPN1LW and OPN1MSW. D, OPN1LW and STRA6. Arrows show coexpression. E. OPN1LW and CALB1.

F. Immunostaining of E16 section with antibodies to STRA6 and CALB1.

G. Double cones (DCs) labeled by eCHIKIN-mediated insertion of GFP into the CALB1 locus. Section is from $\mathrm{E} 17$ retina. $\mathrm{G}$ ' is a high-power picture of a part of $\mathrm{G}$, showing an accessary DC (a) and principal DC (p) based on their position in ONL.

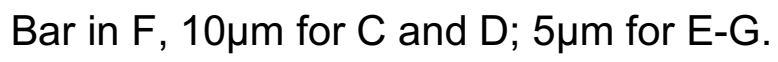


H. Relationship between immature and mature PR clusters assessed by XGBoost. Annotation of clusters is indicated in A. Dev, developing.

\section{Figure 3 -figure supplement 1}

A. Frequency distribution of PR types. Cluster numbers are from Figure 3A.

B, C. Clustering of PRs from E12 and E18 together and visualized in UMAP, showing that the majority of E12 cells are immature types while the majority of E18 cells are mature types. In B, colors represent annotations from E18 PRs. In C, distinct colors show E12 and E18 cells.

\section{Figure 3 -figure supplement 2}

A-D. In situ hybridization of $E 12$ retina $(A, B)$ and $E 20$ retina $(C, D)$ for OPN1LW and ARGHAP18.

E-P. Central and peripheral staining of SLIT1 (E-G), STRA6 (H-J), OPN1LW (K-M), $A R G H A P 18(\mathrm{~N}-\mathrm{P})$ at E16. D-peri, dorsal peripheral; V-peri, ventral peripheral. Bar, $10 \mu \mathrm{m}$.

Q. Summary sketch, showing expression of indicated genes at E16 and E18.

\section{Figure 4 Classification and characterization of horizontal cells}

A. Clustering of E18 HCs viewed by UMAP.

B. Dot plots showing expression of selected genes expressed in all or subsets of HCs. Numbers correspond to clusters in A. Dendrogram above dots shows transcriptional relationships of clusters. Numbers labeled on the tree are p-values computed by multiscale bootstrap resampling, ranging from 0-100, higher value indicates more likely the cluster exists instead of sampling error.

C-L. In situ hybridization with indicated probes at E16. C-I are cross-sections; J-L are en face sections. Arrowheads in C-I mark OPL.

C. Double color in situ hybridization shows coexpression of OXT and IPCEF1.

D-F. Expression of NTRK (D), EGFR (E), and LTK (F) in subsets of HCs.

G-I. Double color in situ hybridization for NTKR/ EGFR (G), LTK/ NTRK (H), and LTK /EGFR (I).

J-L. In situ hybridization of E16 en face sections for NTRK (J), EGFR (K), and LTK (L) showing mosaics of each type.

Bar in L, $5 \mu \mathrm{m}$ for C, G-I; $10 \mu \mathrm{m}$ for D-F, J-L.

\section{Figure 4 -figure supplement 1}

A. Frequency distribution of HCs. Cluster Numbers are from Figure 4A,B. 
B-M. In situ hybridization for OXT and IPCEF1 in central and peripheral retina at E14,

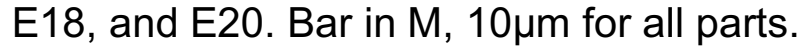

$\mathrm{N}, \mathrm{O}, \mathrm{P}$. Feature plots of E12 HCs, showing expression of markers that label $\mathrm{HC}$ types at E18.

\section{Figure 5 Classification and characterization of bipolar cells}

A. Clustering of E18 BCs visualized by UMAP.

B. Dot plots showing expression of selected genes expressed in all or subsets of BCs. Numbers correspond to clusters in A. Dendrogram above dots shows transcriptional relationships of clusters. Putative ON and OFF types, based on markers in $\mathrm{C}$, are indicated by color.

C. Expression of genes selectively expressed by ON (TRPM1, ISL1), OFF (GRIK1, FEZF1) and rod (PRKCA) BCs in rodents. OTX1 and SOX5 are uniquely expressed in putative $\mathrm{ON}$ clusters.

D-H. eCHIKIN-mediated labeling of cells expressing IRX3 (BC12, D), TPBGL (BC6, E), $\operatorname{RRAD}(\mathrm{BC7}, \mathrm{F}), \mathrm{SLC6A4}(\mathrm{BC} 15, \mathrm{G})$, and ANGPT2 $(\mathrm{BC} 1, \mathrm{H})$. E14 sections at E14 were stained with anti-GFP. Bar $10 \mu \mathrm{m}$.

I-K. Immunostaining with anti-TBBGL (I), anti-SLC6A4 (J), and anti-PRKCA (K). Bar $10 \mu \mathrm{m}$.

L. Summary of BC soma positions in INL and terminal positions in IPL.

\section{Figure 5 -figure supplement 1}

A. Frequency distribution of BCs. Cluster Numbers are from Figure 5A,B.

B-O. In situ hybridization or immunostaining of E16 retina with indicated probes:

B,C. GRIK1 (B) and TRPM1 (B), which mark OFF and ON bipolar cell populations, respectively, in mammals.

$\mathrm{D}, \mathrm{E}$. Double staining with anti-VSX2 (D) and anti-OTX1 (E).

F-O. Expression of markers for BC subsets. In situ hyridization for ERBB4 (F), TPBGL

(G), STRA6 (H), RRAD (I), SLC6A4 (K), PRKCA (L), MMEL1 (M), PENK (N), DACT2

(O). Immunostaining with anti-SOX5 (J). Positions of the BCs expressing ERBB4,

SOX5, PENK, and DACT2 are indicated by asterisk because these are also expressed by $\mathrm{ACs}$ or HCs.

P. Position of BC somata in the INL, calculated from micrographs such as those in B-Q. Positions of soma (dots) were measured, and plotted using the ggplot2 (R) showing the five number summary (the sample minimum, the lower quartile, the median, the upper quartile, and the sample maximum). Edge of OPL is $0 \%$ and edge of IPL is $100 \%$.

Q, R. Section (E16) stained with anti-ERBB4 (Q), anti-STRA6 (R).

Bar in $\mathrm{O}, 10 \mu \mathrm{m}$ for $\mathrm{A}-\mathrm{O}$. Bar in $\mathrm{R}, 5 \mu \mathrm{m}$ for $\mathrm{Q}, \mathrm{R}$. 


\section{Figure 6 Classification and characterization of amacrine cells}
A. Clustering of E18 ACs using UMAP.
B. Dot plots showing expression of the housekeeping gene, GAPDH; pan-AC genes
PAX6 and SLC32A1; genes diagnostic of GABAergic ACs (SLC6A1, GAD1, GAD2) and glycinergic ACs (SLC6A9); and TFAP2 isoforms, TFAP2A and TFAP2B. Numbers correspond to clusters in $A$. Dendrogram above dots shows transcriptional relationships of clusters.
C. Genes expressed by subsets of ACs.
$D, E$. Immunostaining of E16 retina for TFAP2A (D) and TFAP2B (E). TFAP2A is expressed by multiple amacrine types in INL but not in GCL.
F. Immunostaining of E16 retina for CHAT, which is expressed by ON and OFF starburst ACs.
Bar in $E$ is $10 \mu m$ for $D$,E. Bar in $F$ is $10 \mu m$ for $F$.

\section{Figure 6 - Figure Supplement 1}

A. Frequency distribution of ACs. Cluster Numbers are from Figure $6 A, B$.

$B-D$, Immunostaining for NMB in AC17 (B), CHODL in AC40 (C), NPY in AC52 (D).

E-H. Double color in situ hybridization for NPY and NTS (E). NTS and PENK (F), NTS and MAFA $(\mathrm{G})$ and PENK and MAFA $(\mathrm{H})$.

I. Expression of NTS, PENK, MAFA, and NPY in selected AC clusters.

J,K. eCHIKIN-mediated labeling of NTS ACs. Two types of cells are labeled: PENKexpressing AC31 populate the top of the amacrine cell layer, and send arbors in S1-S3 (I), and MAFA-expressing AC58 is at the edge of IPL, and ramifies along S5 (J).

Retinas are from E16 $(\mathrm{B}-\mathrm{H})$ or E14 $(\mathrm{J}, \mathrm{L})$. Bar in $\mathrm{H}$ is $10 \mu \mathrm{m}$ for $\mathrm{B}-\mathrm{H}$. Bar in $\mathrm{K}$ is $10 \mu \mathrm{m}$ for $\mathrm{J}$ and $\mathrm{K}$.

\section{Figure 6 - Figure Supplement 2}

A, Violin plots showing differentially expressed genes in two clusters of E18 chick starburst ACs which are characterized by similar expression of CHAT and ISL1.

B. Dot plots of SLC17A8 (VGLUT3), SDK2, SDK1, and ERBB4 expression in ACs

C,D. Double color in situ hybridization of E16 retina for SLC17A8 (arrowheads) plus SDK2 (C), or SDK1 (D).

E. eCHIKIN-mediated GFP insertion in ERBB4 at E14. The visualized cell stratifies along S2/S4 (arrowheads) which correspondes to SDK2 localization (Yamagata et al., 2002). See Figure 5 - supplement $1 \mathrm{~F}$ for overall expression pattern of ERBB4.

Bar in $D$ is $5 \mu \mathrm{m}$ for $C, D$. Bar in $E$ is $10 \mu \mathrm{m}$. 


\section{Figure 7 Classification and characterization of RGCs}
A. Clustering of E18 RGCs using UMAP.
B. Dot plots showing expression of selected genes expressed in all or subsets of RGCs. Numbers correspond to clusters in A. Dendrogram above dots shows transcriptional relationships of clusters.
C. Dot plots showing expression of genes selectively expressed in RGC clusters.
D, E. Immunostaining of E16 retina for SATB2 and BRN3A/POU4F1 (D) and for SATB1 and SATB2 (E).
F-H. RGCs labeled by eCHIKIN-mediated GFP insertion in TFAP2D (GC23; F), MC5R (GC18; G), and ETV1 (GC15; H).
Bars in $\mathrm{E}$ and $\mathrm{H}, 10 \mu \mathrm{m}$.

\section{Figure 7 - Figure Supplement 1}
A. Frequency distribution of RGCs. Cluster numbers are from Figure 7A,B.
B-I. In situ hybridization of E16 retina for MODX1 in GC34 (B), LOC419389 in GC32
(C), ZIC1 in GC3 (D), ETV1 in GC15 or 21 (E), RUNX1 in GC36 (F), RUNX2 in GC1
$(\mathrm{G}), M C 5 R$ in $\mathrm{GC} 23(\mathrm{H})$, and OPN4.1 in GC41 (I). Bar, 10um.

\section{Figure 7 - Figure Supplement 2}

Double color in situ hybridization on E16 retina for RGC markers. Blue, DAPI.
A. ETV1 and SDK1
B. ETV1 and SDK2.
C. CHRNB2 and TAC1.
D. RUNX2 and CHRNB2
E. RUNX2 and TAC1
Bar, $10 \mu \mathrm{m}$.

Figure 8 - Transcriptomic map of topographic position in Müller glia
A. Clustering of E18 MGs using UMAP. Inset shows relationship between clusters and retinal position.

$B, C$. Violin (B) and feature (C) plots of genes differentially expressed among MG clusters. B also shows that pan-MG genes SLC1A3 and RLBP1 are expressed at similar levels among clusters.

D, E. In situ hybridization for WIF1 (D) and CHRDL1(E) on whole mounts at E13 photographed from the posterior (top panels) or anterior (bottom panels). The black 
structure at the ventral edge in the bottom panels is the intrinsically pigmented pecten oculi. Bar,1mm.

F-Q. In situ hybridization on sections from indicated retinal regions to show positionselective of genes from C in Müller glia. F-I WIF1 and CHRDL1 on E16 dorsal and ventral sections. CHRDL1 is also in a subset of amacrine cells throughout the retina.

J-M. FOXG1 and FOXI2 on E14 nasal and temporal sections.

N-Q. PSCA and TMEM123 on E16 central and peripheral sections. Bar, 10um.

R. Summary of position-dependent expression of genes in Müller glia at E16, based on images such as those in D-Q.

\section{Figure 8 - Figure Supplement 1}

A-F. In situ hybridization for WIF1 (A), CHRDL1(B) at E16, FOXG1 (C), FOXI2 (D) at $\mathrm{E} 14, P S C A(\mathrm{E})$, TMEM123 (F) at E16. Sections were co-stained with anti-glutamate synthetase (anti-GS), showing that these genes are selectively expressed in Muller glia. Bar, 10um.

\section{Figure 8 - Figure Supplement 2}

Co-expression of positional markers in Müller glia at E18 (A) and E12 (B) retina. The xand $y$ - axis are the expression level of the marker genes, and each dot represents one Müller glial cell. Histogram plots on the top and right of each panel show the overall expression level of the two genes.

\section{Figure 8 - Figure Supplement 3}

A. Feature plots with a set of positional genes at E12 (see Figure 8C for expression at E18).

B. In situ hybridization for FGF8 and PSCA at E16, showing co-expression of $F G F 8$ and $P S C A$ at the high acuity area (area centralis). The PSCA+ domain is broader than the

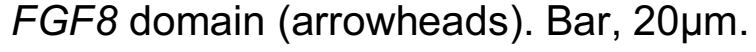

C. Schematic representation for expression of PSCA, FGF8, and TMEM123. Between $\mathrm{E} 12$ and $\mathrm{E} 20, \mathrm{TMEM} 123$ is progressively restricted to peripheral retina and is then downregulated; FGF8 is present in central retina then downregulated; and PSCA appears in central retina between E14 and E16.

\section{Figure 9 - Developmental trajectory of oligodendrocytes}

A. Clustering of E18 oligodendrocytes viewed in UMAP.

B. Dot plots showing expression of selected genes expressed in all or subsets of oligodendrocytes. Numbers correspond to clusters in A. 
C,D. Double-label in situ hybridization showing that BCAS1 and PLP1 are co-expressed in the ganglion cell layer (C) while PDGFR and PLP1 exhibit nonoverlapping expression (D).

E-I. Graded distribution of BCAS1+ oligodendrocytes along the central to peripheral axis at E16. Positions of sections $(\mathrm{E}-\mathrm{H})$ are shown in I

\section{Figure 9 - Figure Supplement}

A. Frequency distribution of oligodendrocytes. Cluster Numbers are from Figure 9A,B. B,C. Feature plots showing expression of oligodendrocyte-characteristic genes that have been studied in mammals $(B)$ and that we found to be selectively expressed in chicks (C).

\section{Figure 10 - Conserved transcriptomic identity of cell classes in mammals and chicks}
A. UMAP visualization of pooled cells from chick, mouse, macaque following unsupervised clustering. Colors distinguish classes identified by reference to canonical
markers (C) and labels previously assigned to each species separately (D).
B. The same as A, but colors indicate species.
C. Feature plot showing the canonical markers of each retina cell class
D. Confusion matrix comparing the class identity by clustering of pooled cells (on y-axis) to the class annotation when each dataset was analyzed individually (x-axis).
E. Dendrogram based on the transcriptomic similarity of cell classes from each species.
F. Dendrogram based on overall retinal cell transcriptomic similarity among the four species.
Figure 11 - Conserved transcriptomic identity of photoreceptor, horizontal and bipolar cell types in mammals and chicks

Consensus dendrogram tree for PR (A), HC (B) and BC (C) types from chick, mouse, macaque and human single cell dataset. In $\mathrm{C}, \mathrm{ON}$ and OFF types are globally separated by a dotted line, but three exceptions from chick BC types are indicated by asterisk.

\section{Figure 11 - figure supplement 1}
A. UMAP visualization of pooled ACs from chick, mouse, macaque and human retina following unsupervised clustering.
$B$, The same as A, but colors code for species. 
C. Relationship of clusters from A to AC types identified in each species separately. Consensus dendrogram tree, built as in Figure 11, is shown at the left. Three groups (VG3, SEG, and SAC) conserved between chick and mammals are highlighted.

Figure 11 - figure supplement 2

A. UMAP visualization of pooled RGCs from chick, mouse, macaque and human retina following unsupervised clustering.

B. The same as A, but colors code for species.

C. Relationship of clusters from A to RGC types identified in each species separately. Consensus dendrogram tree, built as in Figure 11, is shown at the left. A group of ipRGC types conserved among chick and mammals is highlighted. 
Table 1: Numbers of cell types in mouse, primate (Macaque) and chick retina

\begin{tabular}{|l|l|l|l|l|}
\hline Cell class & Mouse & Macaque* & $\begin{array}{l}\text { Chick } \\
\text { (mature) }\end{array}$ & $\begin{array}{l}\text { Chick } \\
\text { (developing or } \\
\text { topographic) }\end{array}$ \\
\hline Photoreceptors & 3 & 4 & 8 & 3 \\
\hline Horizontal cells & 1 & 2 & 4 & 1 \\
\hline Bipolar cells & 15 & 12 & 22 & - \\
\hline Amacrine cells & 63 & 34 & 59 & - \\
\hline RGCs & 46 & 18 & 41 & - \\
\hline Müller glia & 1 & 1 & 1 & 6 \\
\hline Oligodendrocytes & 0 & 0 & 1 & 4 \\
\hline Astrocytes & 1 & 1 & 0 & 0 \\
\hline Total & 129 & 72 & 136 & 14 \\
\hline
\end{tabular}

Mouse: Macosko et al., 2015; Shekhar et al., 2016; Tran et al., 2019; Yan et al., 2020 Macaque: Peng et al., 2019

${ }^{*}$ Peripheral retinal types plus foveal types not found in periphery 
bioRxiv preprint doi: https://doi.org/10.1101/2020.10.09.333633; this version posted October 10,2020. The copyright holder for this preprint (which was not certified by peer review) is the author/funder, who has granted bioRxiv a license to display the preprint in perpetuity. It is made available under aCC-BY-NC-ND 4.0 International license.

A

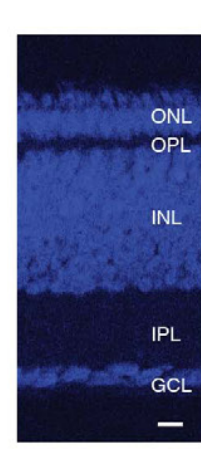

B

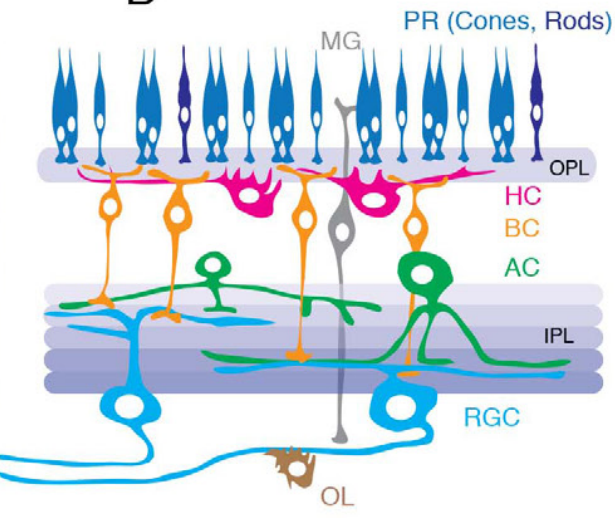

D

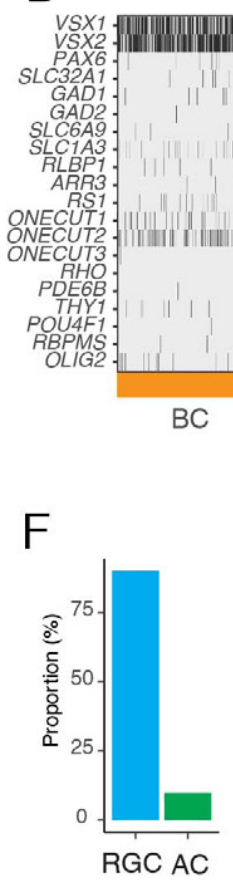

Class-E16

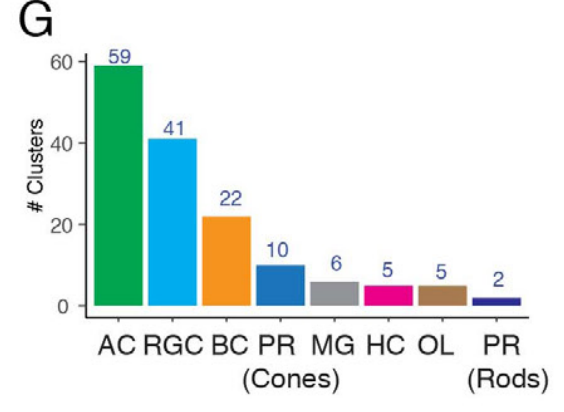

Class-E16+18
C

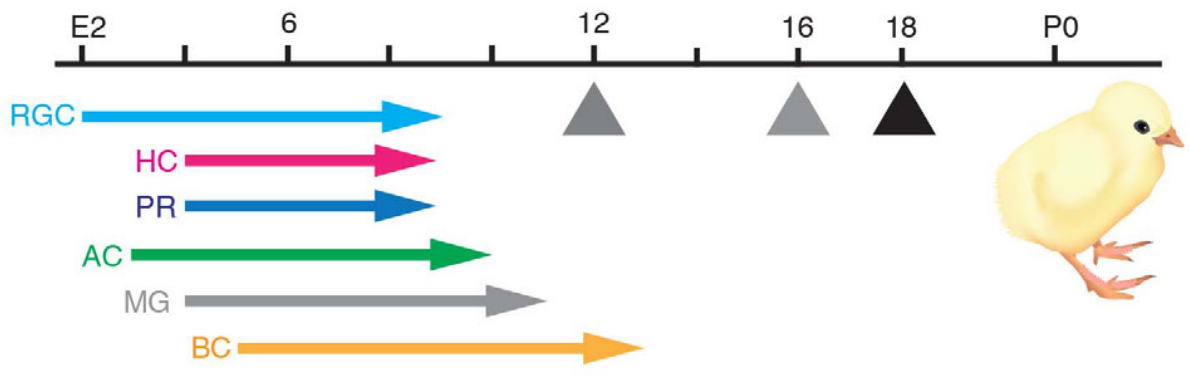

E

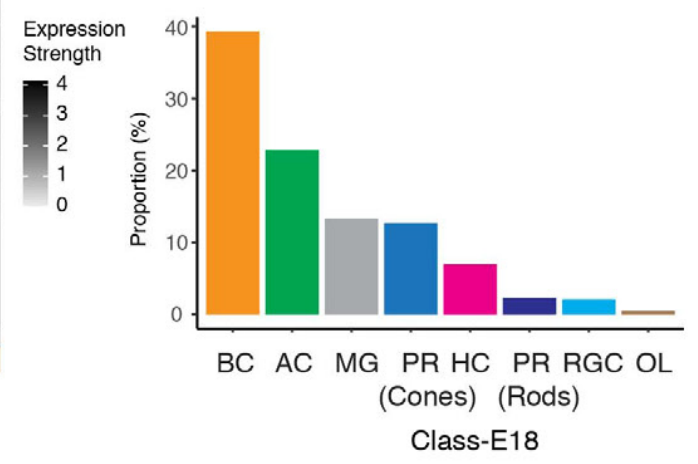

$\mathrm{H}$

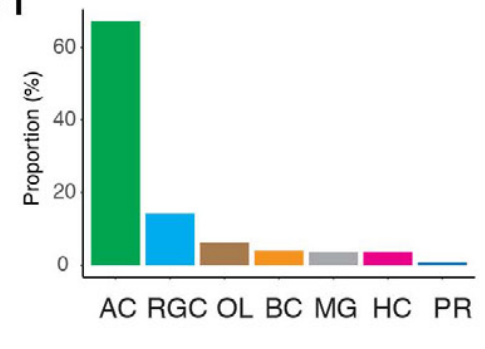

Class-E12 
СHмг2А Емс7

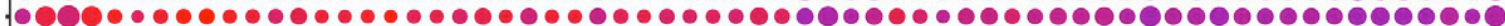

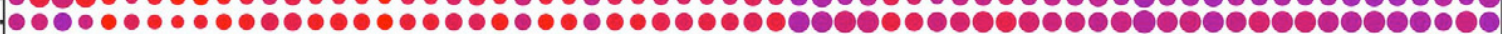

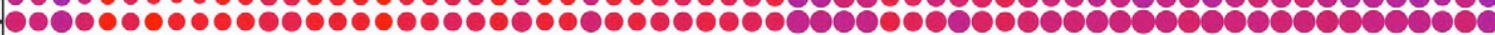

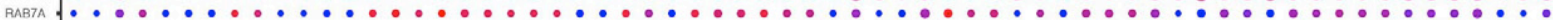

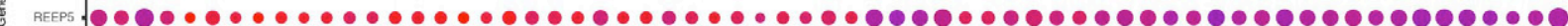
SNAPDS vсP

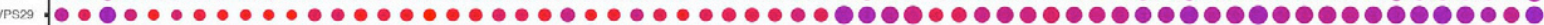

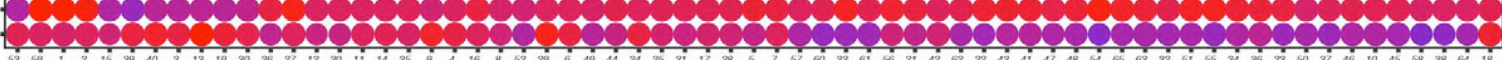

B

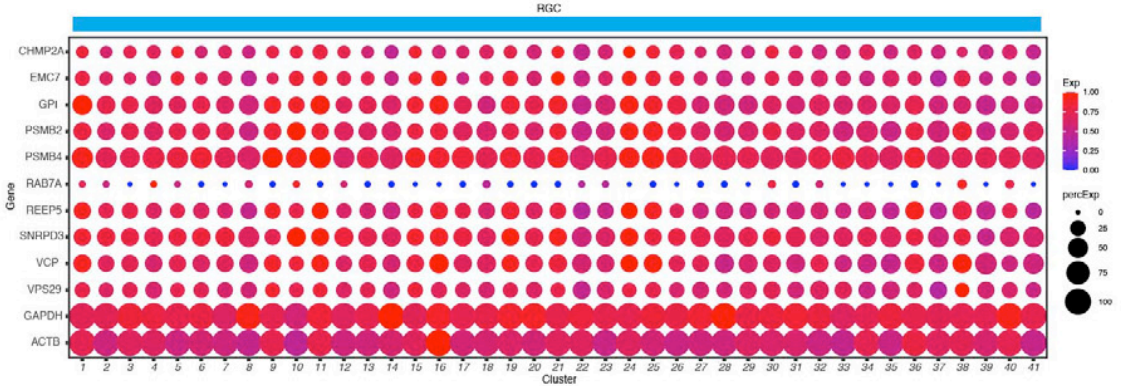

C E12 Retina (56624 cells)

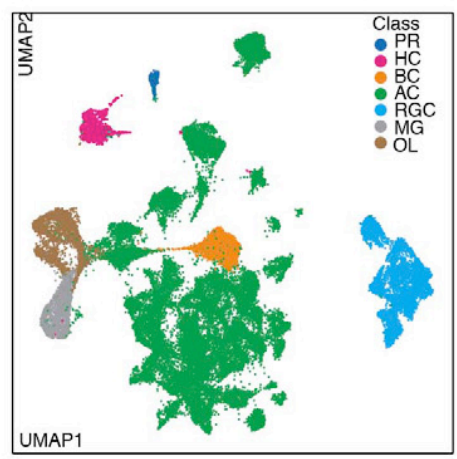

D

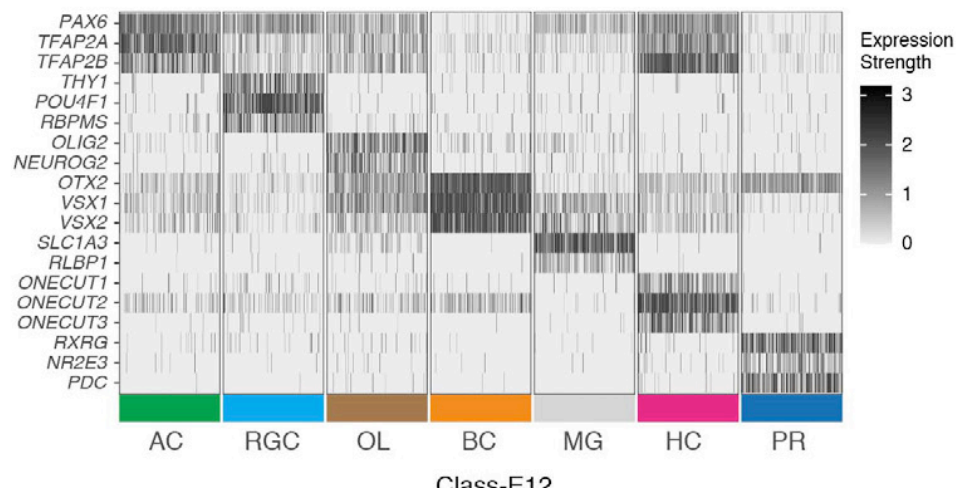

Class-E12

E

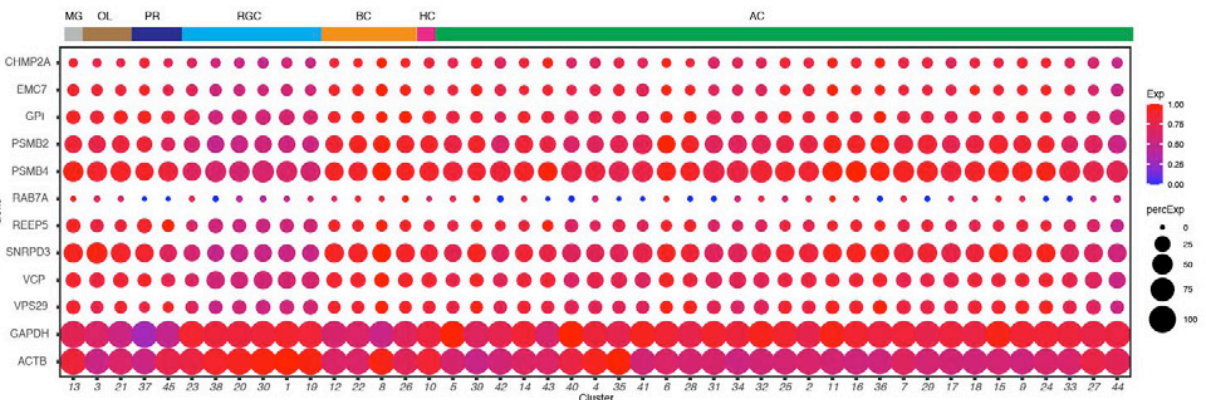

Figure 1 - supplement 1 
bioRxiv preprint doi: https://doi.org/10.1101/2020.10.09.333633; this version posted October 10, 2020. The copyright holder for this preprint (which was not certified by peer review) is the author/funder, who has granted bioRxiv a license to display the preprint in perpetuity. It is made available under aCC-BY-NC-ND 4.0 International license.

A
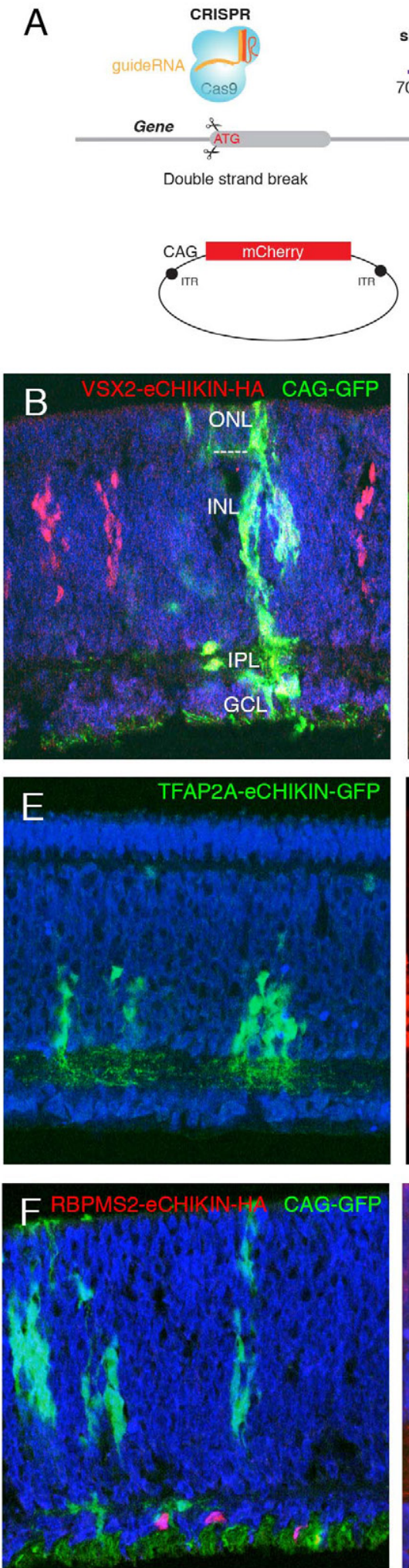

single strand DNA

70 bases HA/GFP/CRE $\overline{70 \text { bases }}$

\section{Homology-directed repair}

HA/GFP/CRE Targeted integration
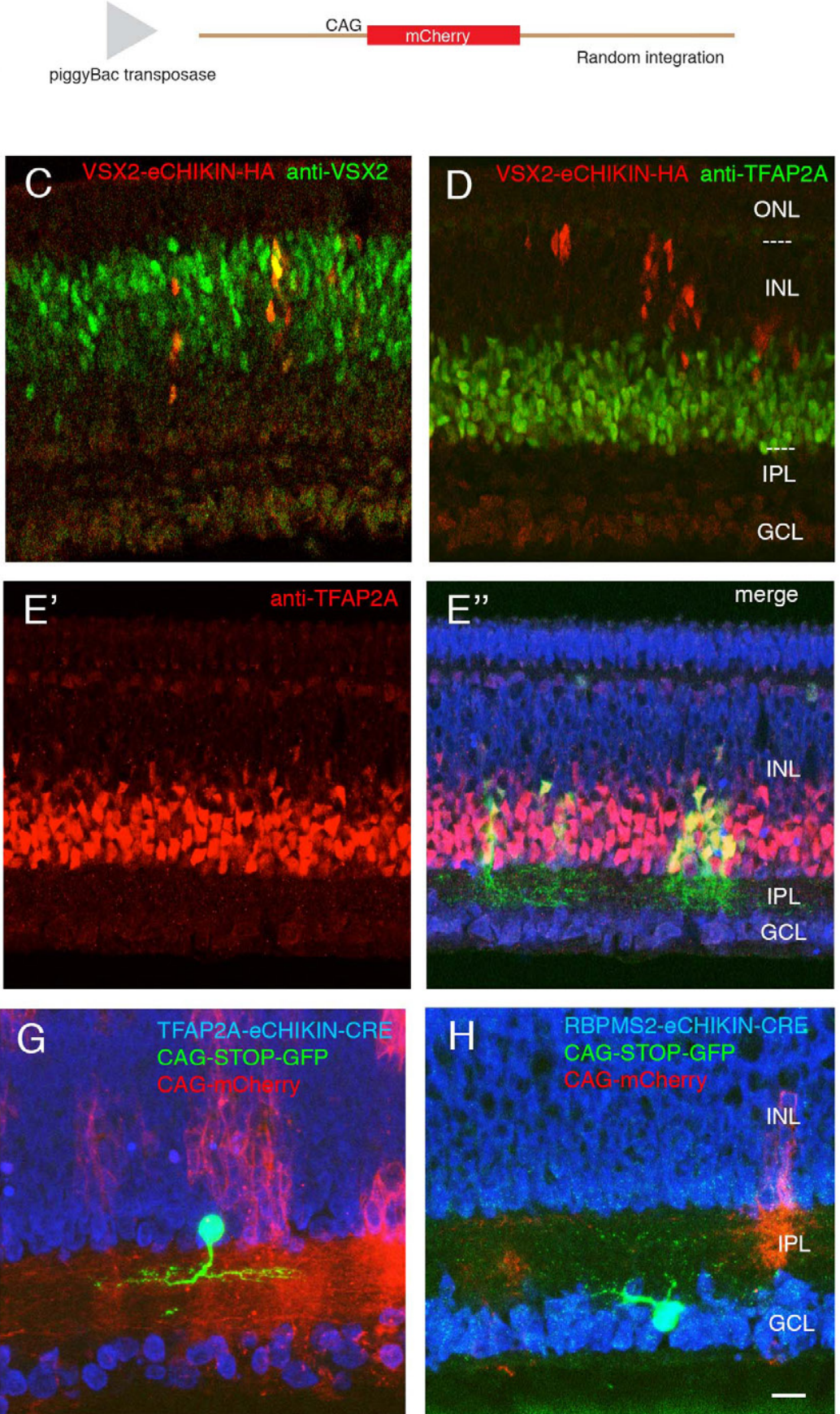
bioRxiv preprint doi: https://doi.org/10.1101/2020.10.09.333633; this version posted October 10, 2020. The copyright holder for this preprint (which was not certified by peer review) is the author/funder, who has granted bioRxiv a license to display the preprint in perpetuity. It is made available under aCC-BY-NC-ND 4.0 International license.

A

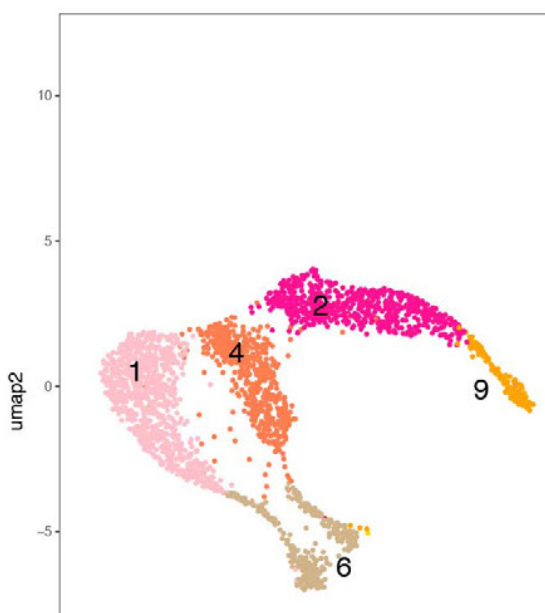

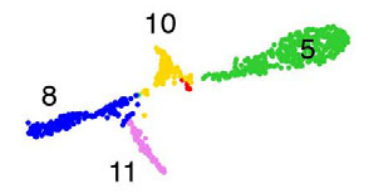

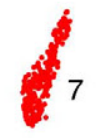

3 Rod

5 Green SC

8 Blue SC

11 Violet SC

7 Red SC

$1 \mathrm{DC}-\mathrm{a}$

4 DC-b

2 DC-C

(1) $\begin{gathered}6 \\ 9 \\ 10\end{gathered} \mid \overbrace{}^{\frac{9}{0}}$

$1{ }_{12}$

umap1
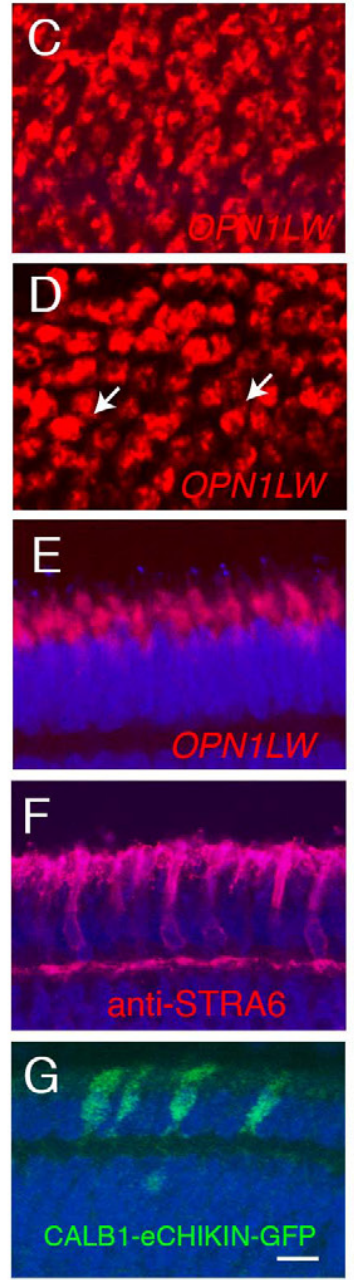
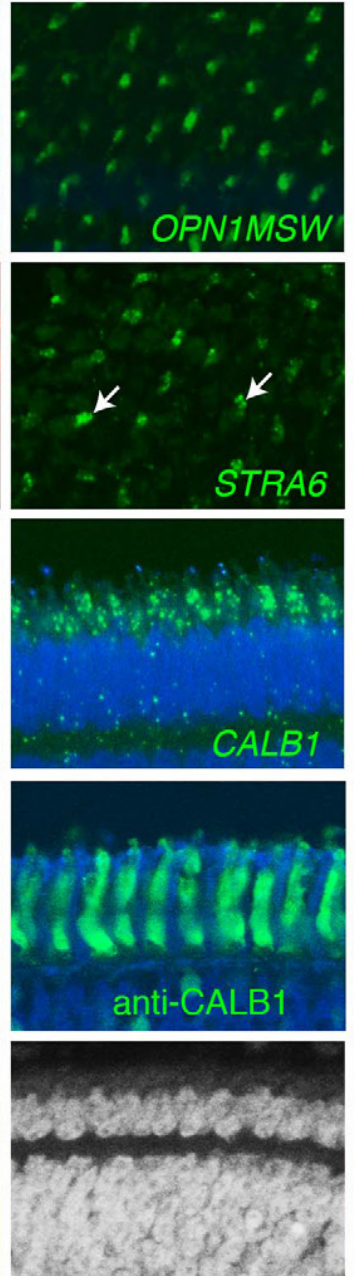
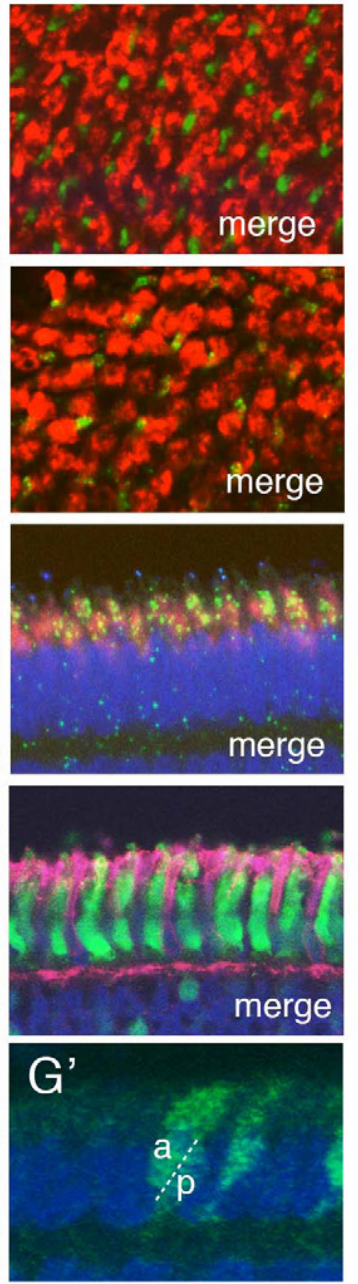

$\mathrm{B}$

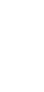

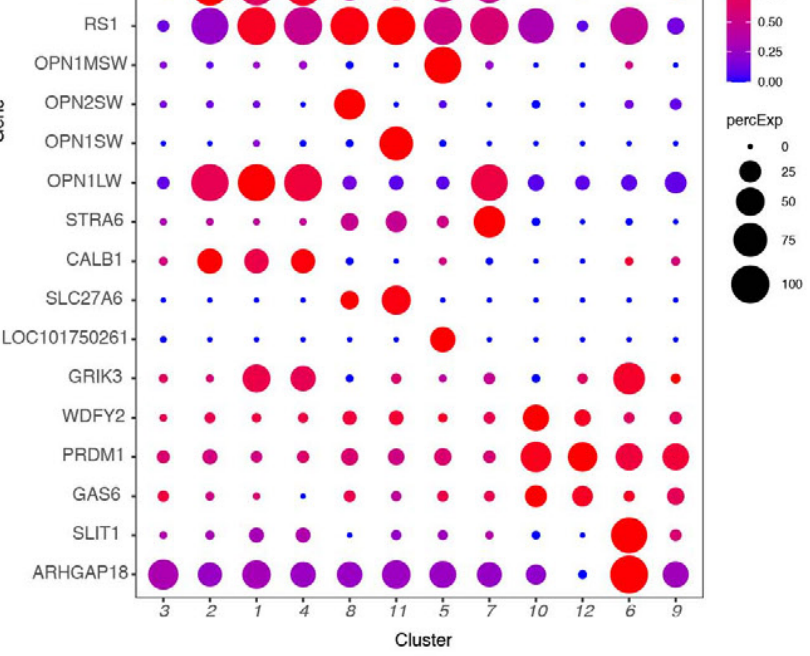

$\mathrm{H}$

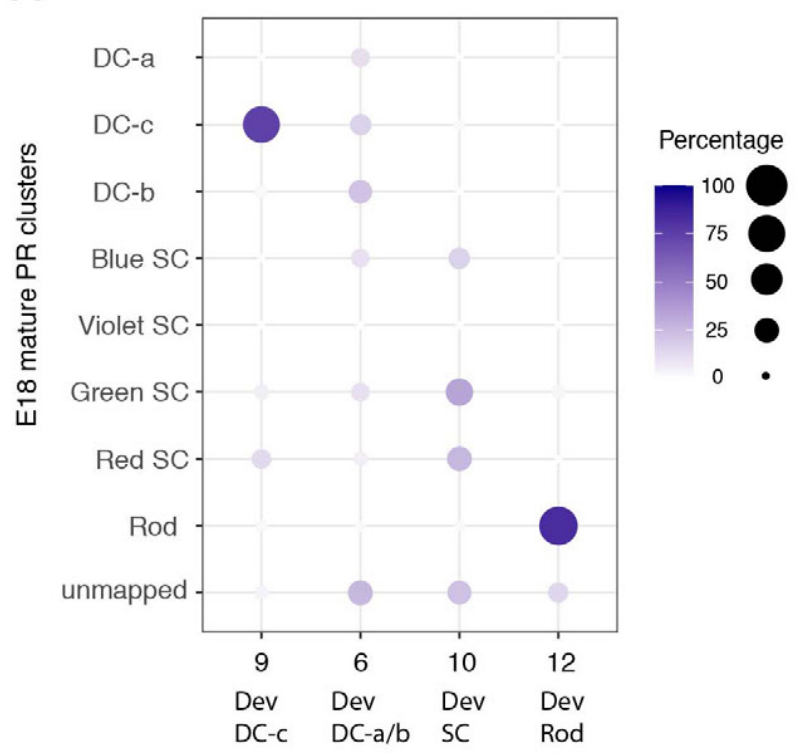

E18 developing PR clusters 
A

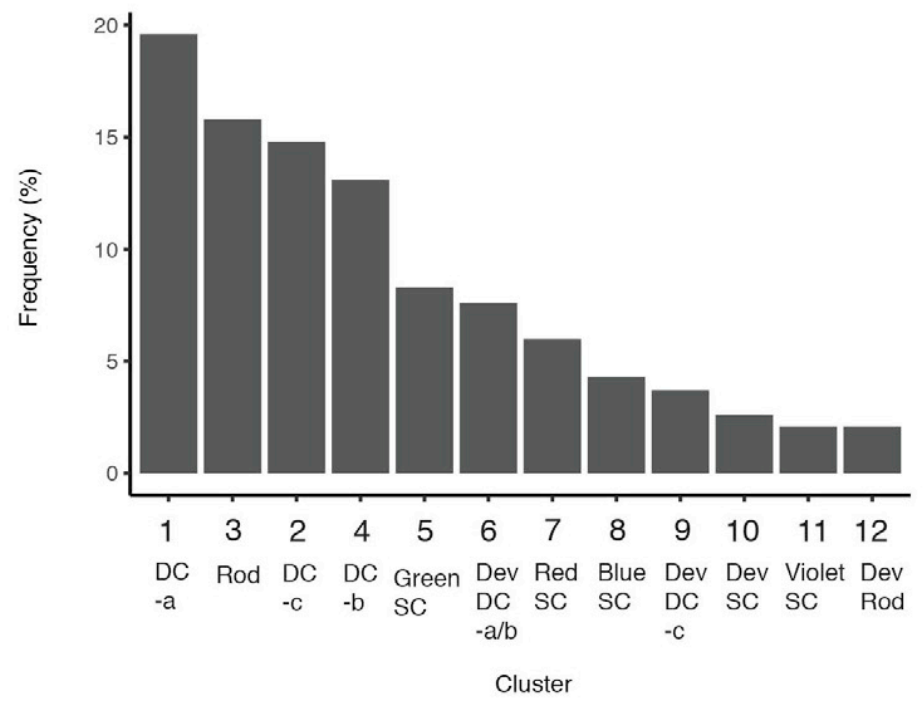

B

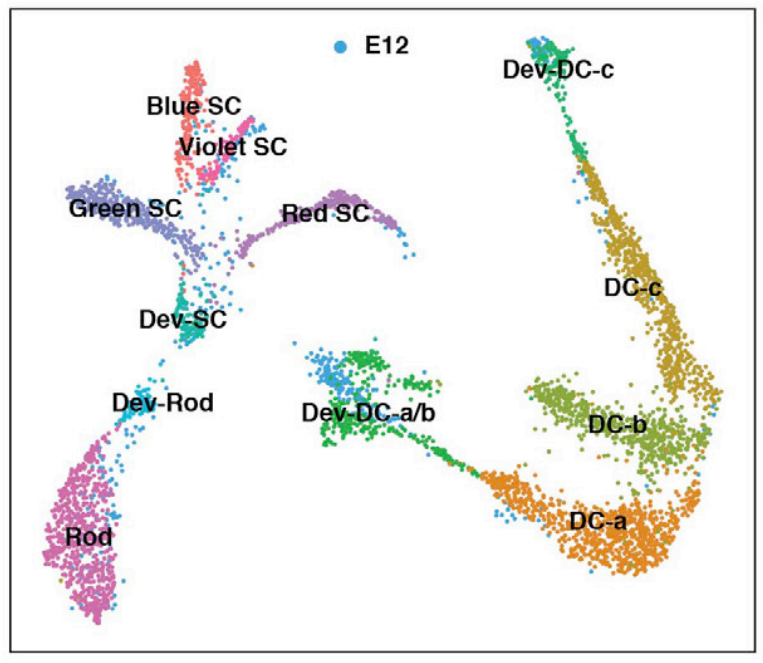

C

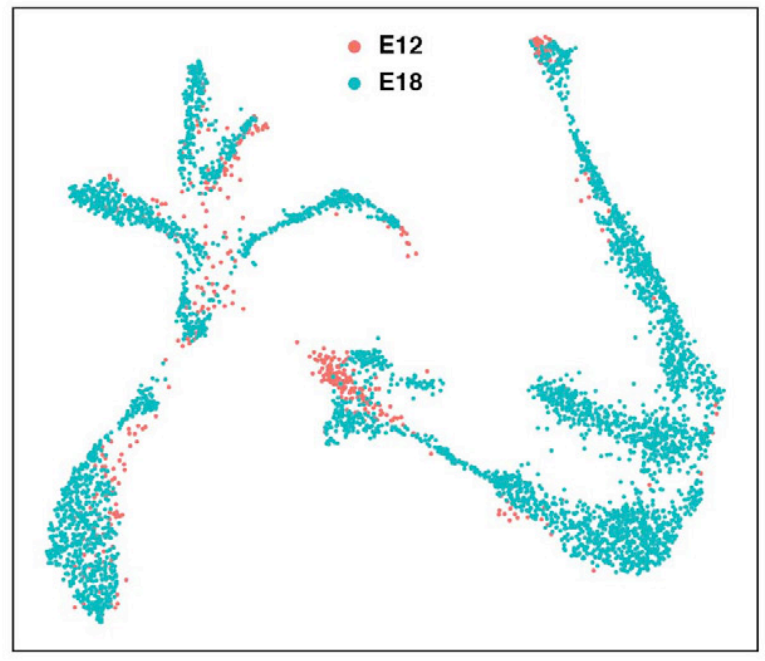


bioRxiv preprint doi: https://doi.org/10.1101/2020.10.09.333633; this version posted October 10, 2020. The copyright holder for this preprint (which was not certified by peer review) is the author/funder, who has granted bioRxiv a license to display the preprint in perpetuity. It is made available under aCC-BY-NC-ND 4.0 International license.

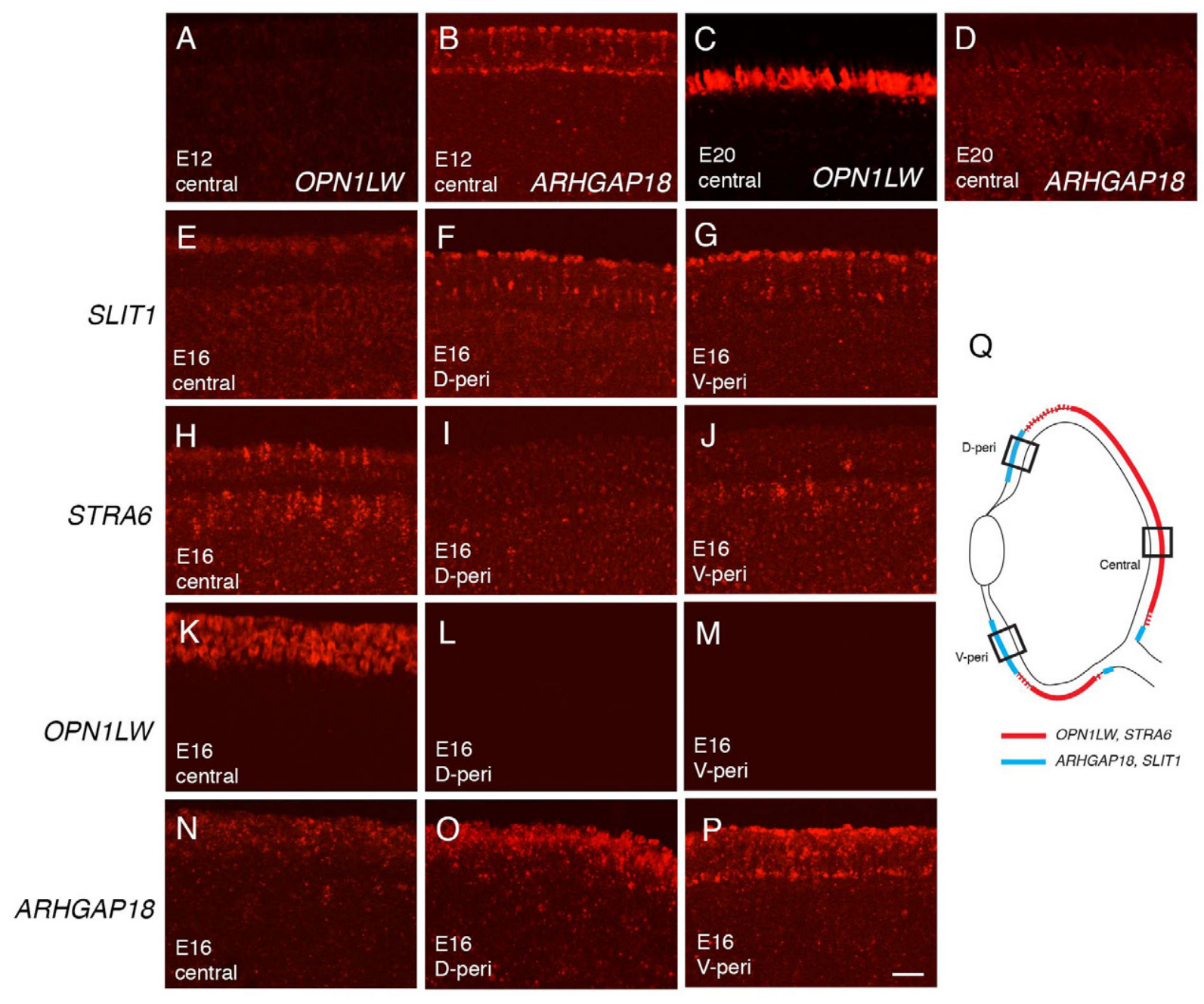

Figure 3 - supplement 2 
bioRxiv preprint doi: https://doi.org/10.1101/2020.10.09.333633; this version posted October 10,2020 . The copyright holder for this preprint (which was not certified by peer review) is the author/funder, who has granted bioRxiv a license to display the preprint in perpetuity. It is made available under aCC-BY-NC-ND 4.0 International license.
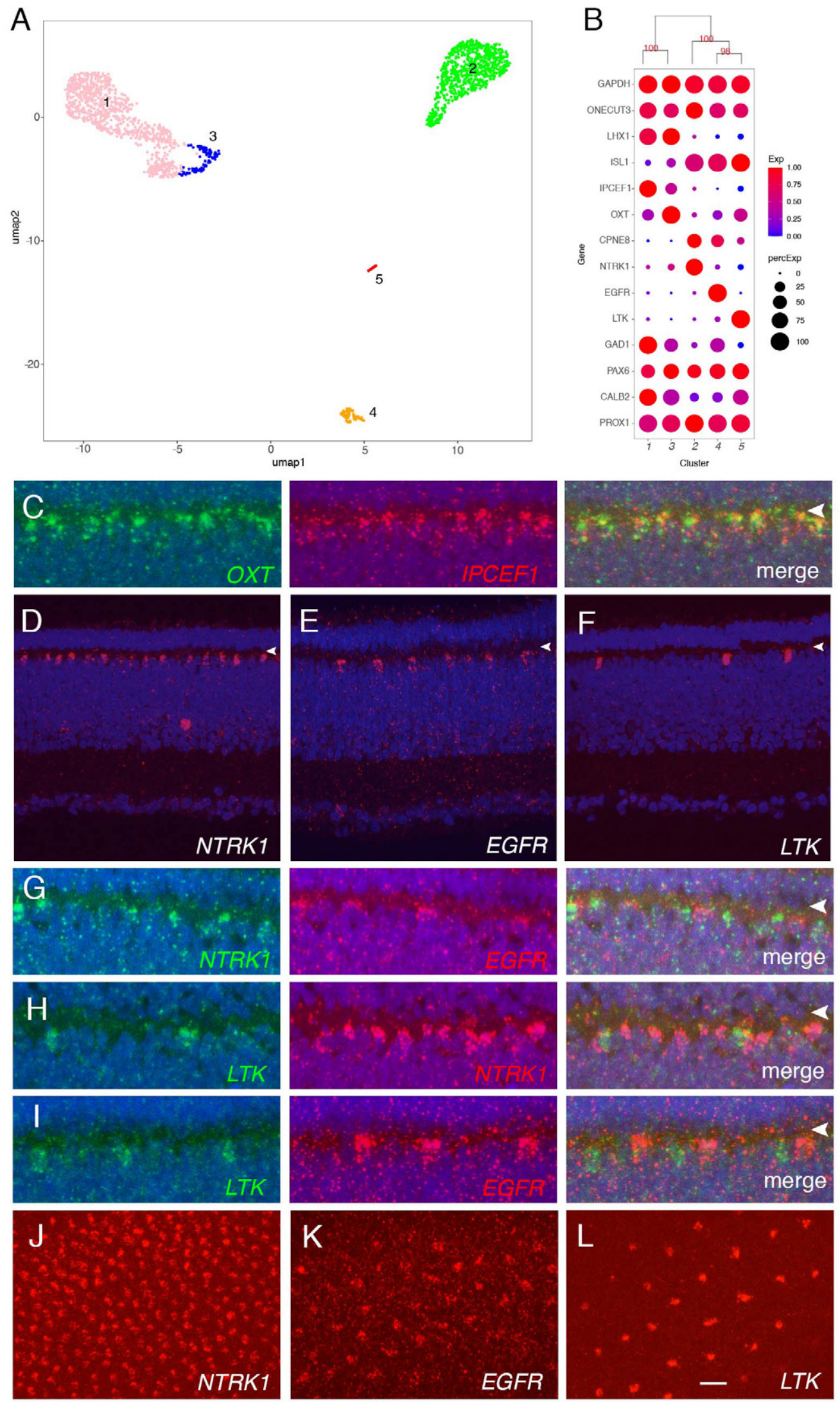

Figure 4 
bioRxiv preprint doi: https://doi.org/10.1101/2020.10.09.333633; this version posted October 10, 2020. The copyright holder for this preprint (which was not certified by peer review) is the author/funder, who has granted bioRxiv a license to display the preprint in perpetuity. It is made

A

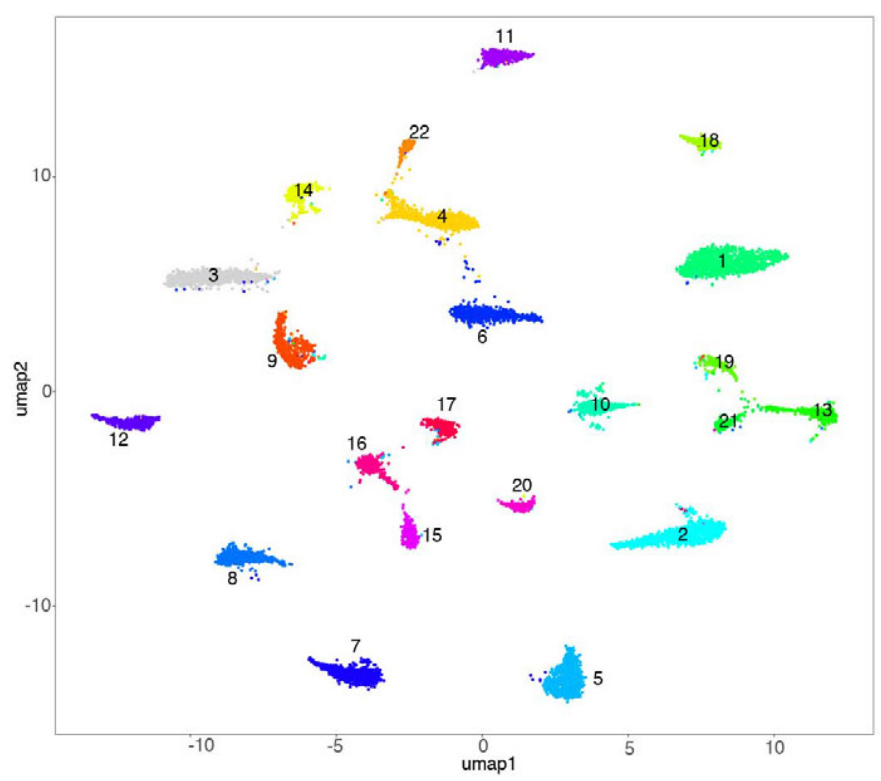

C

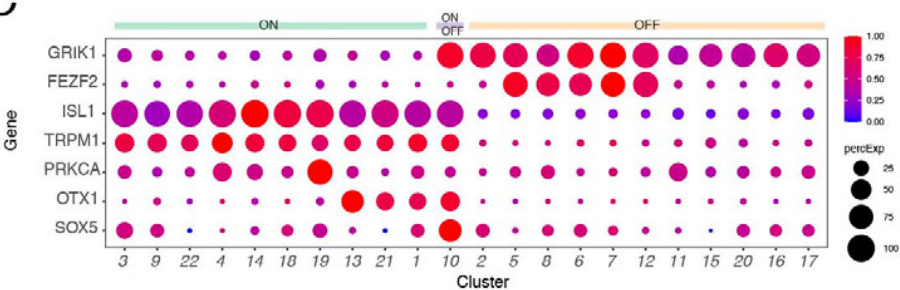

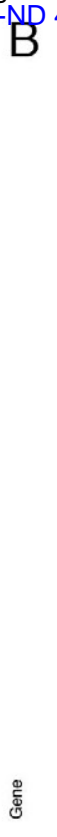

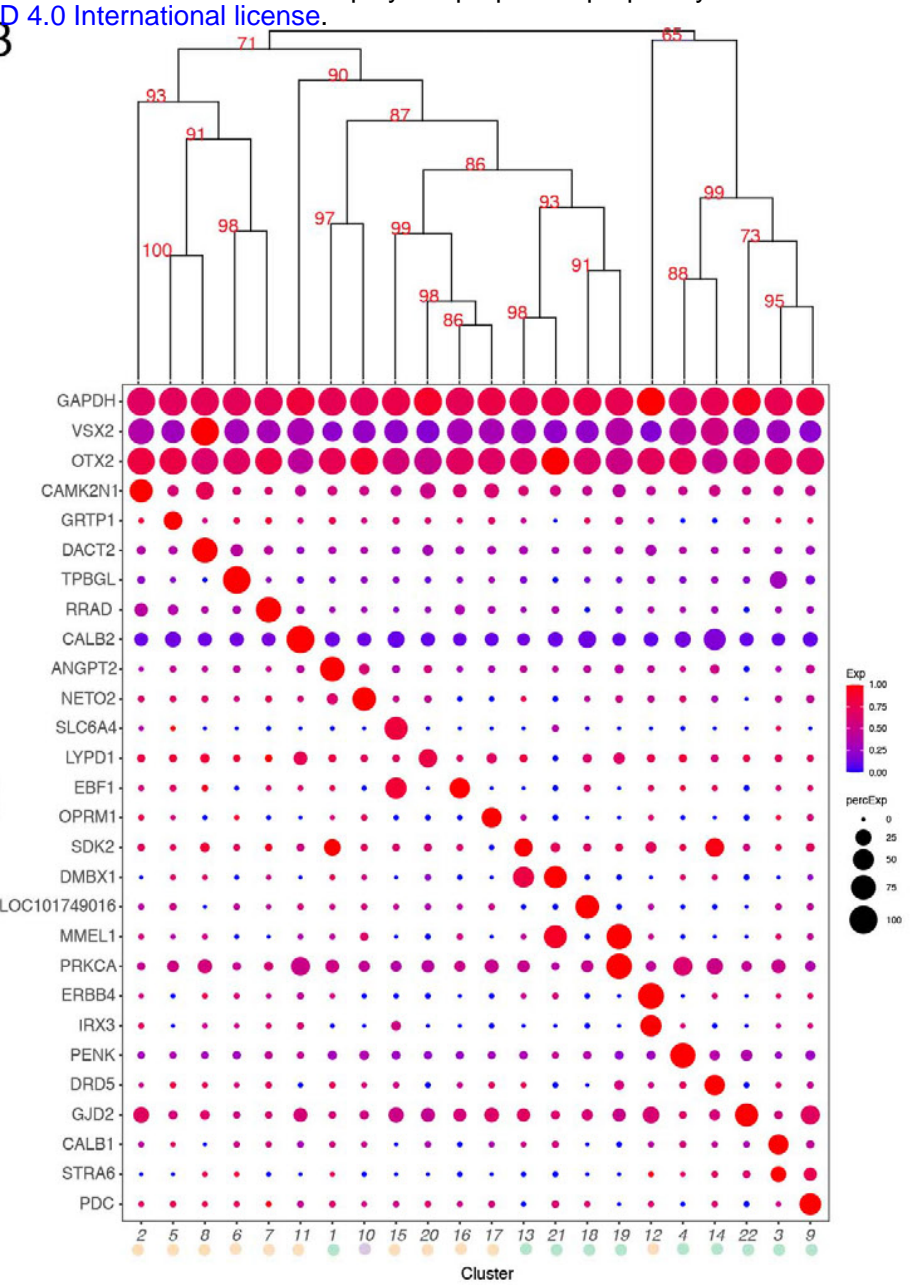

eCHIKIN-GFP
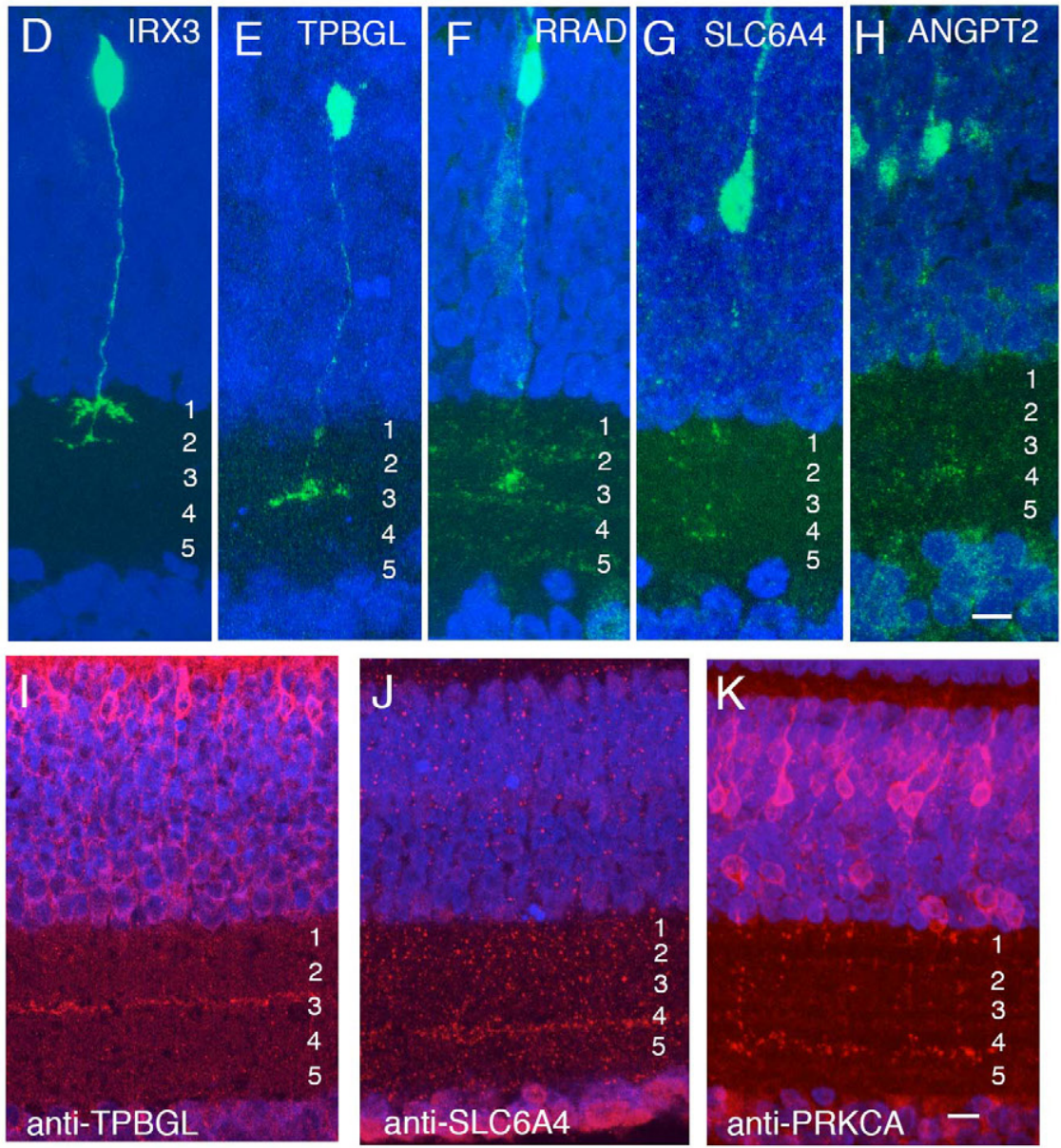

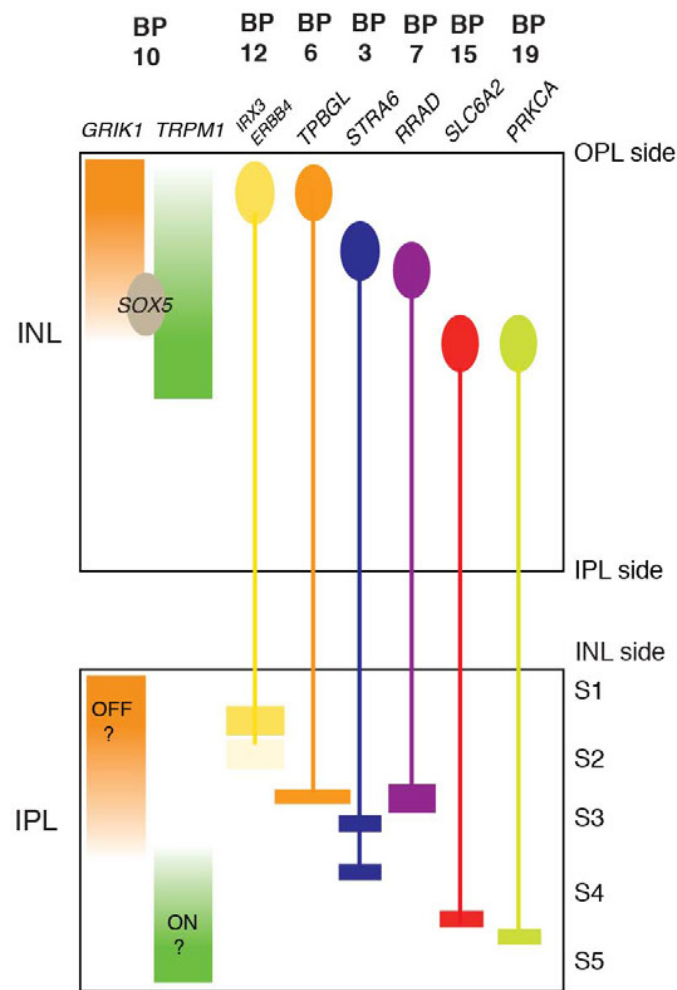

GCL side 

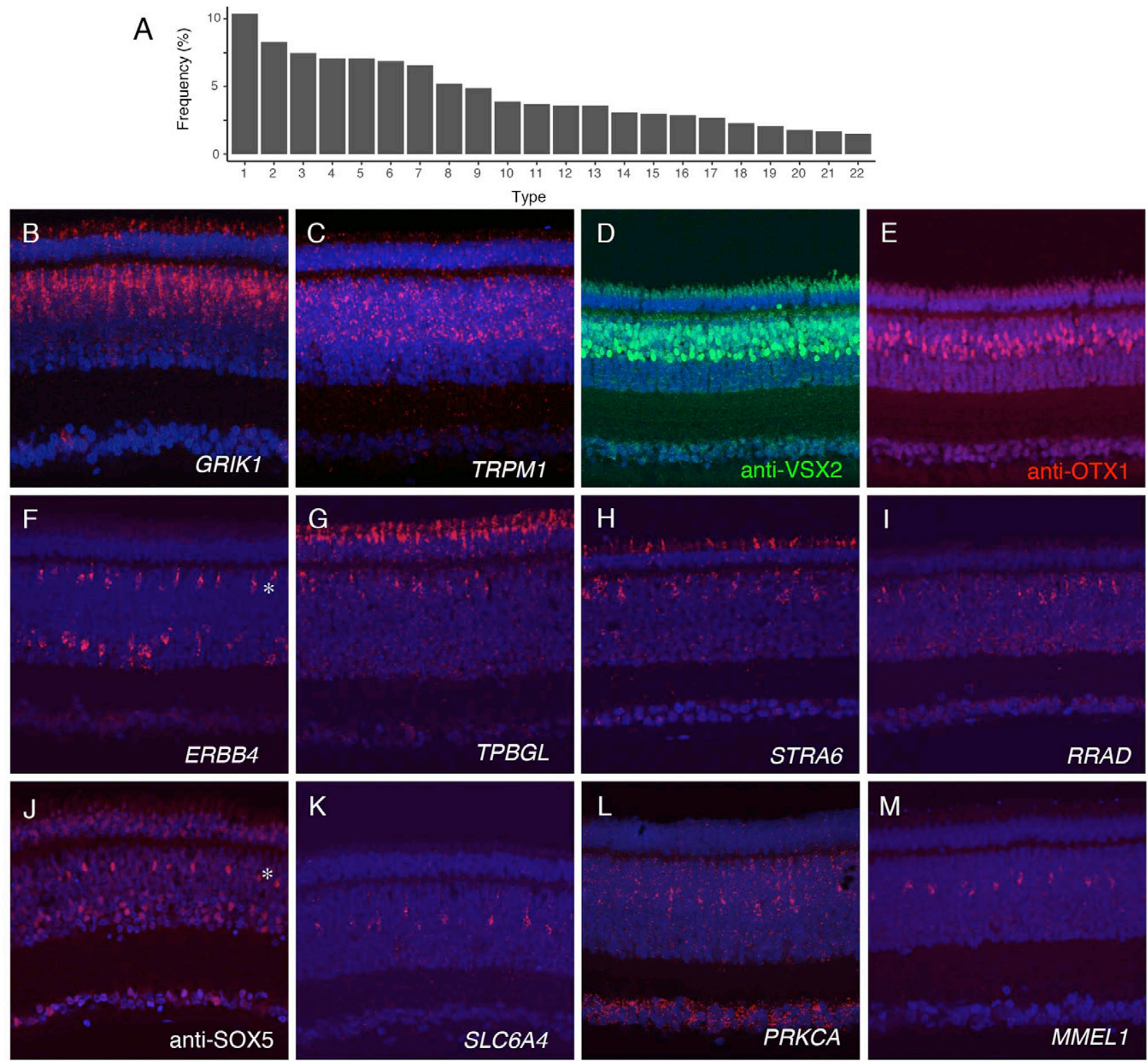

RRAD
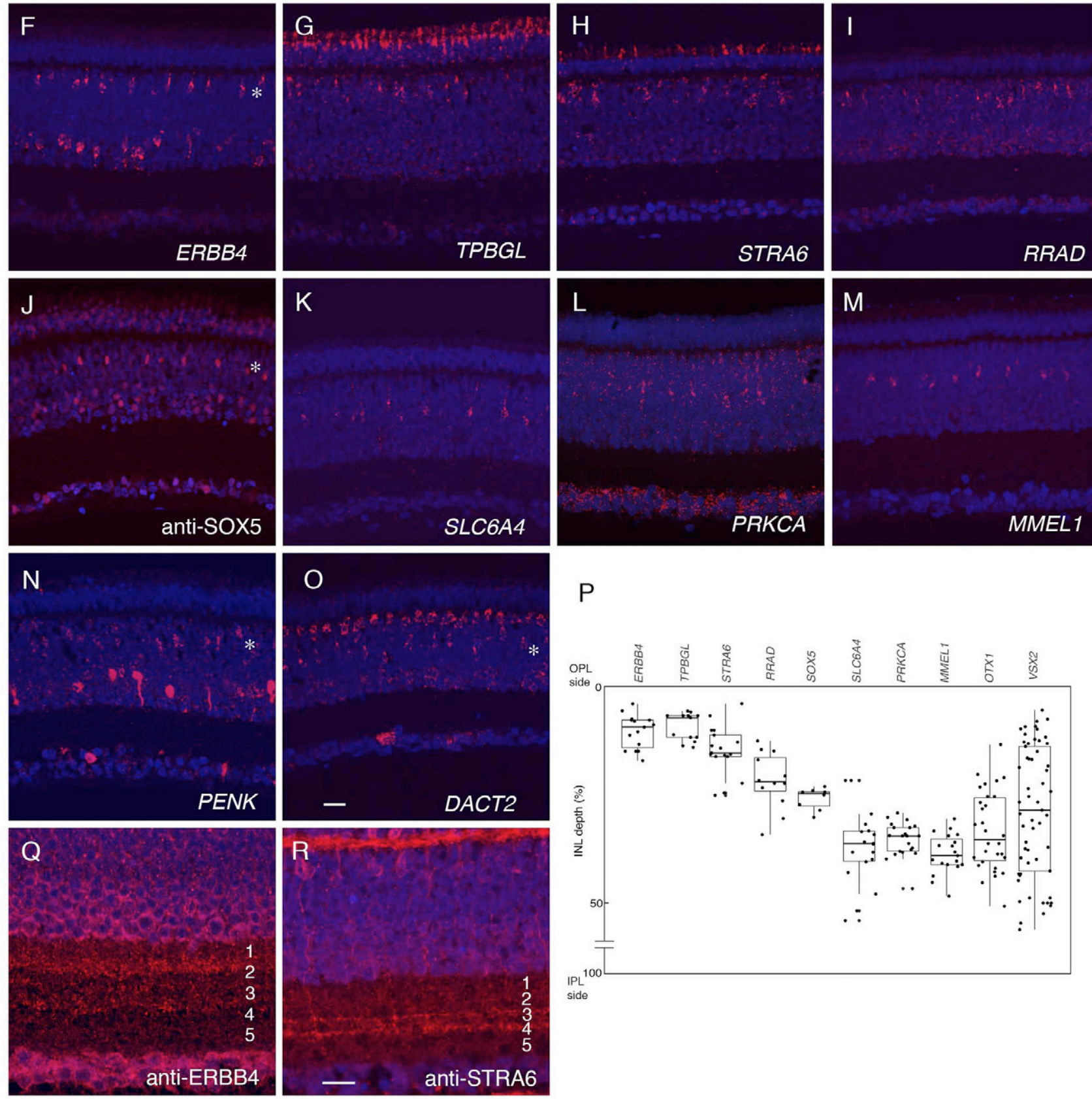

Figure 5 - supplement 1 
bioRxiv preprint doi: https://doi.org/10.1101/2020.10.09.333633; this version posted October 10, 2020. The copyright holder for this preprint (which was not certified by peer review) is the author/funder, who has granted bioRxiv a license to display the preprint in perpetuity. It is made available under aCC-BY-NC-ND 4.0 International license.

A

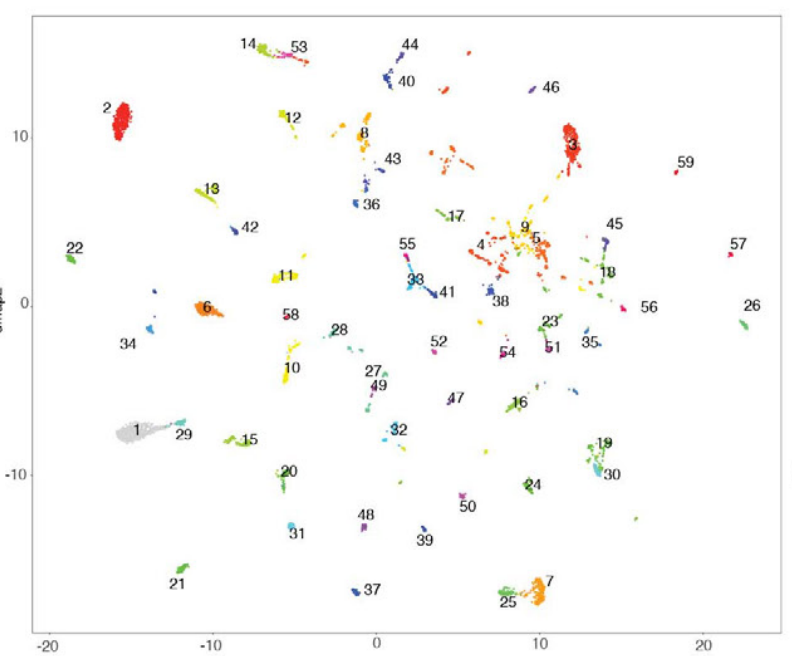

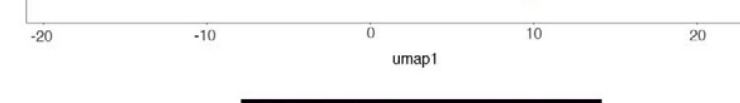
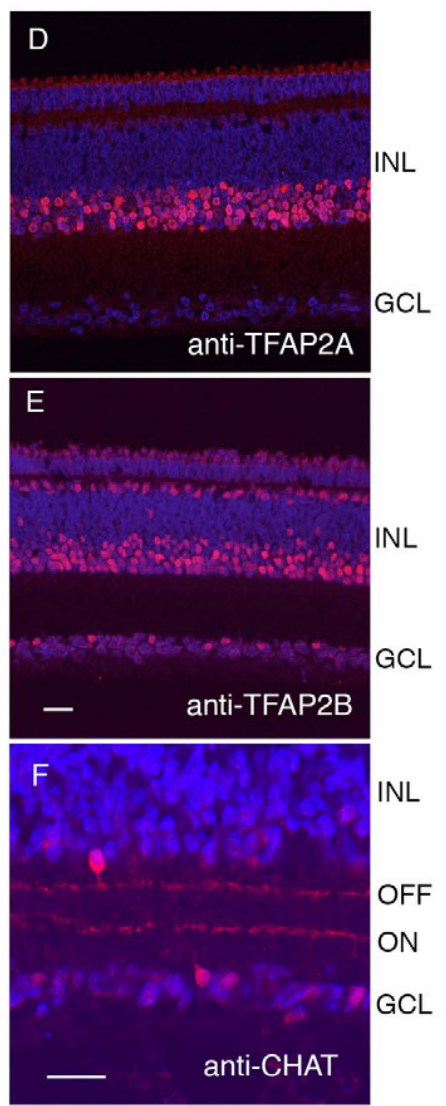

$\mathrm{B}$

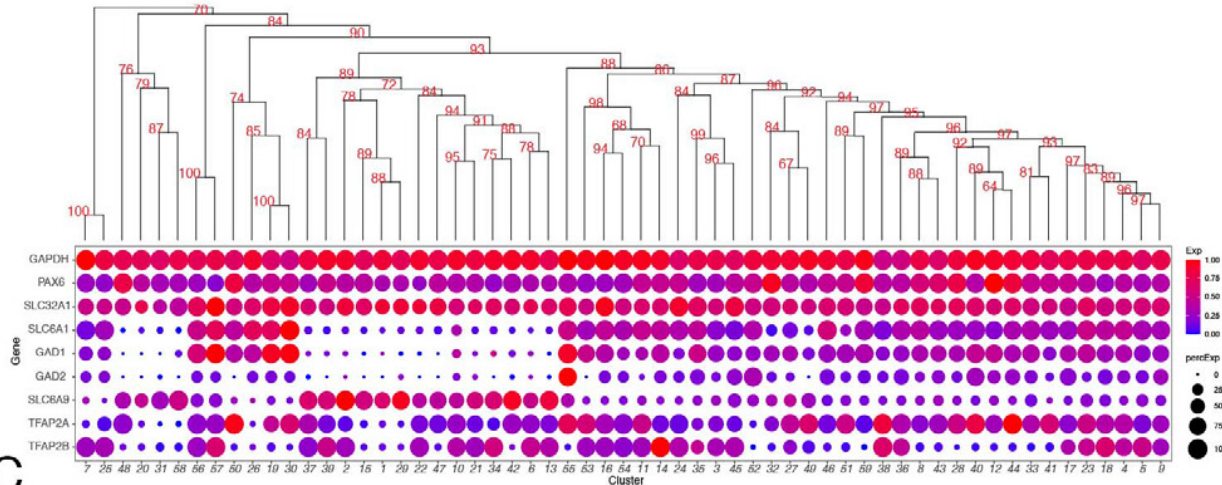

$\mathrm{C}$

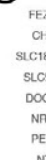

FEZFA.
CHAT.
LCLBAS.
SLCSA7.
DOCZ2.
NAN
PENK.
NTS
MAFA

- $\cdots \cdots \cdots$

(2)

$\therefore$ (a)

$\cdots$

.......................

$\ldots \ldots \ldots$

cos

(1)

$\cdots$

$\therefore \therefore$ :

$\ldots \ldots \ldots \ldots \ldots \ldots$

$\ldots$

•

(1)

a

$\ldots \ldots$

(1)

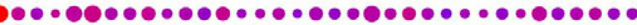

$\ldots$

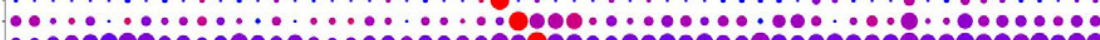

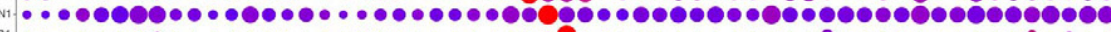

急

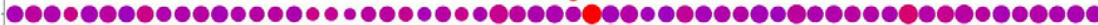

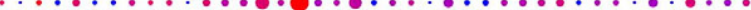

(1) .

(

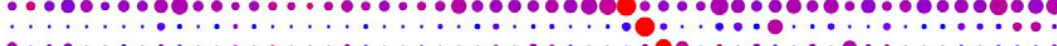

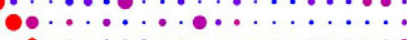

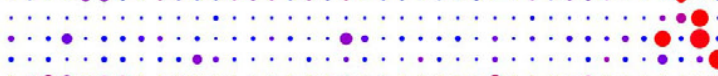

$\ldots$

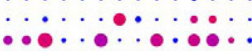

(1)

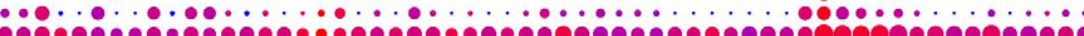

:

o

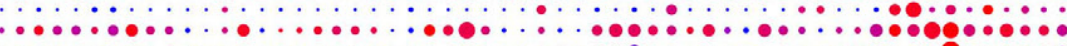

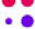

$\therefore \ldots$

$\therefore$

$\ldots \ldots \ldots \ldots \ldots \ldots \ldots$

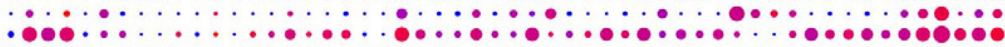

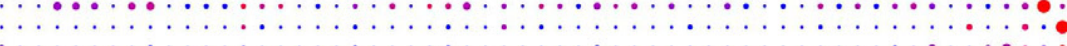

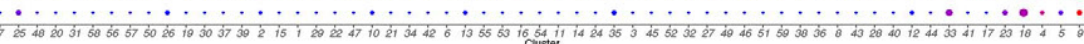




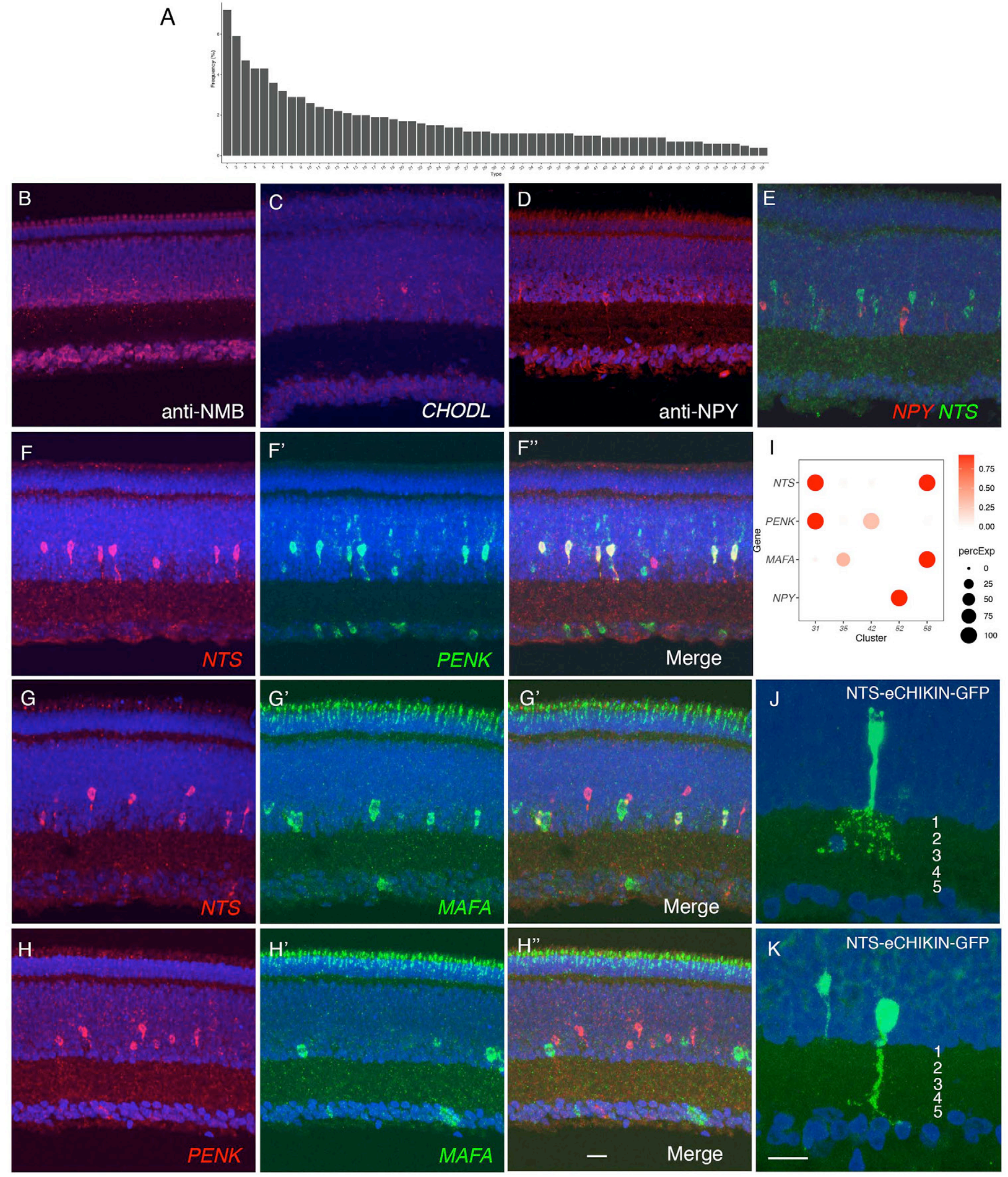

Figure 6 - supplement 1 
A

CHAT
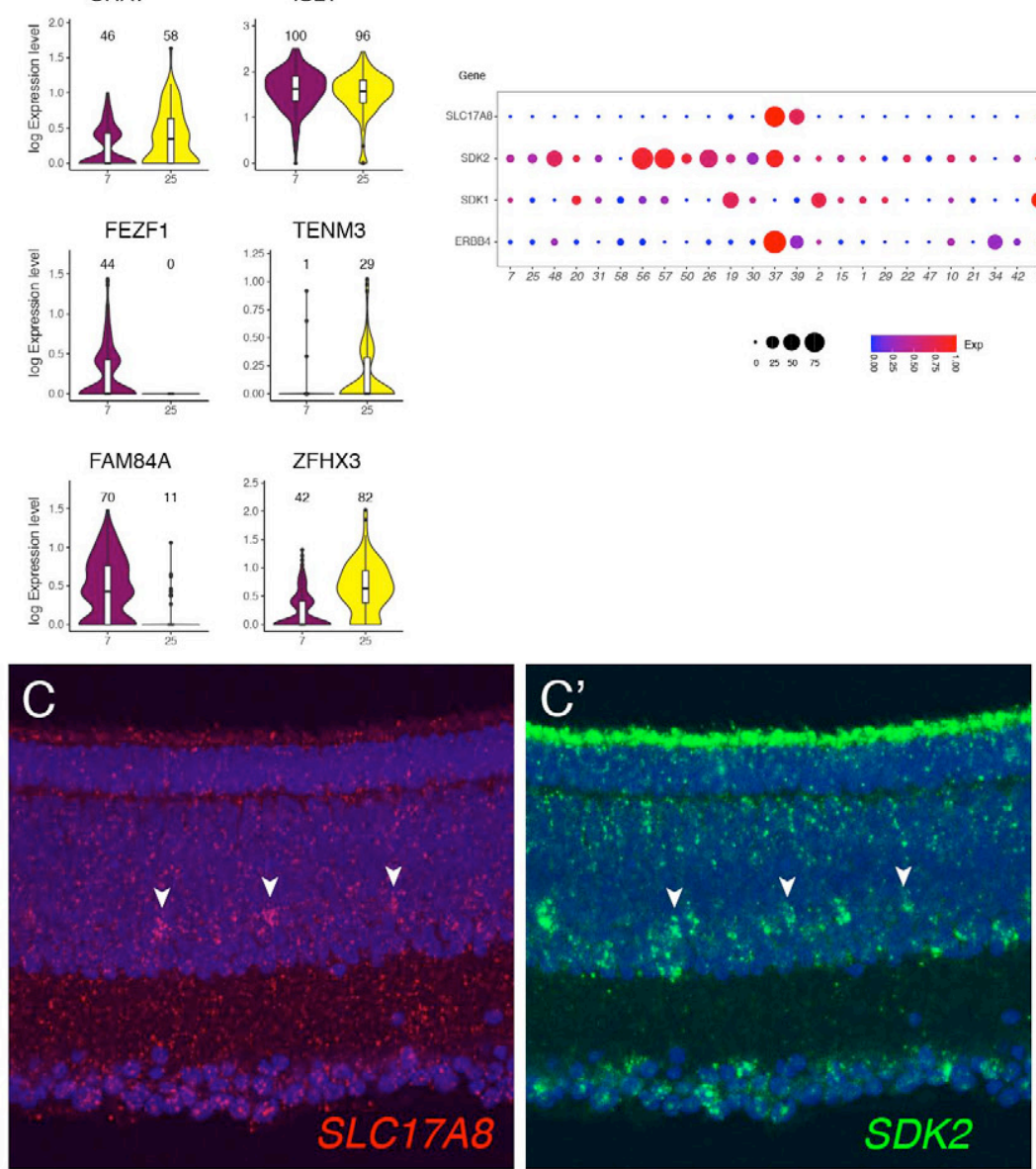

D

SLC17A8

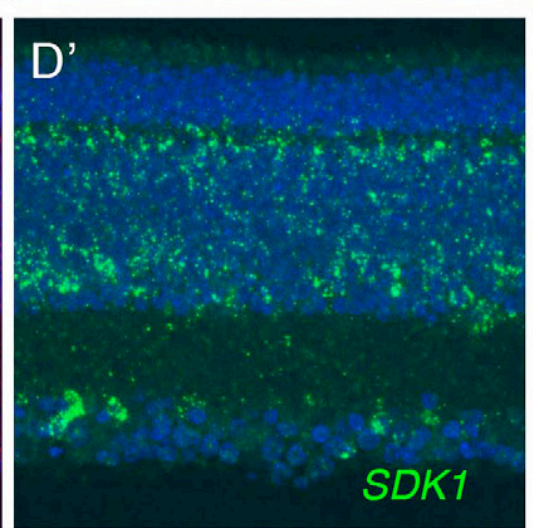

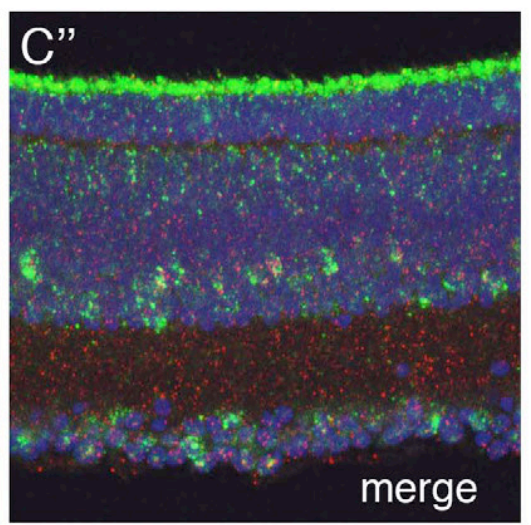

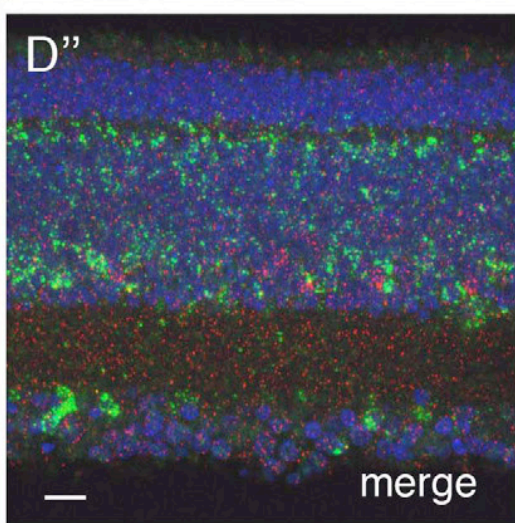

E

$$
\begin{array}{r}
1 \\
<2 \\
3 \\
4 \\
4 \\
5
\end{array}
$$

ERBB4-eCHIKIN-GFP

Figure 6 - supplement 2 
A

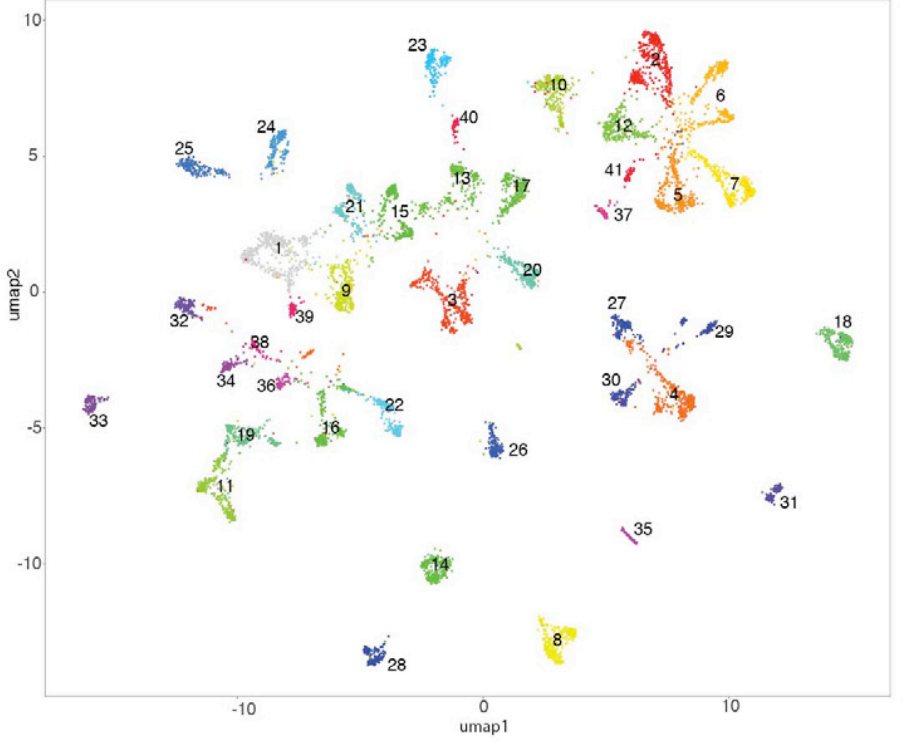

\section{D}
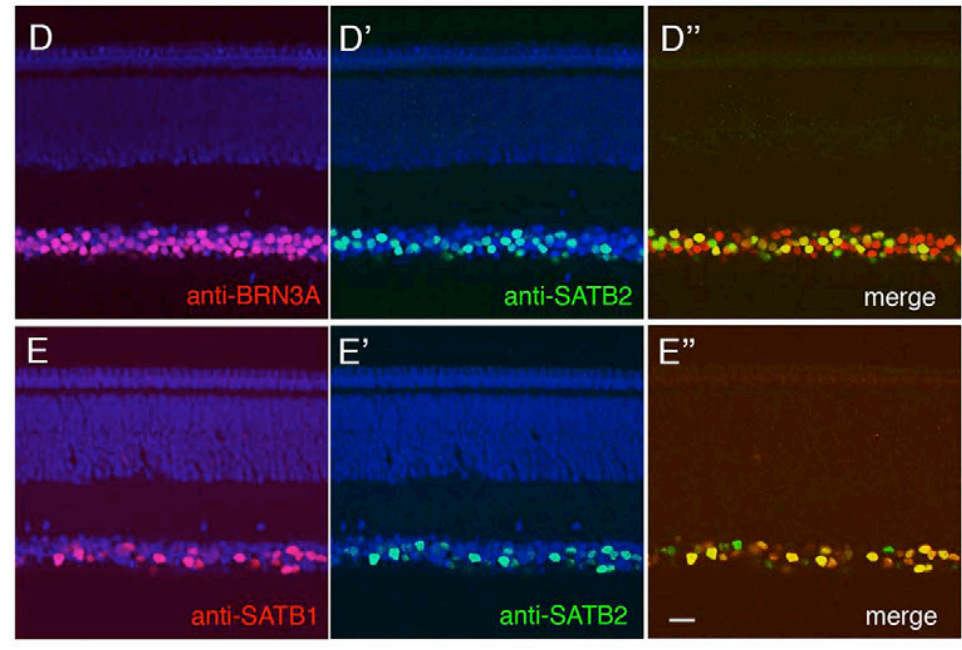

\section{TFAP2D-eCHIKIN-GFP}

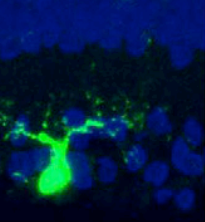

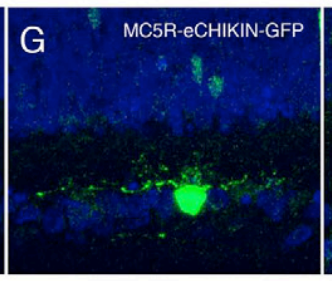

B

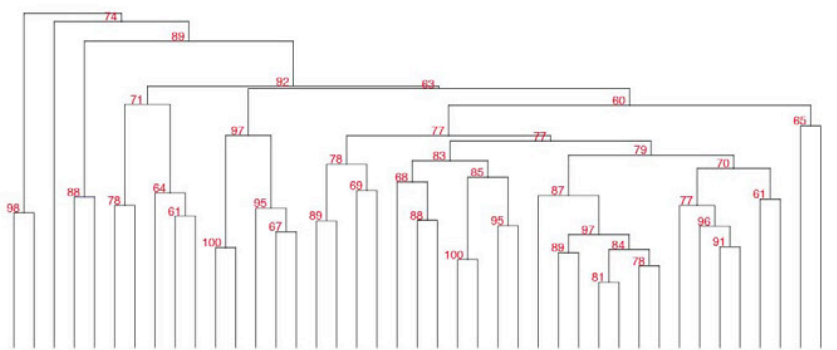

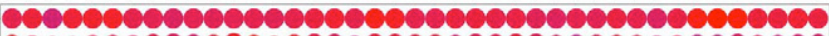

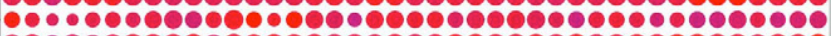

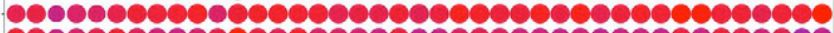

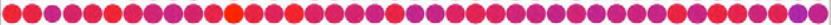

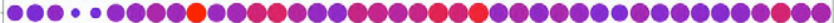
$\bullet \bullet \bullet \bullet \bullet \bullet \bullet \bullet \bullet \bullet \bullet \bullet \bullet \bullet \bullet \bullet \bullet \bullet \bullet \bullet \bullet \bullet \bullet \bullet \bullet \bullet \bullet \bullet \bullet \bullet \bullet \bullet \bullet \bullet \bullet \bullet \bullet$ - *

1.

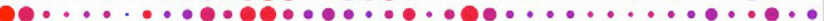

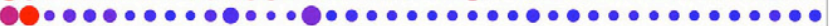

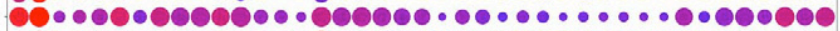

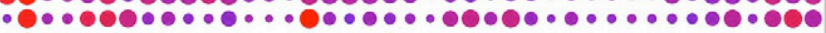
.

СНANE $\bullet \bullet \bullet \bullet \bullet \bullet \bullet \bullet \bullet \bullet \odot \bigcirc \bullet \bullet \bullet \bullet \bullet \bullet \bullet \bullet \bullet \bullet \bullet \bullet \bullet \bullet \bullet \bullet \bullet \bullet \bullet \bullet \bullet \bullet \bullet \bullet \bullet \bullet \bullet \bullet \bullet$

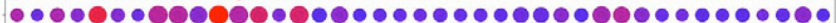

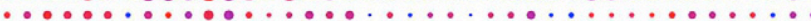

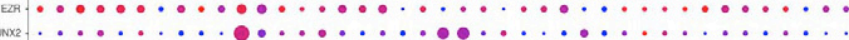

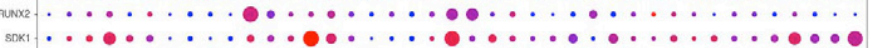

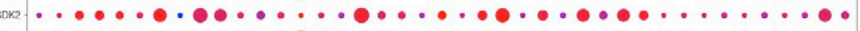
$\ldots \ldots \ldots \ldots \ldots \ldots$ C $\bullet \ldots \ldots \ldots \ldots . . . \ldots \ldots \ldots$ ค 10

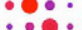

$\therefore$

-

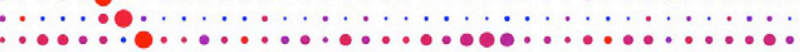
.......

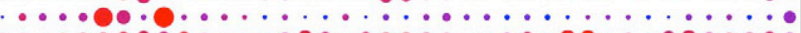

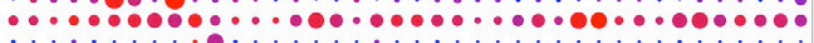
$\therefore \therefore$.

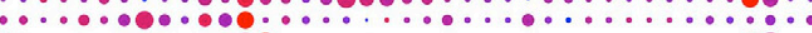
$\ldots \ldots \ldots \ldots \ldots . \ldots . \ldots . \ldots . . . \ldots$ $\bullet \cdots \cdots$ $\cdots$ $\therefore \cdots$ $\ldots \ldots \ldots \ldots$

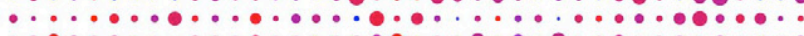
$\therefore: \cdots$ $\ldots \ldots \bullet \bullet \bullet \bullet \bullet \bullet . \bullet \bullet \bullet \bullet \bullet . \bullet \bullet \bullet \bullet \ldots . . . . . . . . \bullet$

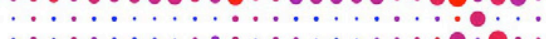

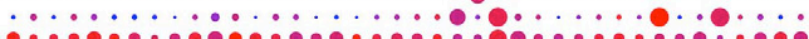
$\mathrm{H} \quad$ ETV1-eCHIKIN-Cre

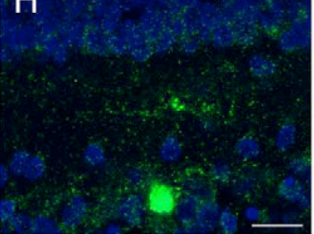


A
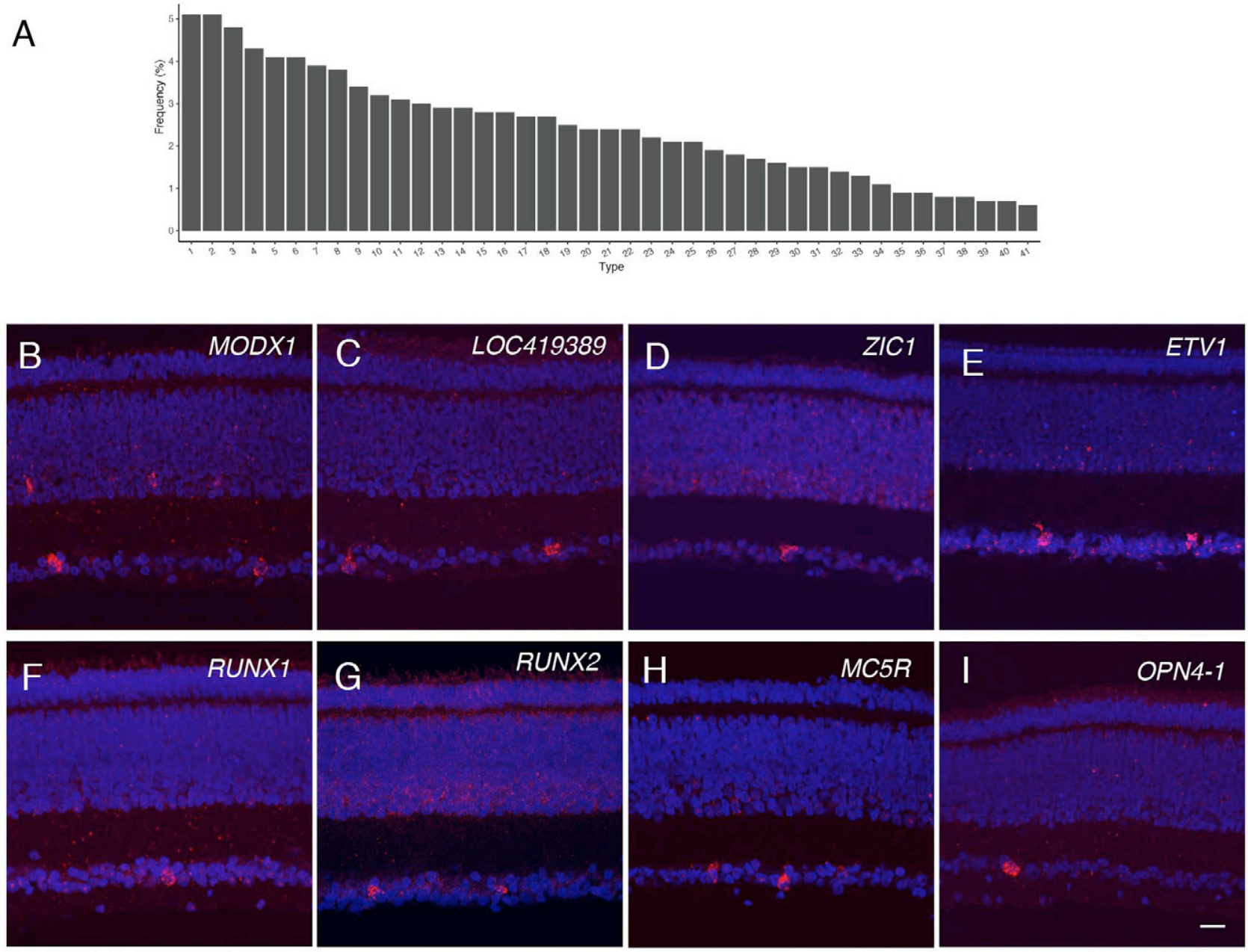

Figure 7 - supplement 1 
bioRxiv preprint doi: https://doi.org/10.1101/2020.10.09.333633; this version posted October 10,2020 . The copyright holder for this preprint (which was not certified by peer review) is the author/funder, who has granted bioRxiv a license to display the preprint in perpetuity. It is made available under aCC-BY-NC-ND 4.0 International license.
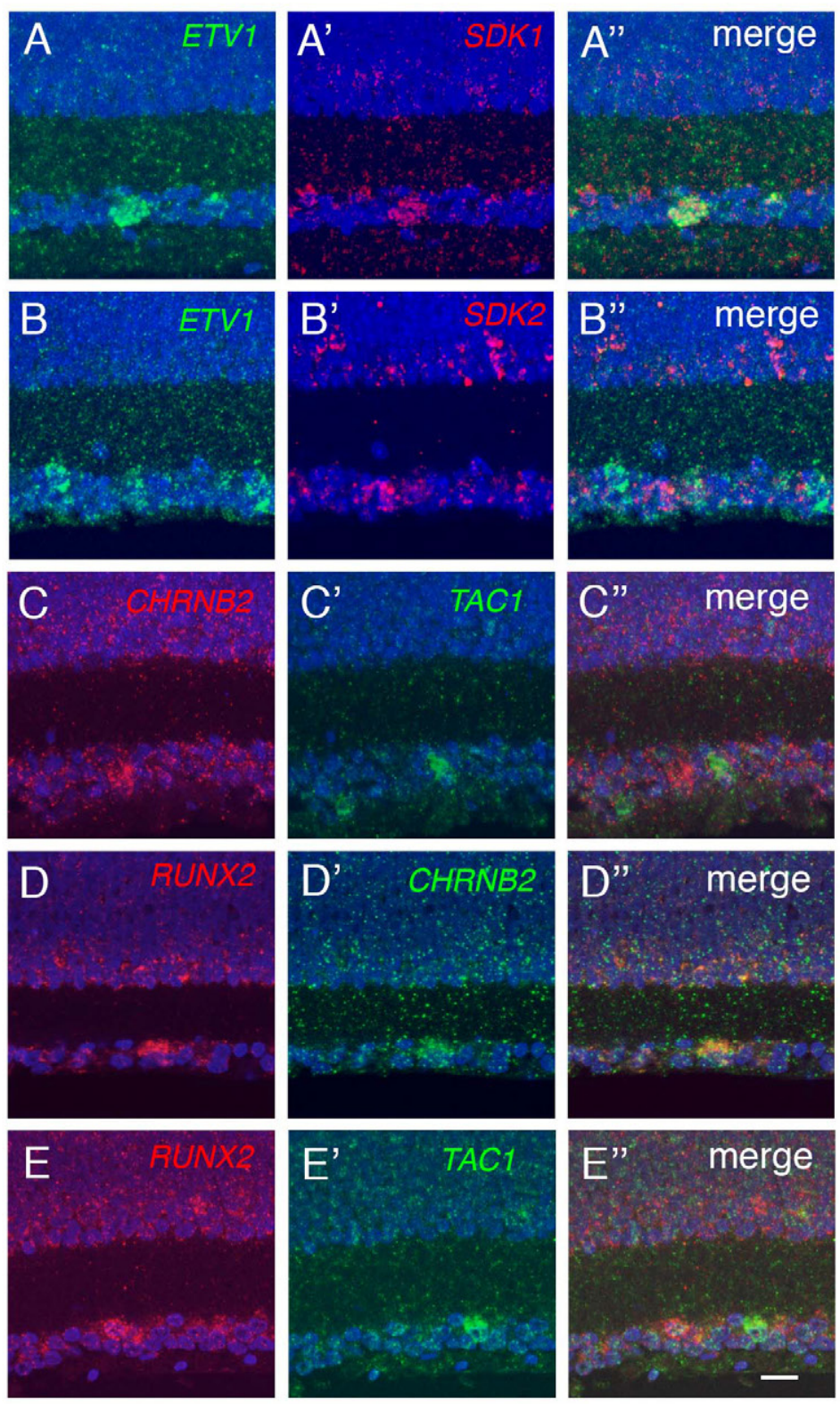

Figure 7 - supplement 2 


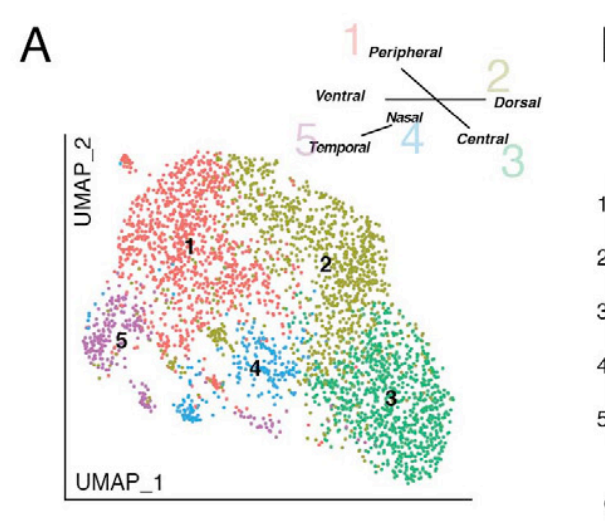

$\begin{array}{lll}\text { B } & \text { D } & \text { E }\end{array}$

C
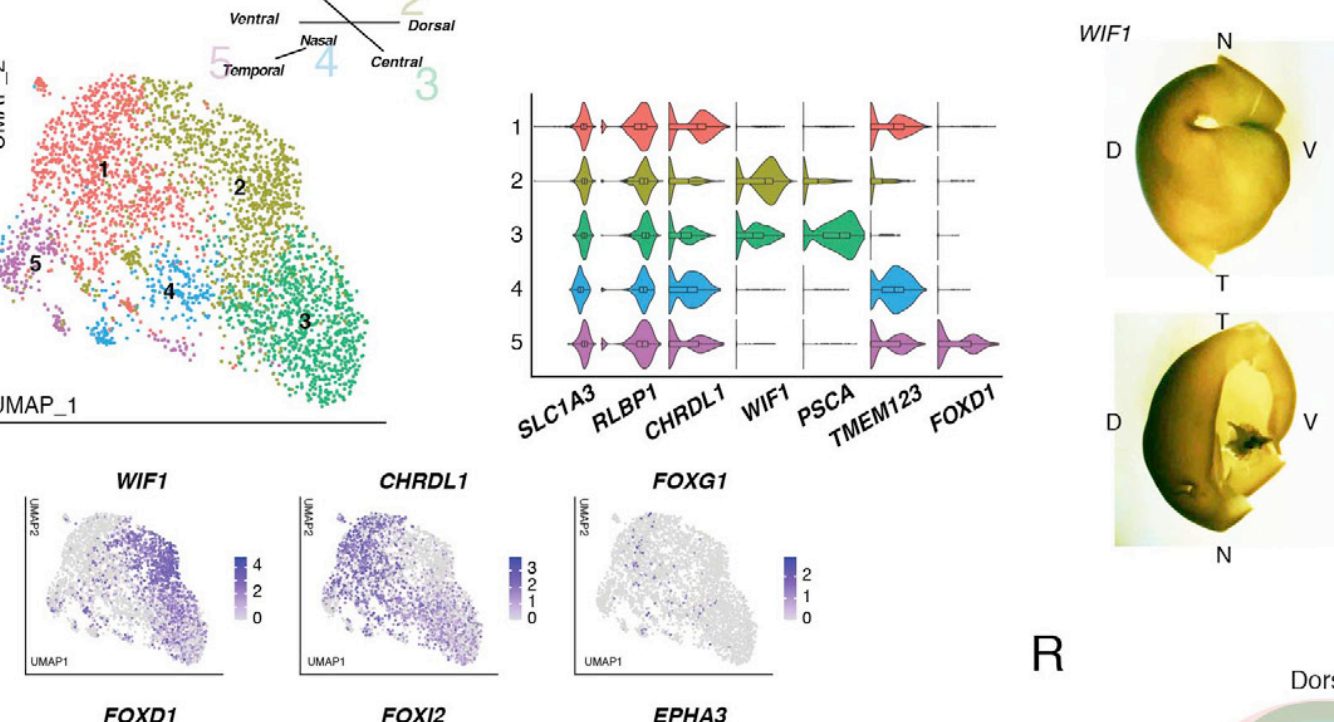

CHRDL 1
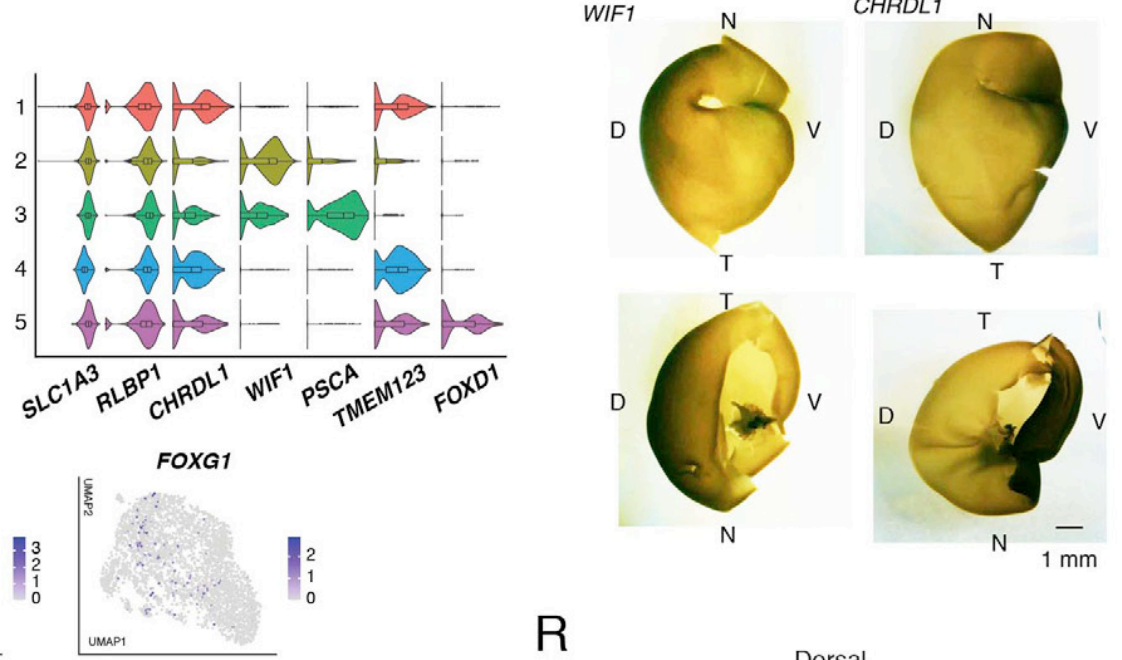

R
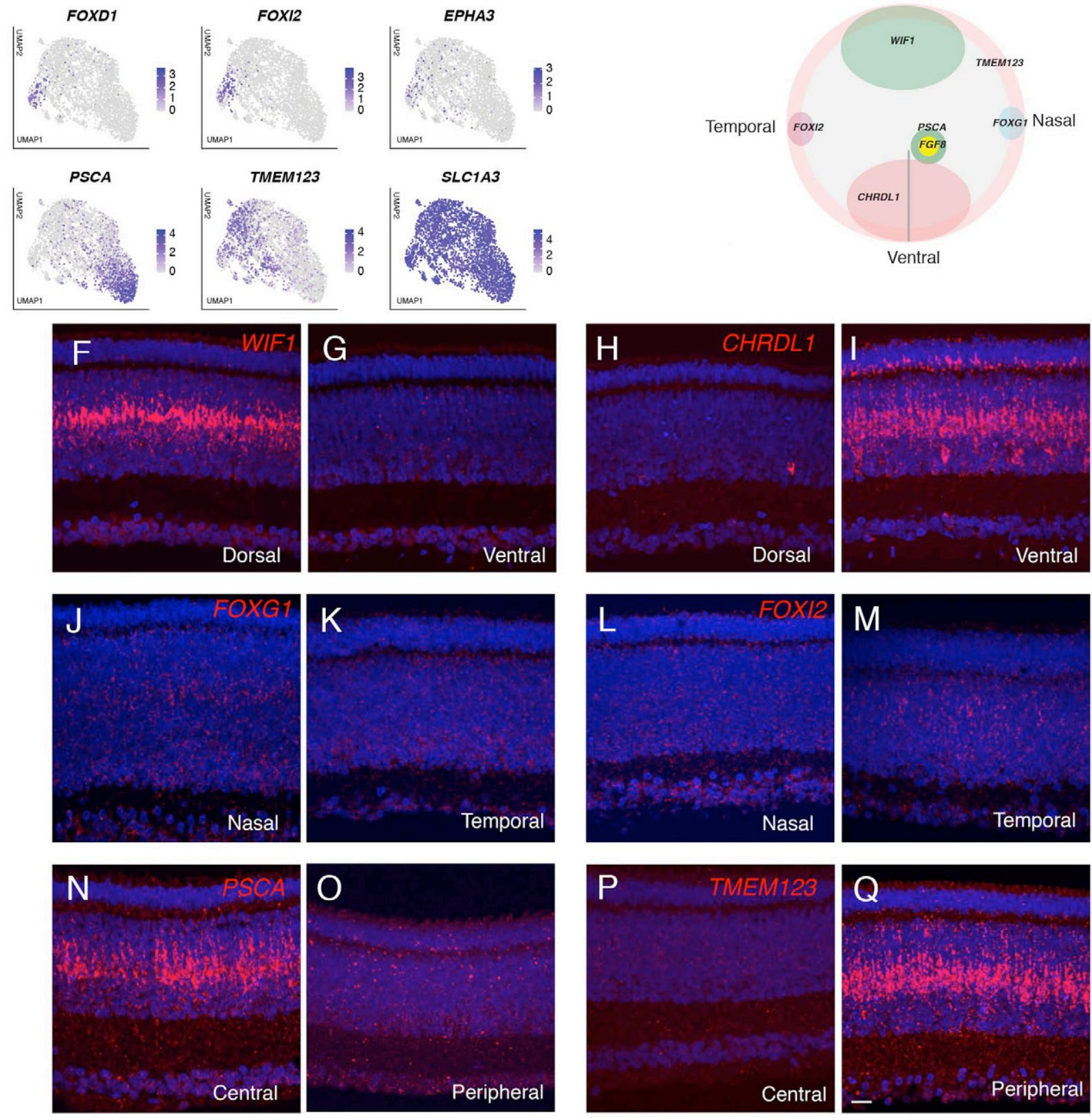

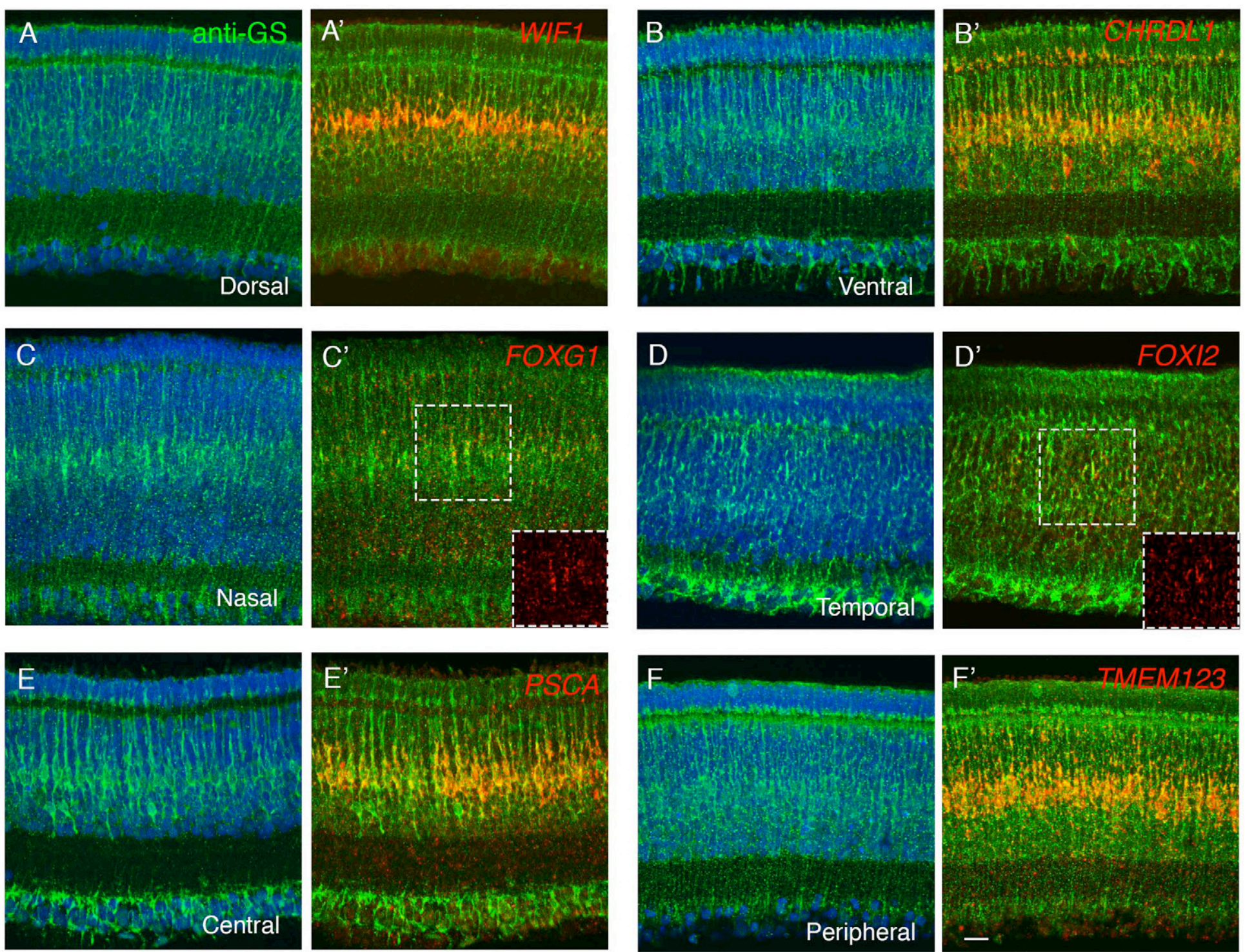

Figure 8 - supplement 1 
A

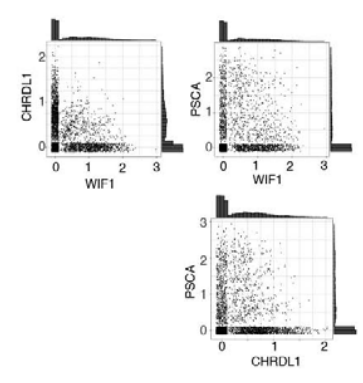

E18
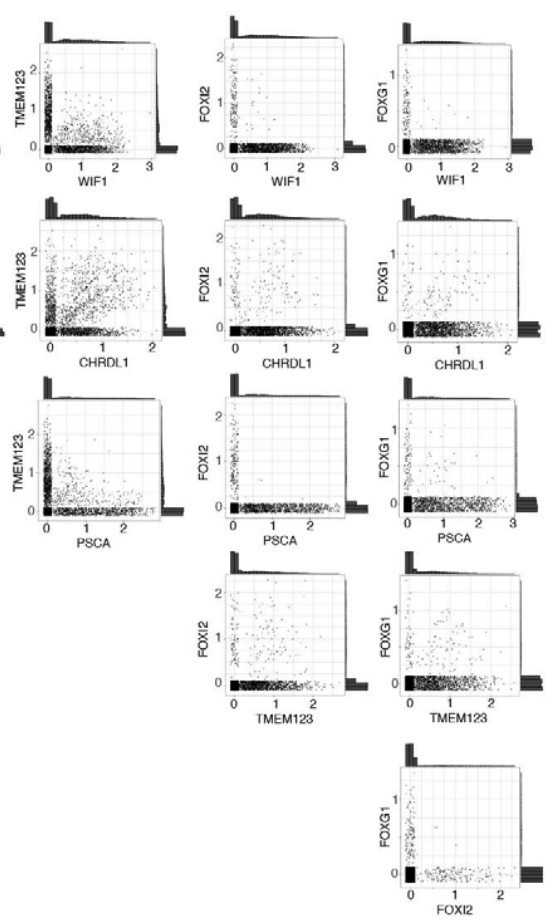

B
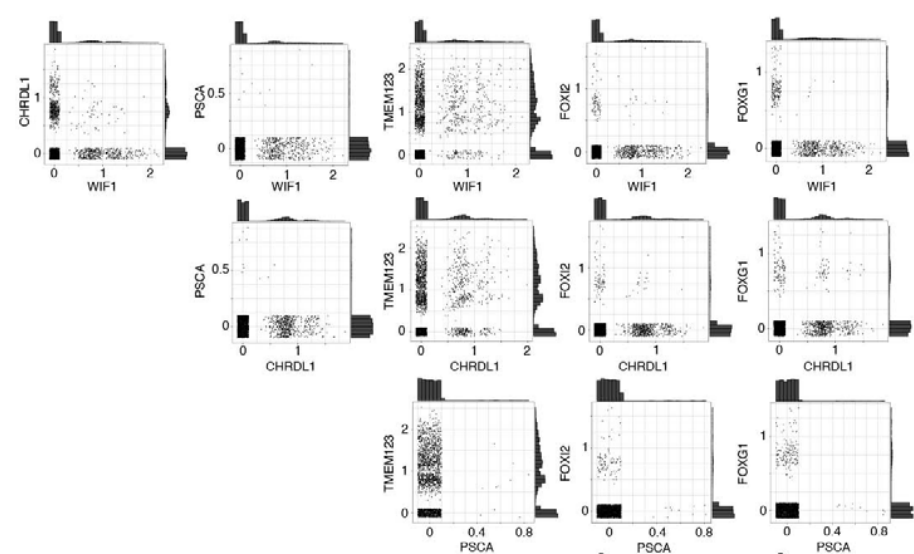

WIF-
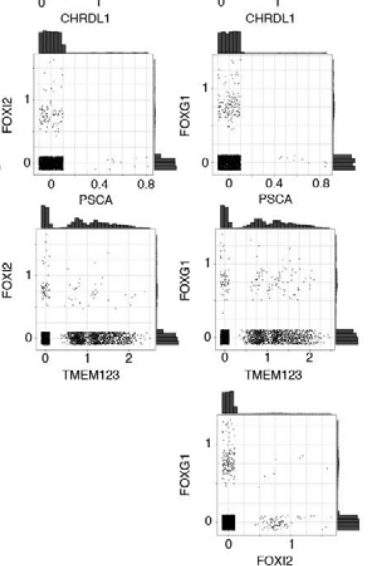

Figure 8 - supplement 2 
A
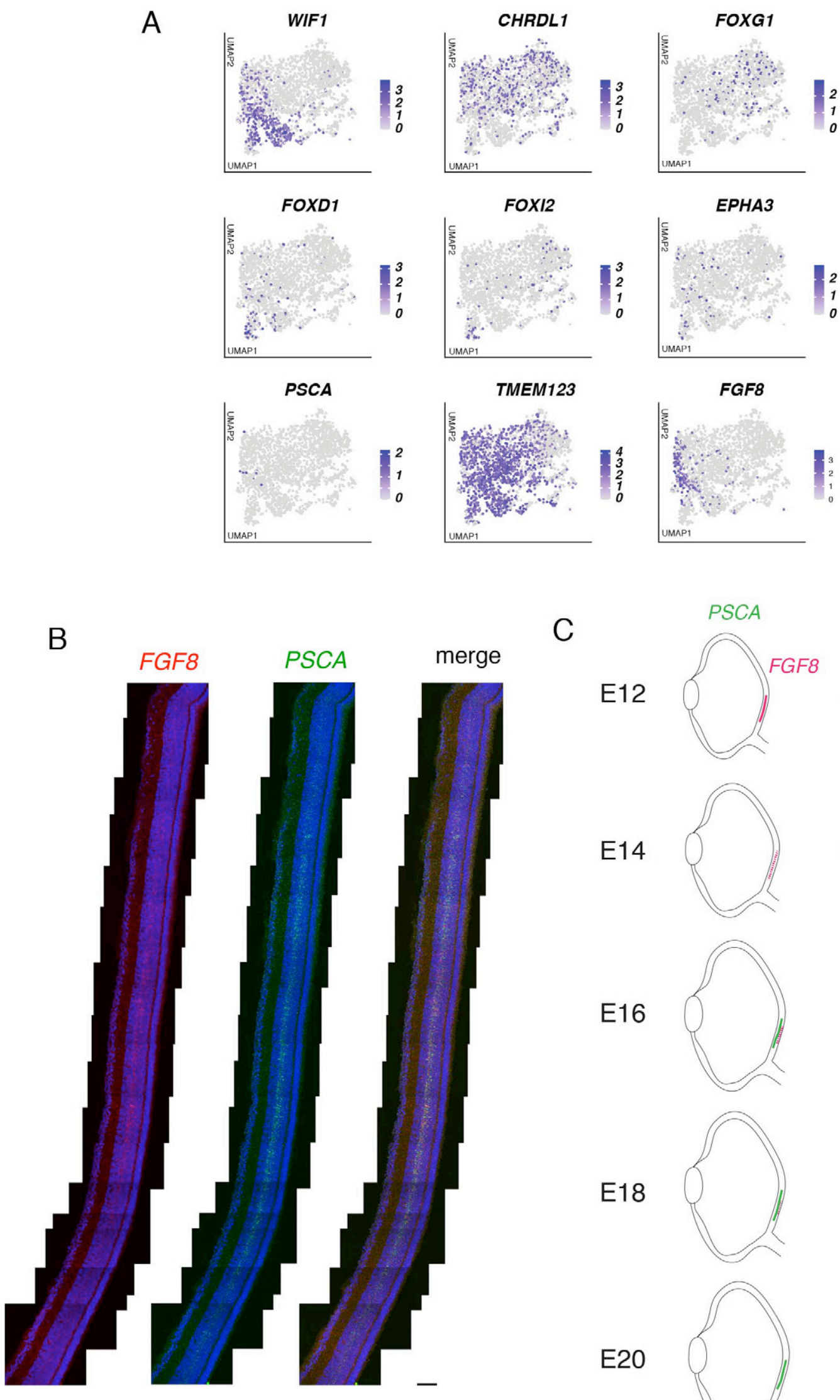

C

E12

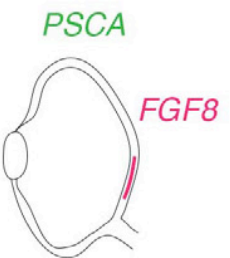

TMEM123

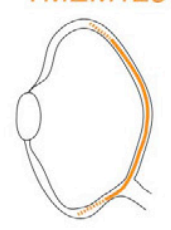

E14
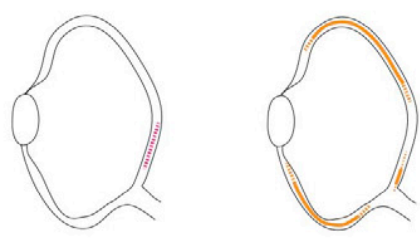

E16
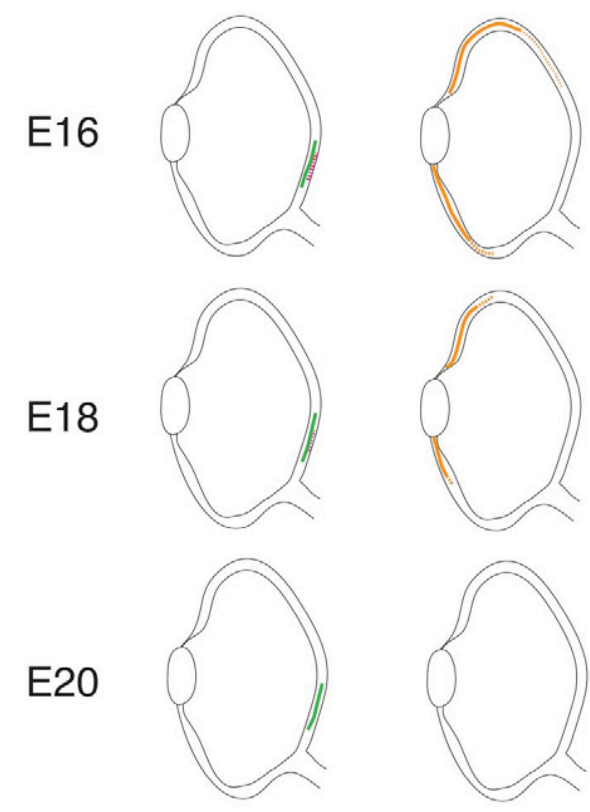

Figure 8 - supplement 3 
bioRxiv preprint doi: https://doi.org/10.1101/2020.10.09.333633; this version posted October 10, 2020. The copyright holder for this preprint A (which was not certified by peer review) is the author/funder, who has grafed bioRxiv a license to display the preprint in perpetuity. It is made
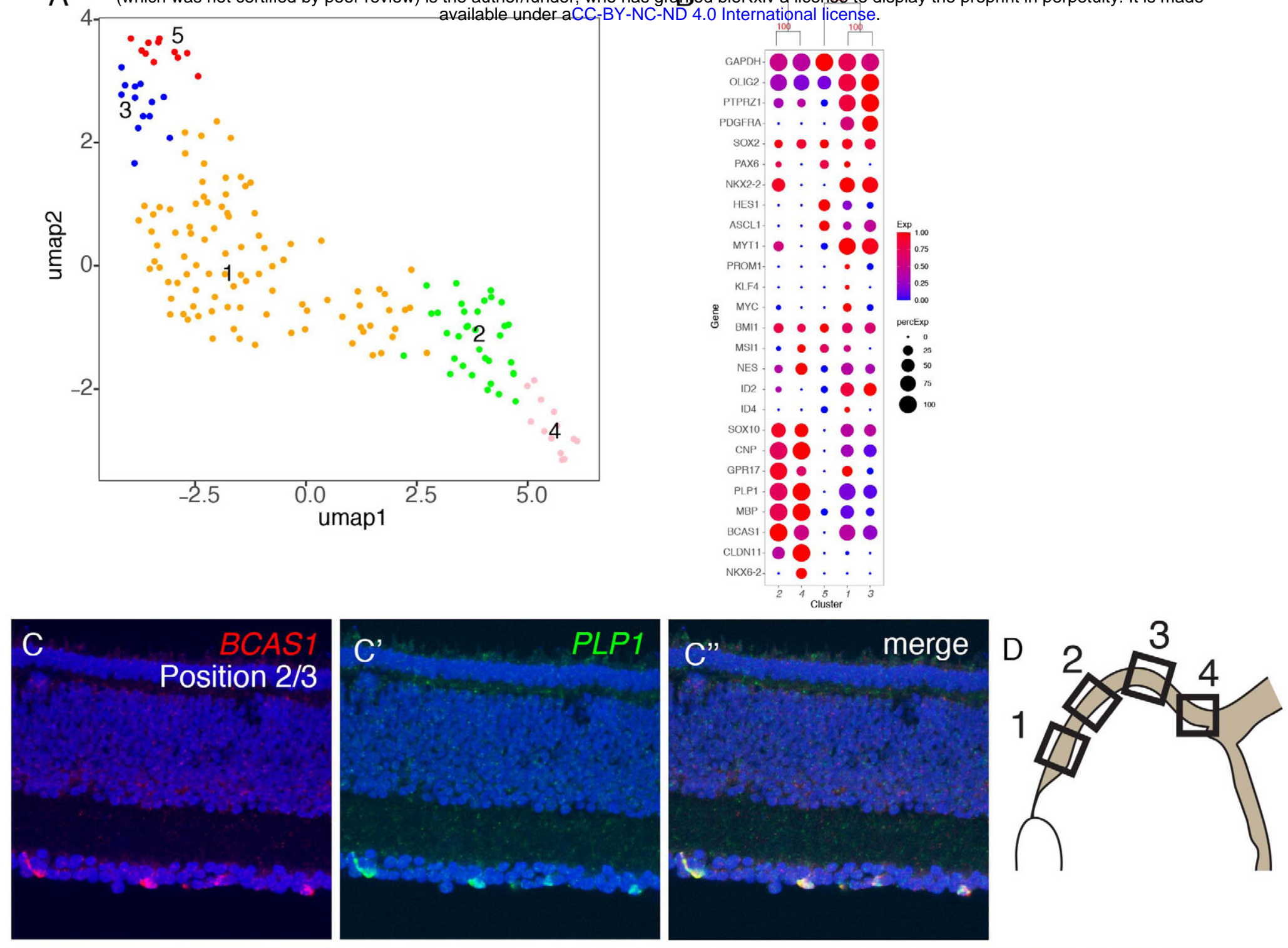

E
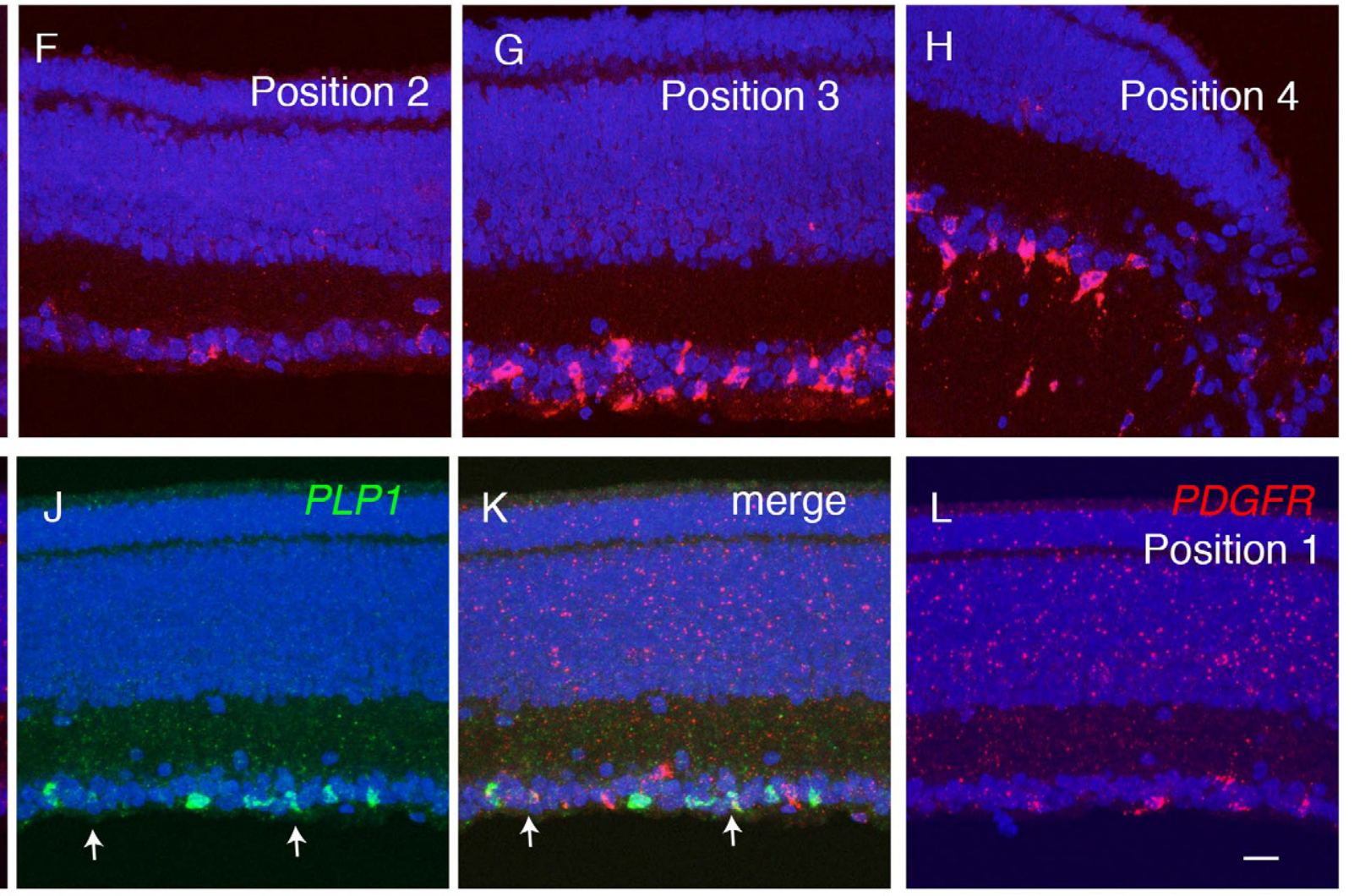

Figure 9 
A

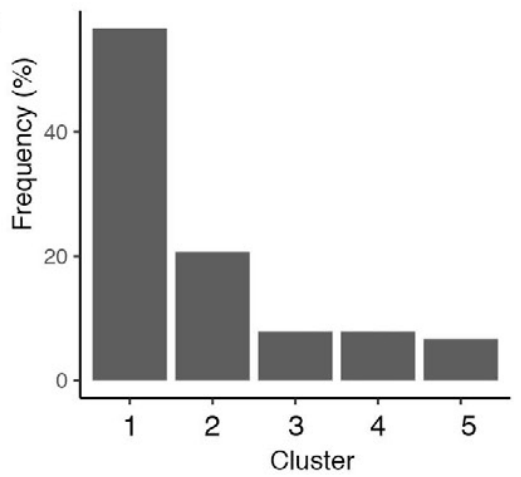

B
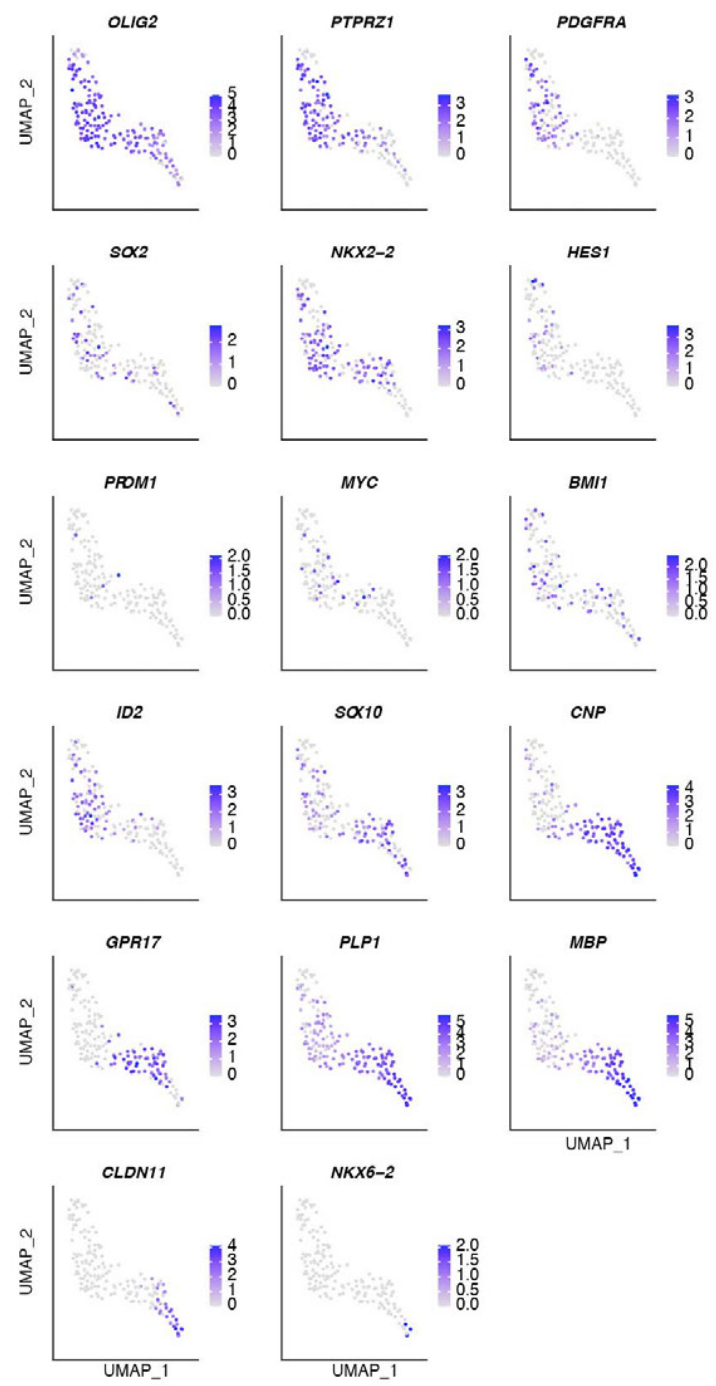

C
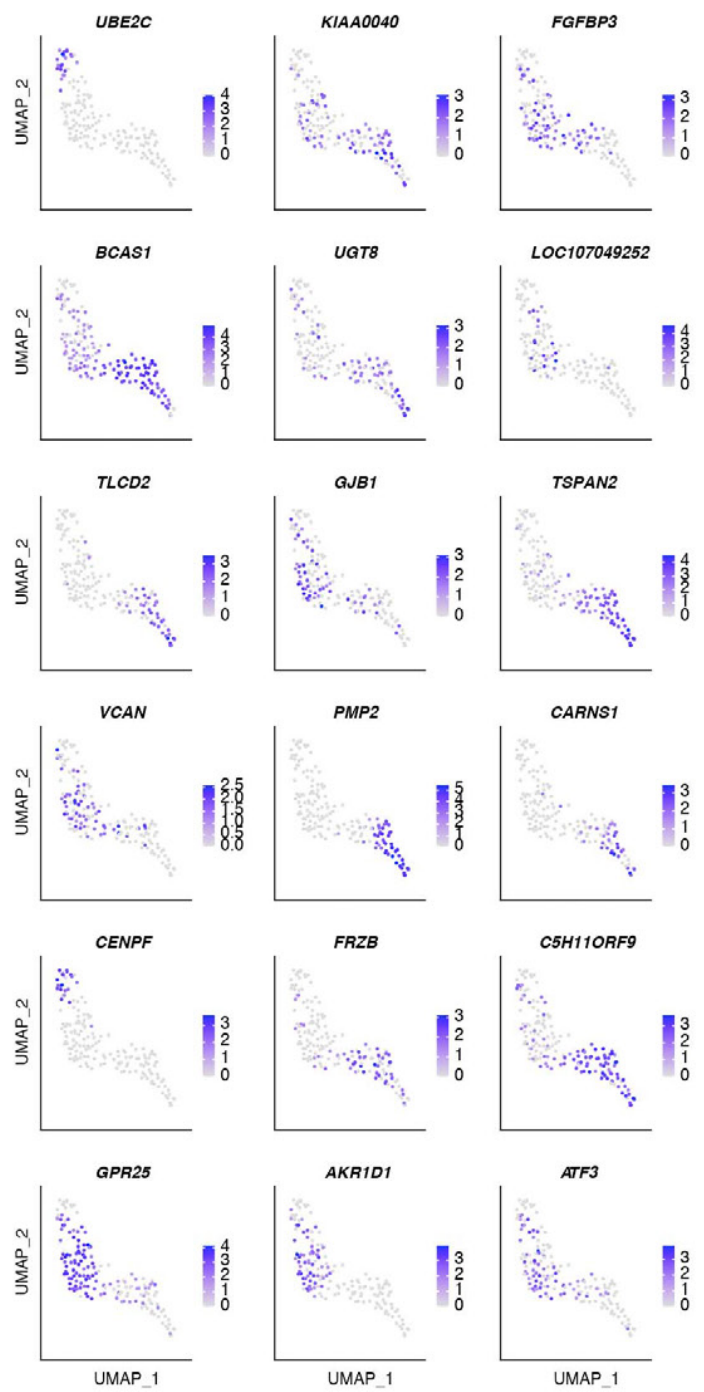
A

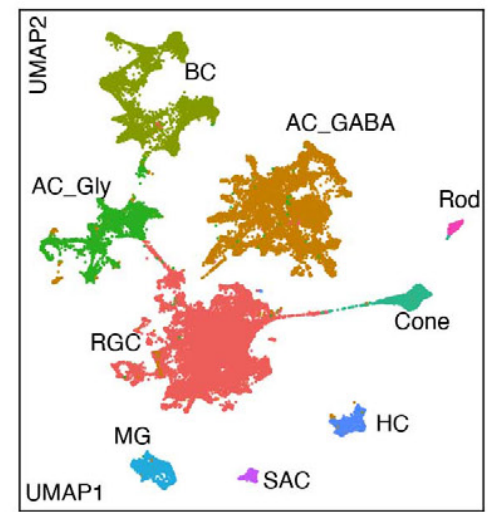

B

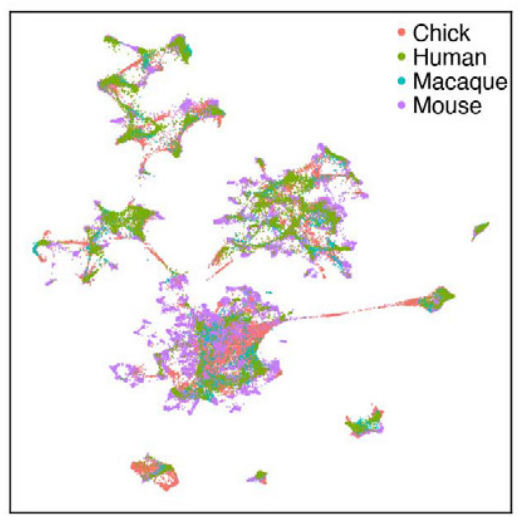

C
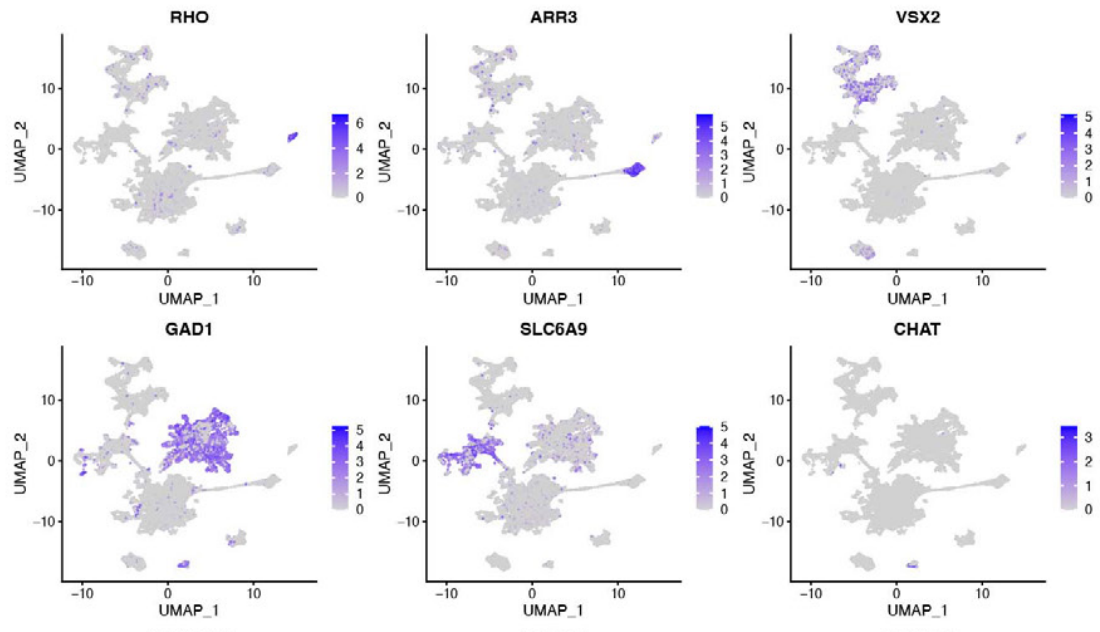

SLC6A9

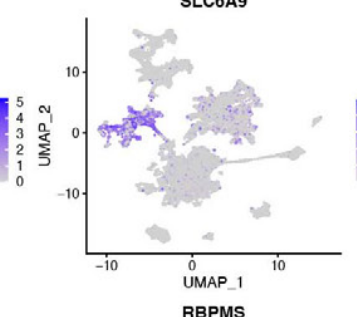

CHAT
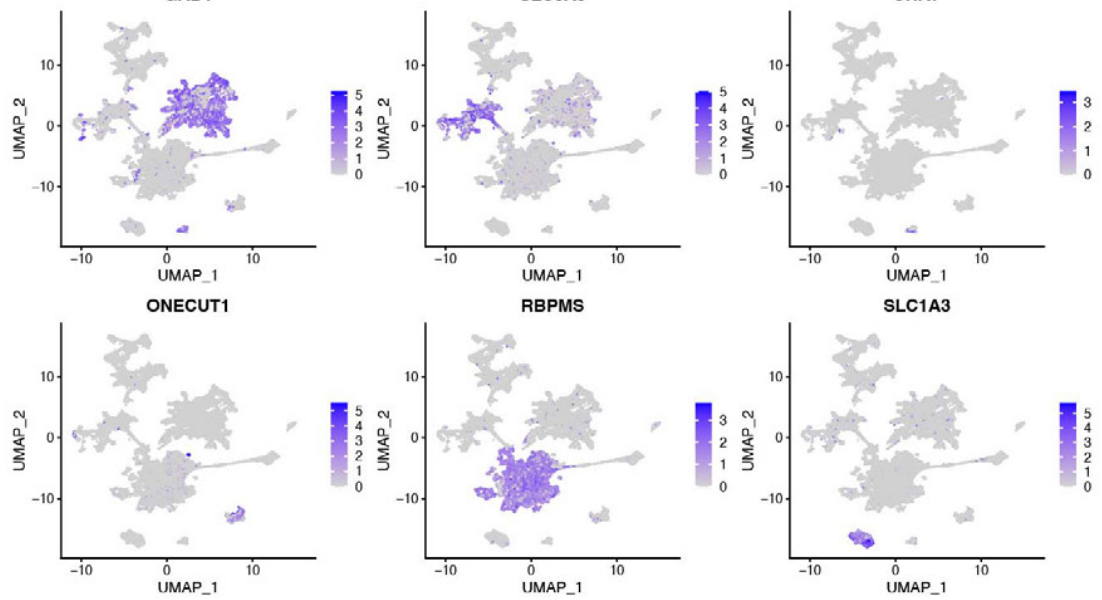

D

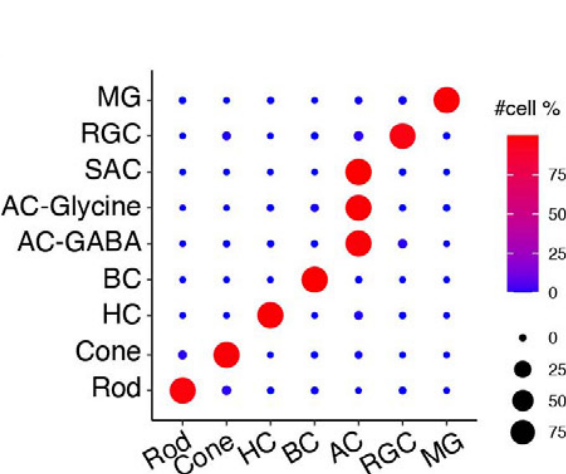

annotation from separated dataset

F

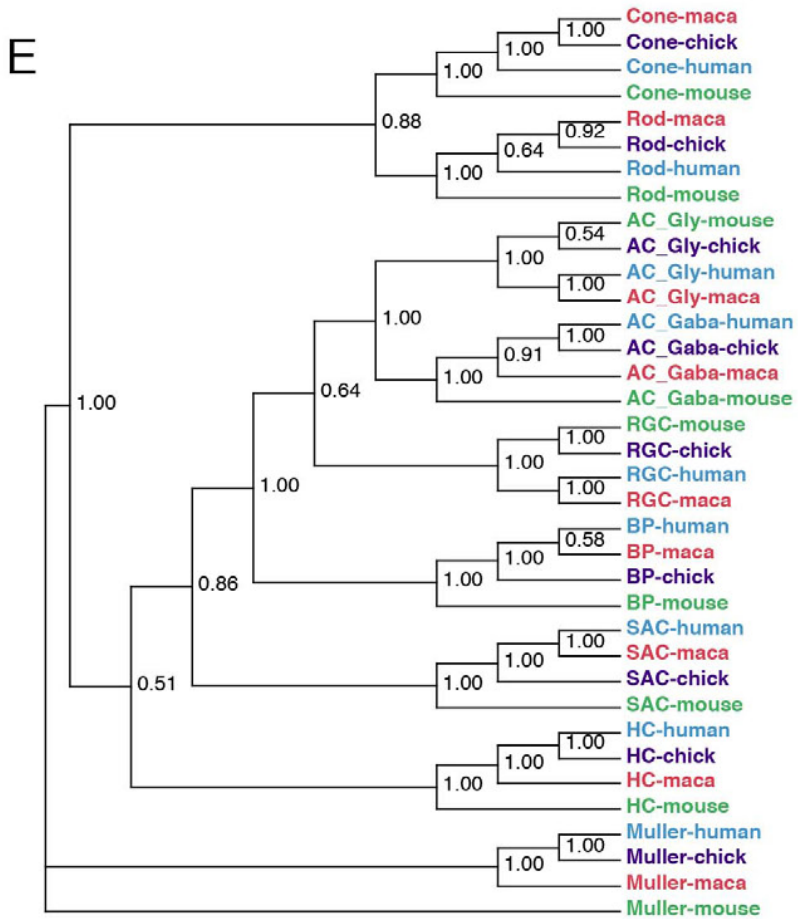


A

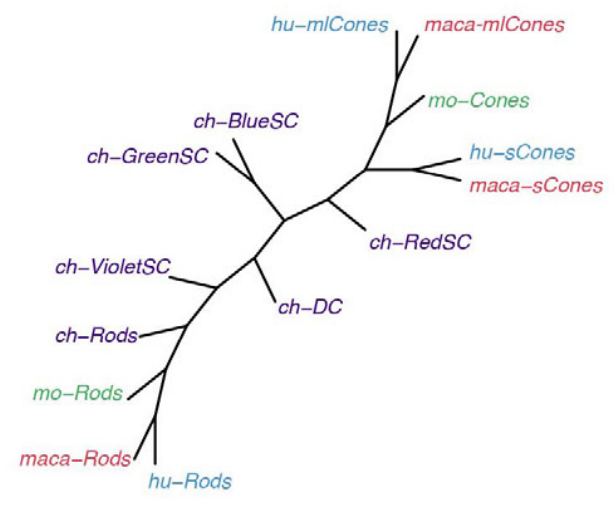

C

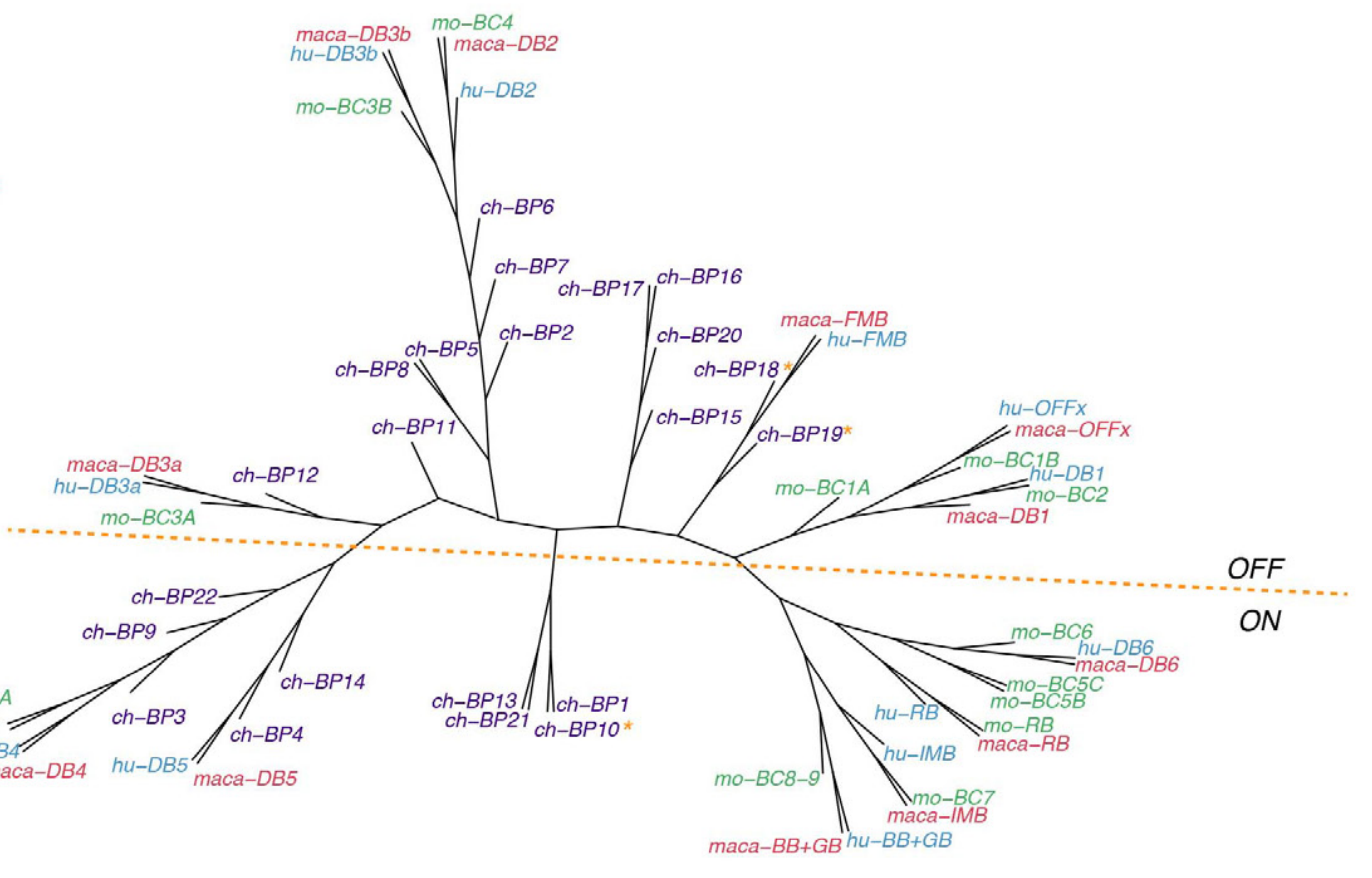


A

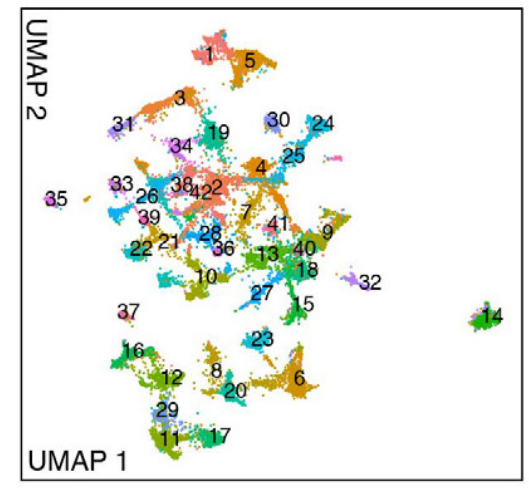

B

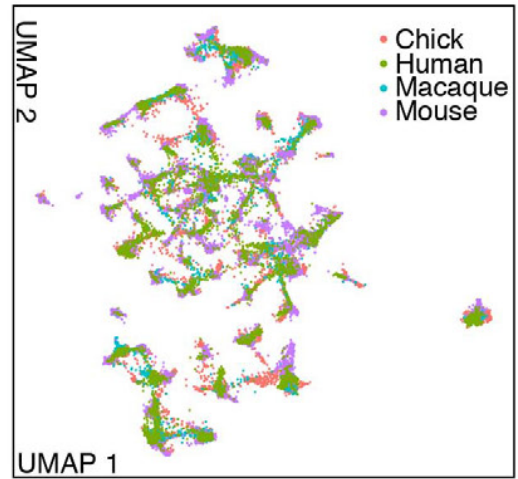

ARI:0.235

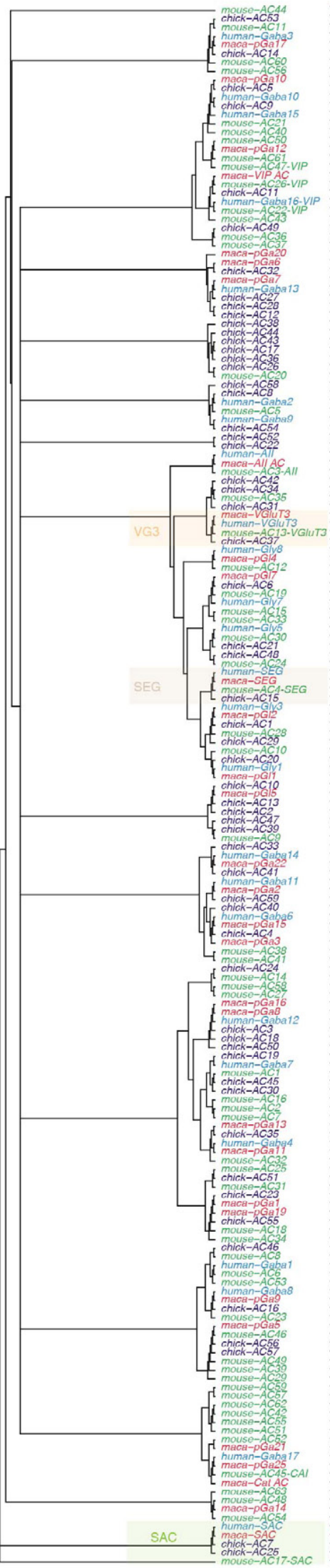

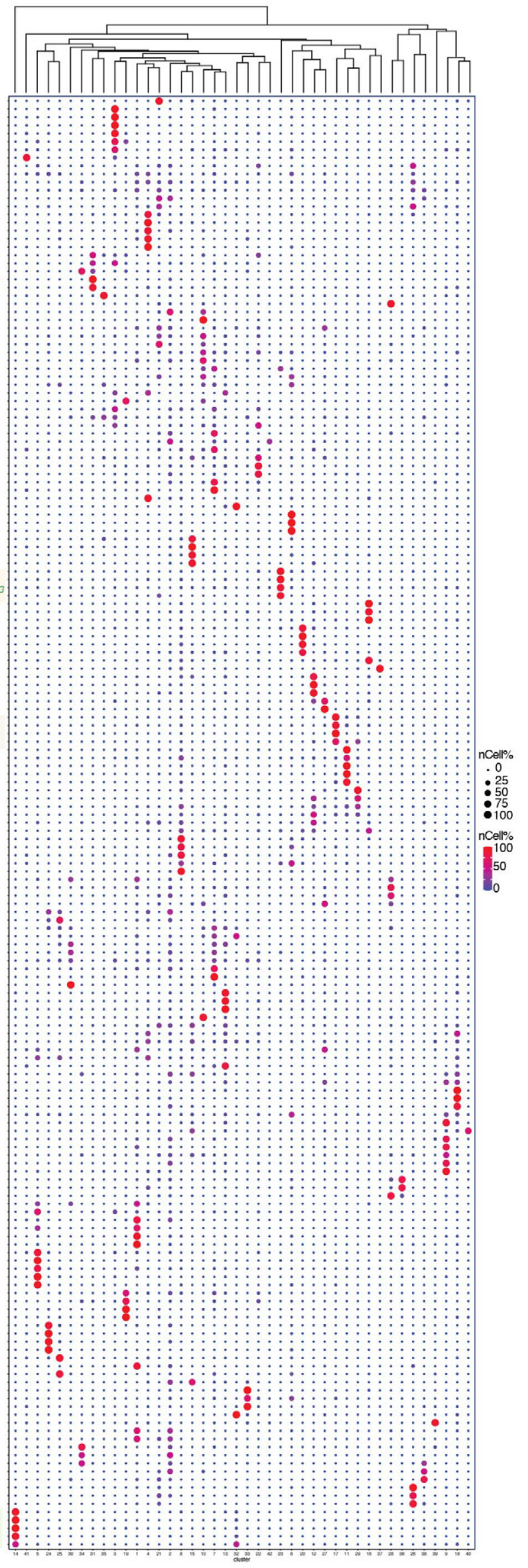

Figure 11 - supplement 1 

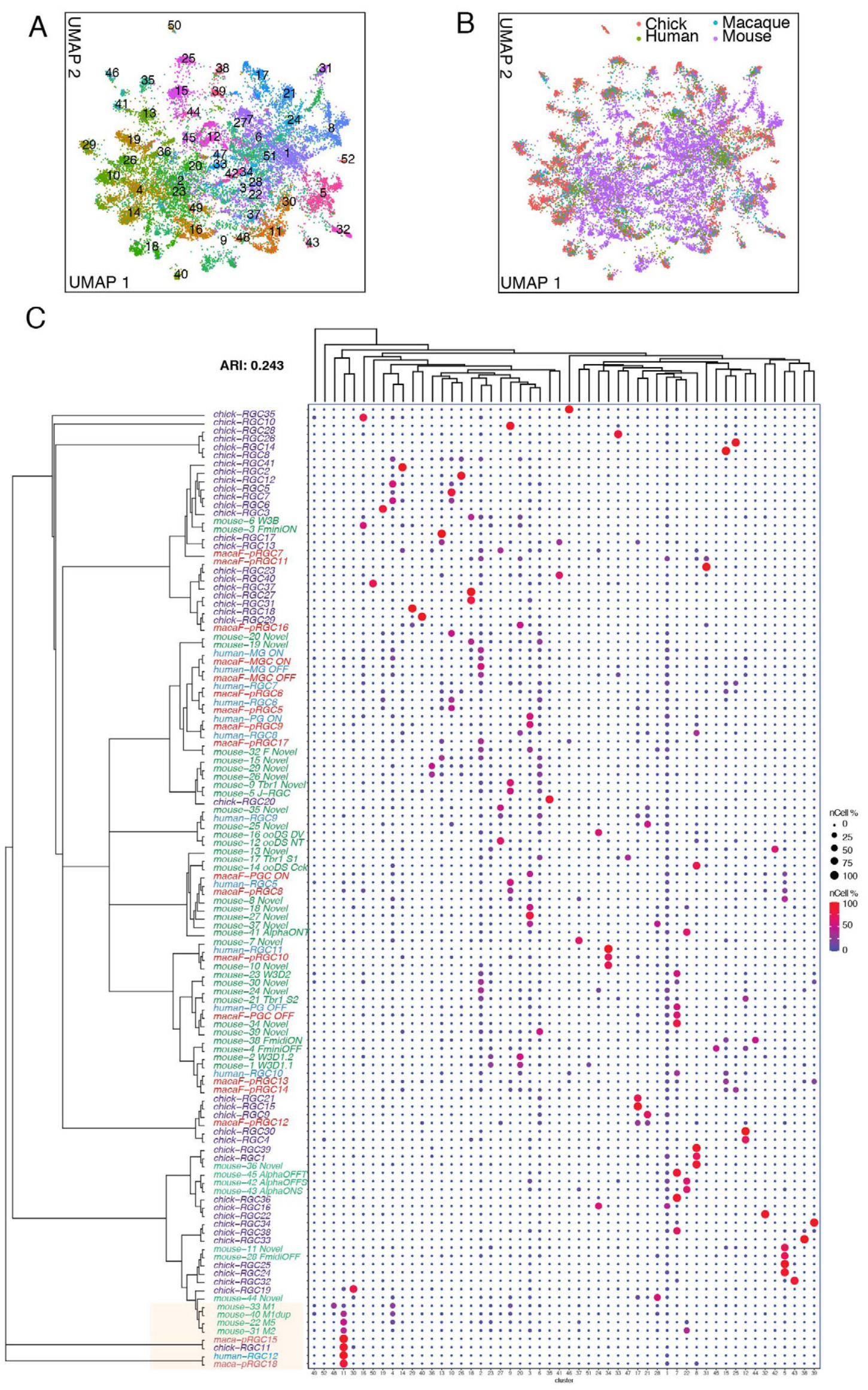

Figure 11 -supplement 2 


\begin{tabular}{|c|c|c|c|c|}
\hline Gene & PCR oligo (5') & PCR oligo (3') & Lengt & \\
\hline ARHGAP18 & CGTGAACTGCCTCAACCACTCCTAAC & GAGTCTTGTCCTGCTTCTCGTGCTTT & & 490 \\
\hline BCAS1 & GAGATAGATGACTGCAACCAGAG & TAGGAGTGGACGATCCTTTCT & & 553 \\
\hline CALB1 & GCTTGGACTTAACACCTGAAATG & GAGATCCTTCAGTAGTGCATCAA & & 503 \\
\hline CHODL & XATGGGGCTGGGACTGGGGCTGGC & ZTTATACCTCCATGCTACTGTCCT & FULL & \\
\hline CHRDL1 & XATGAGAAGAAAGTGGAGATCGGA & ZTTAACAGTGACCCTTTTCAGACT & FULL & \\
\hline CHRNB2 & TGTACGAGGTCTCCTTCTACTC & ATGCAGAGCGTCATCTTCTC & & 433 \\
\hline DACT2 & XATGGGCGCTCCCCAGCTCGTCAG & ZTTAAACCATGGTCATAACCTTCA & FULL & \\
\hline EGFR & GGTCTAGGCATCGGTCTTTAC & CGTTCCTCCAGGTAGTTCATTC & & 512 \\
\hline ETV1 & XATGGATGGATTTTATGACCAGCA & ZTTAATAGACGTAGCCTTCATTAT & FULL & \\
\hline FGF8 & TCATGCACTTGTTCGTCCTC & GCTGGAGTTTCGAGTCCTTT & & 593 \\
\hline GRIK1 & GAACTCCTACAGTGGCCTTAAC & GCAGGCTAGGAGAACATACATC & & 496 \\
\hline GRTP1 & AGAGGCCAGATGACTTTGATTAC & CCTGACAATATCCCACTGCTTTAA & & 417 \\
\hline IPCEF1 & XATGGAAGCTGATGGGAATGCCCT & ZTCATGTAGCACTTTCAGTGACAG & FULL & \\
\hline LOC419389 & GGAAGCACGAGGACAGAAA & CGCGCTCTCCTGGAATAAA & & 451 \\
\hline$\angle T K$ & GCAGCATCTCCTTGGTCTATC & GTCTTCCATCAGCAAAGCAATC & & 454 \\
\hline MAFA & XATGGCCTCGGAGTTGGCCATGAC & ZTCACATGAAGAAGTCAGCGGCAG & FULL & \\
\hline MMEL1 & TGTTCTGCAGTCGCCCTGGTAAT & TCTTCCATGCTCCAGCTTGGTTCT & & 464 \\
\hline MOXD1 & GATAACTCTGGTCTGAGGCTATTC & GTCCTGACTGGTCTGTAGATTTC & & 557 \\
\hline NPY & XATGCAGGGCACCATGAGGCTGTG & ZTCACCACATCGAAGGGTCTTCAA & FULL & \\
\hline NTRK1 & CTTCCTCTCTGTCATGCTCATT & GGTCTCCATGCTTCATGTACTC & & 500 \\
\hline NTS & XATGAGAGCCCAGCTGGTGTGCGT & ZTCAGTAATATGAACTTCTCTTGA & FULL & \\
\hline OPN1LW & XATGGCGGCGTGGGAGGCGGCGTT & ZTTAGGCGGGCGAGACGGAGGAGT & FULL & \\
\hline OPN1MSW & XATGAATGGGACAGAAGGTATCAA & ZCTATGCAGGTGAAACTTGGCTGG & FULL & \\
\hline OPN4-1 & TCTCCTGAGAGGCTCCATAAA & GGTTTGTCTCTGAGGTAGGAATG & & 518 \\
\hline OPRM1 & TGCCATTCCAGAGTGTGAATTA & CACTGCCACCACTACAAGAA & & 503 \\
\hline$O X T$ & XATGTTCTACAAGGCGCTCACCGT & ZCTATGCAAACAGCATTTCTTGGT & FULL & \\
\hline PDGFR & CTGATGTGGAATGGTTGGTTTG & GCTGGATCTAGCTGTAGGTTTC & & 581 \\
\hline PENK & XATGGCGTTGCTGCTGCGGCTCGG & ZTTAAAATCTCATAAATCCACCGT & FULL & \\
\hline PLP1 & XATGGGTCTGTTGGAGTGCTGTGC & ZCTAGAACTTGGTGCCCCGGCCCA & FULL & \\
\hline PRDM8 & TCTACGACAGCATCGCCTTCATC & CAGGTTGTGGAAGTCCGTGGAG & & 533 \\
\hline PRKCA & XATGGCCGACGTGTTCCCGGGCTC & ZTCATGCTACATTTTCTAGGAGGG & FULL & \\
\hline$P S C A$ & XATGAAGGTTTTCTTCATCCTCCT & ZTCACAGTCTGTTGTTCAGGAAGG & FULL & \\
\hline$R R A D$ & XATGACTCTGAACCGCGGCGACAA & ZCTAAAGCACAGATAAGTCATGGC & FULL & \\
\hline RUNX1 & GTACCACAGAGCCATCAAGATAA & CCGTGGACATAGCAGACATAC & & 590 \\
\hline RUNX2 & XATGGCATCAAACAGCCTCTTCAG & ZTCAGTACGGCCTCCAAACGGACT & FULL & \\
\hline SLC6A4 & TGGGAGACAGAGAGACCTGGAGTAAA & GCACCTGTAGAACTTGGCGGGTATAA & & 492 \\
\hline SLIT1 & ATGGACAACTCGGGCAAGCACTA & TAGCCGCTGTGGCACTCACATAC & & 536 \\
\hline STRAG & XATGGCAGCCAACAACTCCGGGGC & ZTCAGGGCCTGGGGGGGCTGAGCT & FULL & \\
\hline TAC1 & CGTCGCCAGGTCTATAAAGTG & TCGCTCGTAATTCTGTGCTATG & & 429 \\
\hline TMEM123 & XATGCGGCTCATCTTTTCCGGCGC & ZTTAAATGATGGCATCGTGTTCAT & FULL & \\
\hline TPBGL & XATGGTCCGCAGGACGCGGCGGGC & ZTCAGAGCCCCCGGGGTGCCGACGG & FULL & \\
\hline WIF1 & XATGGCCGCGGCGGGGCGGCTGTG & ZTCACCAGATATAATTGGATTCGG & FULL & \\
\hline ZIC1 & XATGCTTCTGGATGCTGGACCGCA & ZTTACACGTACCATTCGTTAAAAT & FULL & \\
\hline SLC17A8 (VG3) & ATCACTTGGACATAGCCC & GCTTTCTCCATTGCCTTCTC & & 379 \\
\hline TPBG & CTCAACCTCAGCGACAACT & GTGATATCCCTCCATGTGATCC & & 423 \\
\hline FOXG1 & GCСАСААССТСТСТСТСААТАA & CGAGTCTATCGACGCTCAAC & & 414 \\
\hline FOXI2 & CCTCAGCCAGATCTACCAATAC & TCAGTGCATCTCTCCGT & & 301 \\
\hline
\end{tabular}




\begin{tabular}{|c|c|c|c|}
\hline GENE & CRISPR Target sequence & Arm1 (5' side) & |Arm2 (3' side) \\
\hline ETV1 & TGGAAGAGCACACAGGATGGA & 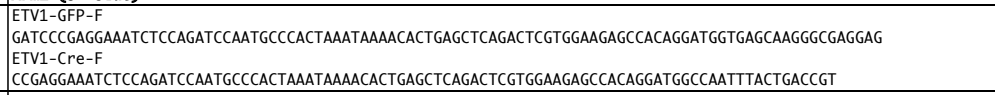 & 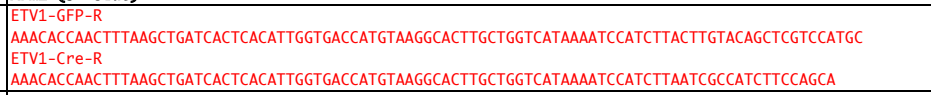 \\
\hline$\overline{R B P M S 2}$ & TATTGAGGTTACTCATGATG & 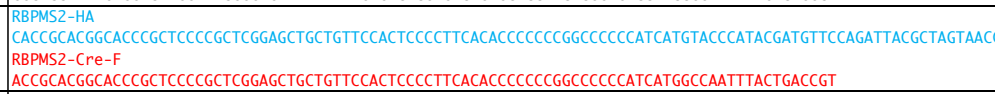 & 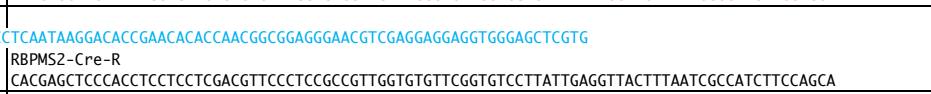 \\
\hline TFAPZA & AGAGCATTTTCATGGGTCGG & 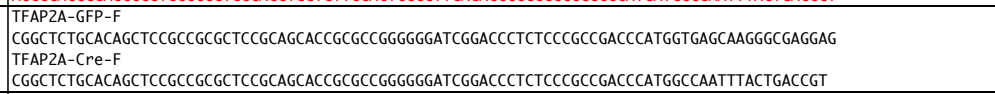 & $\begin{array}{l}\text { TFAP2A-GFP-R } \\
\text { GGCCCGGGGGGGGTTACCTCGCACTCCTCGTACTTGATGTTATCCGTCAGCTTCCAGAGCATTTTTTACTTGTACAGCTCGTCCATGC } \\
\text { TGAPA-Cre-R } \\
\text { GGCCCGGGGGGGGCTTACCTCGCACTCCTCGTACTTGATGTTATCCGTCAGCTTCCAGAGCATTTTTTAATCGCCATCTTCCAGCA }\end{array}$ \\
\hline$\frac{T P B G L}{T P G}$ & GCATGGTCCGCAGGACGCGG & $\begin{array}{l}\text { TPBGL-GFP-F } \\
\text { GGGCGGGGGGGCAGGCAGGCAGACAGCCCC }\end{array}$ & \begin{tabular}{|l} 
TPBGL-GFP-R \\
AGGGGGCCCCAACCAGGGCAGCCCCAAGCAGGGCAGCCCCAGGCCCCGCCGGCCGGCCGCGTCCTGCGGACTTACTTGTACAGCTCGTCCA
\end{tabular} \\
\hline ERBB4 & GCTCCACCACAGCAGCCCCC & \begin{tabular}{|l} 
ERBBA-GFP-F \\
AGGCGGCGGGCTGAGGAGGAGGAAGAGGAGGCGGCGGCGGCGGCGGCGGCGCGATGGCGGCGGCGGCCGGGGTGAGCAAGGGCGAGGAG
\end{tabular} & \begin{tabular}{|l} 
ERBBB-GFP-R \\
GCGCCGCGGCAGCCCTCGGGGCGCCGGCCGCCGCCGCCGGCCAGCACGCAGCAGCTCCACCACAGCAGCCCTTACTTGTACAGCTCGTCCA
\end{tabular} \\
\hline RRAD & CGCCGCGGTTCAGAGTCATG & $\begin{array}{l}\text { RRAD-GFP-F F } \\
\text { GGCGCGGGCCGGAGGGGGAGCGCGGGGCTCTGACGACTCTTCTCCGGGTTCGCAGCCCGGGGTCCCCATGGTGAGCAAGGGCGAGGAG }\end{array}$ & $\begin{array}{l}\text { RRAD-GPP-R } \\
\text { GTGGGAGAAGGCATGCTGCCGCGCCGCTTGTCTAGGTAGCGCAGCTTGTCGCCGCGGTTCAGAGTTTACTTGTACAGCTCGTCCATGC }\end{array}$ \\
\hline$\overline{\text { ANGPT2 }}$ & CAGCCGCATCTTCCCGCCCG & $\begin{array}{l}\text { ANGPT2-GFP-F } \\
\text { CCGCCCGCAGCGCATGGGCGGGGGGCGCTGAGCTCCGAGCTCCGGGCCGGGACCTCCGCGGGGGGGAAGATGGTGAGCAAGGGCGAGGAG }\end{array}$ & \begin{tabular}{|l} 
ANGPT2-GFP-R \\
TCCCGAGGCGTTGATCCCGGGGCGAGAACGATGCTGCAGCCCCACGTGAAGTAGACGCTCAGCCGCTACTTGTACAGCTCGTCCATGC
\end{tabular} \\
\hline$\overline{I R X 3}$ & GCCCAGCTGCGGGAACGACA & $\begin{array}{l}\text { IIX3-GPP-F } \\
\text { CCTTCTCTCCTTCTTCCCTTCTGCCCCCCCCTCCCTACCCTTCCCCCCTCCCCACCCCCCCCGCACCATGGTGAGCAAGGCGAGGAG }\end{array}$ & \begin{tabular}{|l} 
IRX3-GFP-R \\
AGCGGCGGCTGCCGGGGGCTCGGCGGGGTACAGCGGGCTGATGTACTGGTAGCCCAGCTGCGGGAACGATTACTTGTACAGCTCGTCCA
\end{tabular} \\
\hline$\overline{C A L B 1}$ & CTGCACCCCCATCATGACGG & $\begin{array}{l}\text { ACL1-FFP-F } \\
\text { CCGCTCGGCCGCGGGCACAGTCAGCACCGCGGACAGCGCCCCCGGCTGAGCCCCCTCTGCACCCCCATCATGGTGAGCAAGGGCGAGGAG }\end{array}$ & $\begin{array}{l}\text { CALB1-GFP-R } \\
\text { AGTGGTCCAGATCTCGAAGAACTGGGCGGCCGAGATCTCCACGCCCTGCAGGTGGGTCTCCGCCGTCTACTTGTACAGCTCGTCCATGC }\end{array}$ \\
\hline$\overline{\text { NTS }}$ & СAACACCACGCACACCAGCT & $\begin{array}{l}\text { NTS-GFP-F } \\
\text { TGTTCTCTCTCTCTCCGTCTCTCCCCAGGATTTATGGACTTTACTTTCTAGAGAGGGGGGCGACAAGGATGGTGAGCAAGGGCGAGGAG }\end{array}$ & $\begin{array}{l}\text { NTS-GFP-R } \\
\text { GGGGCTACCTGAGCAGAGGCTGCAGGAGGCCAAGGCCAGCAACACCACGCACACCAGCTGGGCTCTTTACTTGTACAGCTCGTCCATGC }\end{array}$ \\
\hline$\overline{V S X 2}$ & GACCGACGGCCGCAGCATGA & 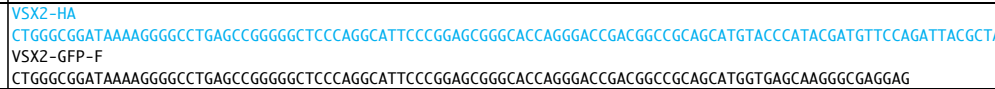 & 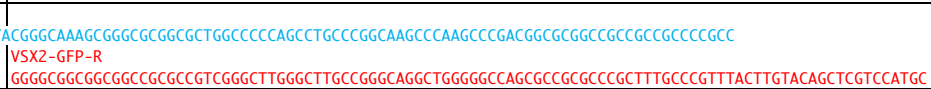 \\
\hline$\overline{S L C 6 A 4}$ & CAACTGGGCAGGAGAAACCT & $\begin{array}{l}\text { SLLC6A4-GFP-F } \\
\text { GGGAAATAGGTGAAGGGGACTGGGTGCTGCTGCCTATCTGCAACTGGGCAGGAGAAACCTTGGAAAAATGGTGAGCAAGGGCGAGGAG }\end{array}$ & $\begin{array}{l}\text { SLCC6A4-GFP-R } \\
\text { GGTTACAGTCTGAGATACCTTTCTTGGAAGTCAGTGGCTGAGTCTCATTGCTCGTTGCCTTATTTTCTTACTTGTACAGCTCGTCCATGC }\end{array}$ \\
\hline $\begin{array}{l}\text { MCSR } \\
-15\end{array}$ & TTTAGAAACATACAGTTGCG & $\begin{array}{l}\text { MCSR-GFP-F } \\
\text { ACACTCCTTGCAAGTCCCTCAGAGAGAAGAGAAAGTGTTTGCTTCCAGACATGAACACATCCTCGCAAATGGTGAGCAAGGGCGAGGAG }\end{array}$ & $\begin{array}{l}\text { MCSR-GFP-R } \\
\text { ACTTGCTCTTGACAGTAGGCACAGTAAATTGCTGCCAAAGGCACTCAGGTTTAGTTCAGAAACATACTACTTGTACAGCTCGTCCATGC }\end{array}$ \\
\hline $\begin{array}{l}\text { TFAP2D } \\
\end{array}$ & GCTTGGATGCCTGGAGTCCG & $\begin{array}{l}\text { TFAP2D-GFP-F } \\
\text { CAGTTTGGGTTTCTTTTCACTTCTTCCTTTCAGATACGTCATGACGGATCAAACAGTTACCGTTTGATGGTGAGCAAGGGCGAGGAG }\end{array}$ & $\begin{array}{l}\text { TFAP2D-GFP-R } \\
\text { AAGTGAGAGGAGGGGGAGGAATAGGGGACGGTGGAGTTGGCCACGGACTCCAGGCATCCAAGCTGCTACTTGTACAGCTCGTCCATGC }\end{array}$ \\
\hline
\end{tabular}

Red: Strand used for single strand amplification
Blue: Synthesized single strand DNA

\section{Supplemental Table 2}

Sequences of homology arms used to generate eCHIKIN probes 